University of Louisville ThinkIR: The University of Louisville's Institutional Repository

Electronic Theses and Dissertations

$8-2016$

\title{
A moderated mediation model of minority stress and resilience factors in sexual minority Christian college students : comparison between PROCESS and SEM.
}

Elisabeth R. Latino

University of Louisville

Follow this and additional works at: https://ir.library.louisville.edu/etd

Part of the Counseling Psychology Commons

\section{Recommended Citation}

Latino, Elisabeth R., "A moderated mediation model of minority stress and resilience factors in sexual minority Christian college students : comparison between PROCESS and SEM." (2016). Electronic Theses and Dissertations. Paper 2546.

https://doi.org/10.18297/etd/2546

This Doctoral Dissertation is brought to you for free and open access by ThinkIR: The University of Louisville's Institutional Repository. It has been accepted for inclusion in Electronic Theses and Dissertations by an authorized administrator of ThinkIR: The University of Louisville's Institutional Repository. This title appears here courtesy of the author, who has retained all other copyrights. For more information, please contact thinkir@louisville.edu. 


\title{
A MODERATED MEDIATION MODEL OF MINORITY STRESS AND RESILIENCE FACTORS IN SEXUAL MINORITY CHRISTIAN COLLEGE STUDENTS: COMPARISON BETWEEN PROCESS AND SEM
}

\author{
By \\ Elisabeth Romines Latino \\ M.A., Boston College, 2011 \\ B.A., Taylor University, 2009
}
A Dissertation Submitted to the Faculty of the College of Education and Human Development of the University of Louisville in Partial Fulfillment of the Requirements for the Degree of

Doctor of Philosophy in Counseling and Personnel Services

\author{
Department of Counseling and Human Development \\ University of Louisville \\ Louisville, Kentucky
}

August 2016 



\section{A MODERATED MEDIATION MODEL OF MINORITY STRESS AND RESILIENCE FACTORS IN SEXUAL MINORITY CHRISTIAN COLLEGE STUDENTS: COMPARISON BETWEEN PROCESS AND SEM}

\section{By}

Elisabeth Romines Latino

M.A., Boston College, 2011

B.A., Taylor University, 2009

A Dissertation Approved on

July 132016

By the following Dissertation Committee

Mark Leach, PhD: Dissertation Chair

Jill L. Adelson, PhD

Stephanie Budge, $\mathrm{PhD}$

Brighid Kleinman PhD 


\section{DEDICATION}

"Nobody asked you do the thing. It's your dream, not anyone else's. It'll be

hard, but it was your idea." - Kyle Latino, referring to something other than my dissertation, but it felt pretty applicable at the time. 


\section{ACKNOWLEDGEMENT}

Thanks to Dr. Mark Leach for his guidance and support in conceptualizing and writing this dissertation. Thanks to Dr. Jill Adelson for going above and beyond the role of committee member, in providing support and resources for the analytical portion of this study. Special thanks also to Dr. Amanda Mitchell for

proving information, support, and access to her software to help me complete my study. Without her generosity of time and spirit, this dissertation would not be close to completion. 


\begin{abstract}
TITLE: A MODERATED MEDIATION MODEL OF MINORITY STRESS

AND RESILIENCE FACTORS IN SEXUAL MINORITY CHRISTIAN

COLLEGE STUDENTS: COMPARISON BETWEEN PROCESS AND SEM
\end{abstract}

Elisabeth Romines Latino

August $9^{\text {th }}, 2016$

Summary: (350 words) The present study has built upon previous sexual orientation minority stress research to explore sexual minority Christian college students' experiences with subtle on-campus discrimination at Christian and secular colleges. Specifically, the roles of various protective and distress factors in relationship to overall psychological distress were examined. Data were gathered by inviting participants to take a one-time online survey through Qualtrics. Links to the survey were distributed through social media, listserves, and contacts with LGBT campus organization leaders. Samples sizes varied based on the method utilized to address missing data (listwise deletion $n=134$, multiple imputation $n=207$ ) and conduct the analyses. Two methods of analysis were used (Structural Equation Modeling in SPSS AMOS 23 and PROCESS in SPSS 22) to more completely explore the conditional effects of school type, social support, and religious and sexual identity integration. These variables were hypothesized to moderate the proposed mediating relationship of internalized heterosexism between the predictor of homonegative microaggression and the outcome variable 
of psychological distress. In all three moderated mediation models, Christian and sexual orientation identity salience were controlled for.

Results indicated that internalized heterosexism partially mediated the relationship between the predictor of homonegative microaggression and the outcome variable of psychological distress in both methods of analysis. Conditional indirect effects of three moderators (Christian or secular college, social support, and identity integration) were also modeled. The results of both methods of analysis did not support the hypothesis that any of the three moderators were related to the path between homonegative microaggression and internalized heterosexism. Poor to borderline acceptable model fit was observed in all three models when SEM analysis was utilized, warranting cautious interpretation of results. The meaning and limitations of the results of this study and future directions in this area of research are discussed. 


\section{TABLE OF CONTENTS}

DEDICATION ............................................................

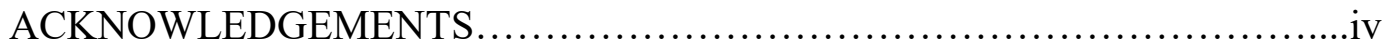

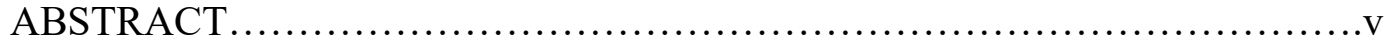

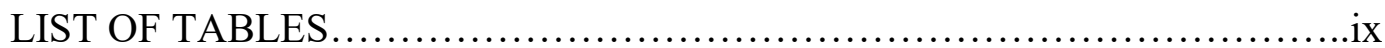

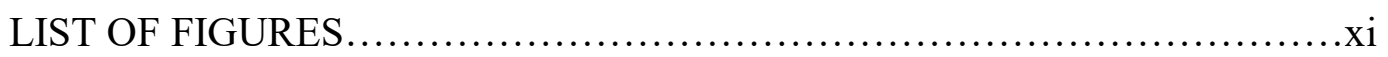

CHAPTER 1: LITERATURE REVIEW .....................................

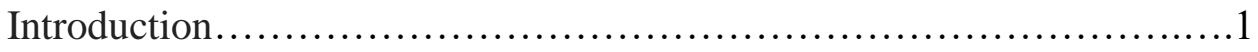

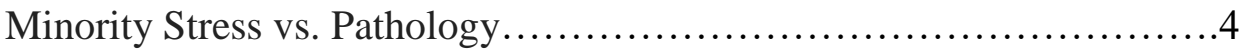

Theoretical and Empirical Support for the Minority Stress Model.........7

Overt Discrimination............................................. 14

Subtle Discrimination............................................ 15

Internalized Heterosexism............................................

Building off Earlier Minority Stress Research.........................30

Protective Factors.....................................................

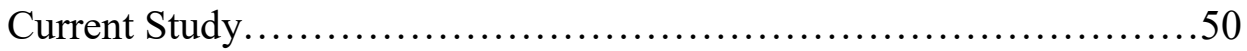

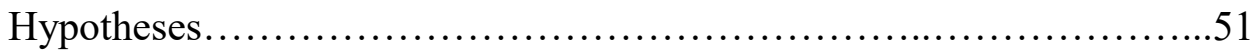

CHAPTER 2: METHODS................................................ 53

Sample..............................................................

Demographics.................................................... 56

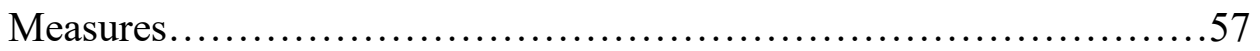

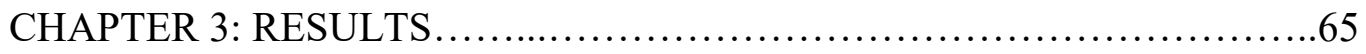


Assumptions................................................68

Analysis.......................................................73

CHAPTER 4: DISCUSSION....................................... 111

REFERENCES ..................................................... 135

APPENDICES................................................... 149

CURRICULUM VITA............................................... 157 


\section{LIST OF TABLES}

$\begin{array}{lll}\text { TABLE } & \text { PAGE }\end{array}$

1. Correlations Among Measures....................................... 70

2. Descriptive Statistics............................................... 74

3. School Type Measurement Model Modifications.........................77

4. Bootstrapped Regression Weights School Type........................81

5. Bootstrapped Direct, Indirect, Total Effects.......................81

6. PROCESS Model Summary School Type.............................84

7. School Type Conditional Indirect Effects.............................85

8. Social Support Measurement Model Modifications.......................86

9. Bootstrapped Regression Weights Social Support......................90

10. Bootstrapped Direct, Indirect, Total Effects.........................90

11. PROCESS Model Summary Social Support...........................93

12. Social Support Conditional Indirect Effects.........................99

13. Identity Integration Measurement Model Modifications..................96

14. Bootstrapped Regression Weights Identity Integration..................100

15. Bootstrapped Direct, Indirect, Total Effects.........................100

16. PROCESS Model Summary Identity Integration.....................102

17. Identity Integration Conditional Indirect Effects......................104

18. Alternative Measurement Model Modifications.......................105

19. Alternative Bootstrapped Regression Weights.......................109 
20. Bootstrapped Direct, Indirect, Total Effects..........................109 


\section{LIST OF FIGURES}

\section{FIGURE}

PAGE

1. Meyer's Minority Stress Model.......................................... 8

2. School Type Measurement Model Post-modification...................78

3. School Type Structural Model........................................80

4. School Type Moderated Mediation Model in PROCESS ...............83

5. Social Support Measurement Model Post-modification.................87

6. Social Support Structural Model Post-modification......................89

7. Social Support Moderated Mediation Model in PROCESS.............92

8. Identity Integration Measurement Model Post-modification............97

9. Identity Integration Structural Model Post-modification...............99

10. Identity Integration Moderated Mediation Model in PROCESS........102

11. Alternative Measurement Model Post-Modification.....................106

12. Alternative Structural Model...................................108 


\section{CHAPTER 1: LITERATURE REVIEW}

\section{Introduction}

Within the past decade, multiple researchers have chosen to examine the relationship between minority stress factors and psychological distress in sexual minority individuals. A clear relationship has so far been established between sexual orientation minority status and higher levels of psychological distress (e.g. Cochran \& Mays, 2009; Cochran, Sullivan, \& Mays, 2003; Meyer, 2003). The current literature suggests that sexual orientation based discrimination and prejudice create unique minority distress that in turn leads to negative well-being outcomes (Fingerhut, Peplau, \& Gable, 2010; Lehavot \& Simoni, 2011; Meyer, 2003; Smith \& Ingram, 2004). This literature supports the theory that sexual minority individuals have higher levels of psychological and physiological disorders than non-sexual minority individuals due to external stigma and discrimination and not internal factors like sexual orientation (Meyer, 2003). Further research has supported that the relationship between minority stress and psychological distress is partially mediated by the internalization of external stress or internalized heterosexism (Szymanski \& Ikizler, 2013).

Despite this increase in knowledge, there remain a few gaps in the current research. While researchers are increasingly exploring the process of minority stress and some are focusing on exploring the impact of subtle heterosexist discrimination qualitatively, such as microaggressions, on sexual minority 
individuals, little quantitative research has been conducted using homonegative microaggression as a predictor of psychological distress (Nadal, Rivera, \& Corpus, 2010; Silverschanz, Cortina, Konik, \& Magley, 2008; Wright \& Wagner, 2012). Additionally, in the studies that have quantitatively examined sexual minority stress there has been no exploration of complex models such as a moderated mediation model to observe the mediating role of internalized sexual minority stress across protective factors such as environment, social support, and religious and sexual identity integration. The lack of complex analysis in the literature seems counterintuitive when one considers the utility of complex models in conceptualizing minority stress within individuals with intersecting identities. Specifically, religious and sexual identities have been found to complicate the relationship between minority stress and psychological distress within an individual. Some research has pointed to the negative impact a religious identity can have on identity acceptance (Loon, 2003; Sherry, Adelman, Whilde, \& Quick, 2010) and it's lack of protection against substance use only in sexual minority individuals (Rostosky, Danner, \& Riggle, 2007). Other researchers have suggested that concepts such as religious and spiritual identity integration (Gold, \& Stewart, 2011; Kocet, Sanabria, \& Smith, 2011; Rodriguez \& Oullette, 2000; Yip, 1997) or belonging to an LGBT affirming religious organization can positively relate to sexual minority individual's well being (Longo, Walls, \& Wisenki, 2013). Hatzenbuehler, Pachankis, \& Wolff (2012) added some nuance to this relationship by finding that in LGB youth the religious climate can act as a 
protective factor against health risk factors such as substance abuse and risky sexual behavior only if the climate is "supportive of homosexuality."

The complex relationship between sexual and religious identity becomes particularly relevant during the traditional college age. The traditional college ages of 18-22 years typically create space outside of one's family of origin for identity exploration and therefore may be a critical time for the development of healthy identity integration. For college campuses that have sexual minority Christians within their student body, the identity development perspective is especially relevant. The amount of discrimination a sexual minority college student experiences on campus has been shown to relate to psychological distress (Silverschanz, Cortina, Konik, \& Magley, 2008; Woodford, Han, Craig, Lim, Matney, 2014) Additionally, sexual minority students at religiously affiliated high schools have been found to have lower "levels of outness" and more alcohol related problems (Stewart, Heck, \& Cochran, 2015).

As most higher learning institutions are impacted by the psychological well-being of their students due to this factor's relationship with use of student health services, attrition, social, and academic success, campus administration should have reason to be concerned by the level of psychological distress sexual minority Christian students experience (Watson, 2003.) Campus administration may have the ability to mitigate these negative outcomes by providing, encouraging, or allowing the formation of social support groups for marginalized identities and to make systemic changes to reduce heterosexist discrimination on campus. Allowing access to factors that could positively impact sexual minority 
Christian college students' well-being, such as social support groups, may be a important to LGB Christian students well being in religious campus setting. However, this issue is complicated when Christian college campuses, in addition to having a responsibility for student well-being, have a commitment to the tenants of their affiliated denomination, which may not allow for support of sexual minority students. This conflict has been highlighted by several recent news stories about tension between students and campus administration surrounding the issue allowing sexual minority support groups on certain Christian campuses (Mitchell, 2016).

In an effort to explore these factors, the relationship among a religious or secular campus environment, and various additional well-being factors, the present study has built upon past research on minority stress factors to explore sexual minority Christian college student's experiences with on-campus discrimination at Christian and secular colleges.

\section{Minority Stress vs. Pathology}

It has been well-established that sexual minority individuals face more targeted, individual acts of aggression than heterosexual individuals (Center for Disease Control, 2011). In 2009, Herek surveyed 662 LGB adults and found that $20 \%$ of LGB individuals had been the victim of a personal or property crime based on sexual orientation. Additionally, 50\% reported being the victim of verbal harassment and 10\% experienced housing or job discrimination. LGB participants in another study were found to be more likely to report discrimination than heterosexual participants and were more likely to report that the impact of 
heterosexist discrimination was harmful to their quality of life (Mays \& Cochran, 2001). The National Survey of Midlife Development found that LGB individuals reported higher levels of heterosexist discrimination, and that $42 \%$ of those individuals attributed the discrimination to their sexual orientation. Additionally, the study found that higher levels of discrimination related to higher levels of stress-based psychological disorders. Unfortunately, the LGB sample used in the study was small $(\mathrm{N}=73)$ and older males were over-represented in the sample. Despite the limitation in this study, heterosexist discrimination's negative impact on mental health has been supported in a number of other studies using larger samples. An earlier study using a larger sample of 1,067 lesbian and gay participants living in the southern United States found that victimization due to sexual orientation based hate crimes had a positive significant association with depression in gay men and lesbian women (Otis \& Skinner, 1996). Additionally, in this study Otis and Skinner also examined the role of social support as a predictor of depression. The authors found that a lack of social support was positively associated with depression in gay men and lesbian women.

Historically, two theories have been posited to explain the high prevalence of mental illness in LGB individuals; a pathologizing approach and a minority stress approach. Viewing sexual minority research through the lens of the minority stress theory is a shift from past discriminatory treatment and conceptualization of sexual minority individuals by many social science researchers. The field of psychology once pathologized sexual minority identities, attributing higher occurrence of psychological distress mental health disorders in 
LGB individuals when compared to heterosexual individuals as evidence of the abnormality of LGB sexual identities. Some of this research was used to create a narrative that LGB identities are "abnormal" and therefore in need of psychological treatment such as conversion or reparative therapies. While the American Psychological Association (APA) condemns the pathologization or treatment of LGBT identities, some research organizations not affiliated with the APA (e.g. National Association for Research \& Therapy of Homosexuality, Family Research Council) continue to pathologize LGB identities by conceptualizing them as abnormal and needing treatment (APA, 2006; Robinson \& Spivey, 2007). Research of this nature has been used to support systemic mistreatment and alienation of LGB individuals in both the psychological sciences and society as a whole. Meyer stated that a pathologized view of LGB identities results from failing to acknowledge the socially constructed nature of what is "normal" or "abnormal." Society creates a culture where LGB identities are considered abnormal in the face of heterosexual "normality." The social construction of LGB identities as "abnormal" facilitates an environment of social stress, where heterosexuality is rewarded and accepted and LGB identities are set apart from the "norm" through discrimination, prejudice, invalidation and microaggression. The minority stress theory is rooted in a feminist perspective which differs from the previous, pathologized view of sexual minority identities by acknowledging that adherence to societal constructs is the cause of social stress. Internal stress or distress is theorized to be not the result of inherent "abnormalities" or "pathologies." Instead, social constructs and hierarchies 
reward those who have privilege and punish those who lack privilege. If LGB identities are viewed as abnormal in society, individuals who identify as LGB miss out on privilege and are subjected to a variety of internal and external stressors that are created by societal values.

\section{Theoretical and Empirical Support for the Minority Stress Model}

To understand the rationale for this study, it is first necessary to explore the minority stress theory in which it is based. In addition to the feminist rationale for conceptualizing the prevalence of LGB distress factors through the minority stress lens, there is strong theoretical and empirical support for the minority stress perspective. Minority stress theory is an alternative to the classic conceptualization of stress. Classic stress theory is individualistic in nature and states that individuals experience specific life events or external stressors that motivate, inhibit or overwhelm (Aneshensel, 1992). External stressors can differ in how they facilitate the internal process of stress. For example, the stressor of an impending academic exam can act as a motivator for one student to study an appropriate amount of time, or it could overwhelm a student and cause avoidance of studying. Stress should therefore be conceptualized not as a burden within itself but as the interaction between the burden and the individual's resources and ability to bear the burden (Aneshensel, 1992; Smith, 1987). Feminist theory expanded upon the concept of individualized stress by acknowledging the existence of social stress and its relationship with psychological distress (Aneshensel, 1992; Dohrenwend, 2000; Meyer, 2003). Instead of defining stress as the result of individual personal life events, social stress theory broadens the 
definition of stress to include environmental social factors as added sources of chronic stress. Similar to the way high levels of general chronic stress have been shown to have a negative impact on individuals' mental health, social stress can also negatively impact well-being (Aneshensel, 1992).

Research on the effects of social stress has shown that stress caused by social environments can lead to negative mental and physical outcomes. Dohrenwend (2000) synthesized three lines of research (i.e. the relationship between SES and psychiatric disorders, social causation-social selection differences, and the psychological consequences of exposure to extreme situation) targeting the relationship between environmental stress and psychological distress, and created a model that explained the various event, environment, and coping factors that impact psychological functioning. This model was adapted and utilized by Meyer (2003) to describe LGB minority stress (see Figure 1).

Figure 1

Meyer's Minority Stress Model

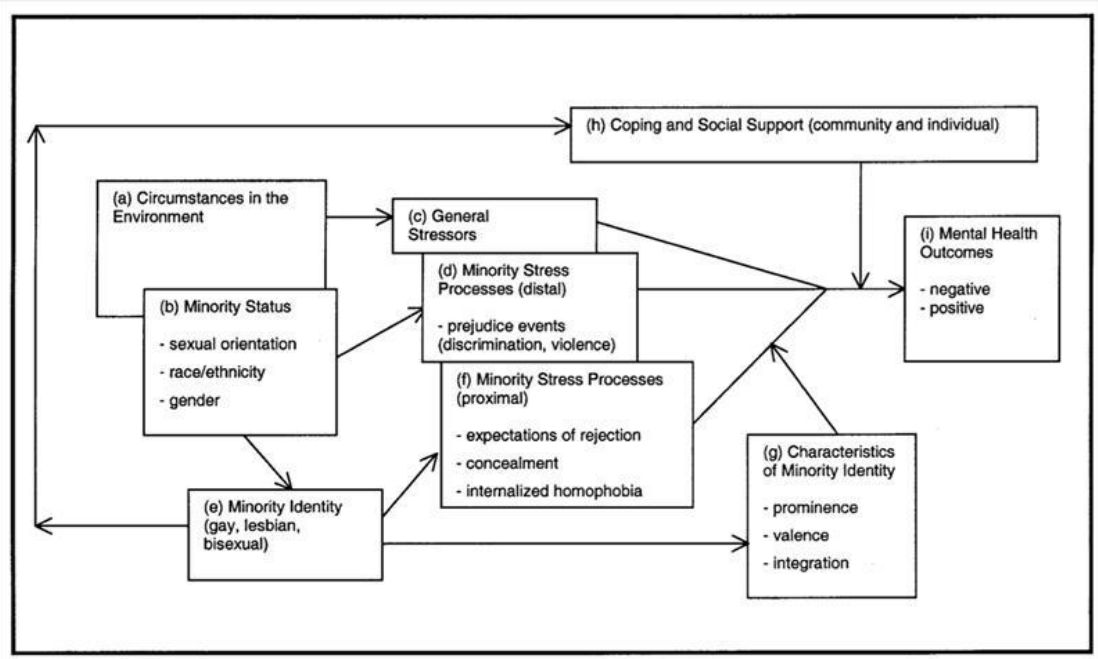

Figure 1.

Minority stress processes in lesbian, gay, and bisexual populations. 
Like social stress theory, minority stress theory reflects the negative impact a social environment can have on the individual. Minority stress theory differs from social stress theory in that it describes the impact of marginalization based on societal attitudes towards one or more groups on the individual (Dohrenwend, 2000). Marginalized groups and individuals would include those who have historically experienced discrimination for gender, racial/ethnic, religious, sexual orientation, and socioeconomic status identities. Marginalizing social environments can contribute to social stress by creating a culture of prejudice or discrimination towards groups and individuals that are rejected by the majority culture. Stress is then placed on the marginalized individual to adapt or survive to fit with the majority culture. Minority stress theory states that individuals who belong to minority groups are exposed to unique social pressures and therefore experience higher levels of unique social stress (Meyer, 2003). The process of constant conformity, suppression or resistance can cause a unique stress within the minority individual called "minority stress" (Meyer, 2003). Minority stress is then defined as chronic and additive to the typical day-to-day stressors all individuals experience, and the chronic prejudice, discrimination experienced by members of minority groups contributes to negative mental and physical health outcomes (Meyer, 2003).

Minority stress theory was originally applied to the racial distress experienced by black individuals in a predominately white social environment. The term has since expanded to include chronic discriminatory stress experienced by a variety of "out-groups" including sexual orientation minority individuals 
(Nadal, Wong, Issa, Meterko, Leon, \& Wideman, 2011). Earlier research in support of the minority stress theory has shown that not only do sexual orientation hate crimes lead to psychological distress in lesbian and gay individuals, but they increase levels of anxiety, posttraumatic stress, anger, and depression more than if the individual was the victim of non-biased crimes (Herek, Gillis, \& Cogan, 1999). This finding indicates that LGB individuals are not inherently psychologically "weaker" but that sexual orientation targeted discrimination is a unique stressor with unique outcomes.

Meyer described the concept of LGB minority stress as a chain of causal and reactive elements. His model begins with environment circumstances, which overlap with individual's sexual orientation, racial/ethnic, or gender minority status. The present study's proposed research model is based on Meyer's theoretical model and as such utilizes proximal (internalized heterosexism) or distal (homonegative microaggression) stressors as mediators and predictors, respectively. The concepts of proximal and distal stressors, originally conceived by Lazarus and Folkman in 1984 are utilized by Meyer to differentiate between types of minority stress. Distal minority stressors are defined as event-based prejudices such as discrimination and violence that an individual is subjected to as a result of being identified as having a minority identity. This means that distal minority stress does not hinge on the individual's self-perception of having a minority identity, only on the perception of others. An individual could identify completely with the majority culture and still face distal minority stress if they are perceived to be part of a marginalized group. 
The second aspect of minority stress, proximal stress, specifically relates to how an individual relates to their own identity in the context of a larger discriminatory world. Proximal minority distress does not need an outside trigger to enact. It is the result of the chronic discrimination, which can shape the way an individual with a minority identity predicts and anticipates discrimination. Proximal stress does not require the outside recognition of an individual's minority identity. In fact, uncertainty about the transparency of one's identity can be a source of proximal stress as the individual experiences anxiety regarding potential or uncertain discrimination. Proximal stress can also include concerns about concealment, expectations of rejection and internalized homophobia/heterosexism. Repetitive distal stress is necessary for the formation of proximal stress. The combination of proximal and distal stressors creates the chronic inescapable stress that makes minority stress so impactful to individuals' well-being.

This outcome is illustrated in Meyer's model as he stated that both negative and positive mental health outcomes can result from the influence of minority stress. As mentioned when describing classic stress theory, the same external stressors do not always create the same outcomes across individuals or context. While minority stress has negatively impacted many LGB individuals' mental and physical health and well-being, it is important not to overlook that resiliency, social support, and identity acceptance and integration can transform the experience of minority stress into a catalyst for healthy identity formation and social bonding among minority individuals (Crocker \& Major, 1989; Meyer, 
2003; Nadal et al., 2011). Past research has highlighted that the experience of ingroup cohesiveness and support can act as a protective factor against some of the potential negative effects of racial minority stress (Branscombe, Schmitt, \& Harvey, 1999; Crocker \& Major, 1989; Miller \& Major, 2000; Meyer, 2003; Postmes \& Branscombe, 2002). Specifically, Branscombe et al. (1999), found a significant negative relationship between the attribution of the cause of general negative events to prejudice and psychological well-being in African American individuals. However, the negative impact on psychological well-being was alleviated when individuals exhibited strong minority group identification. This result supported the hypothesis that the perception of distal minority stress could positively influence strong in-group identification, which could then alleviate distress. There is little research examining the possible positive outcomes of sexual orientation minority stress, but the complexity of social support's relationship with minority stress and psychological distress deepens when intersecting and potentially conflicting identities are examined.

In an effort to examine the relevance of the minority stress when applied to LGB individuals, Meyer conducted a meta-analysis in 2003 of 8 studies that explored the differences in psychological distress factors between heterosexual and LGB individual groups. While the author noted the limitations in treating a diverse group of sexual orientations as one homogenous group, obtaining an overarching view of the effects of minority stress on LGB individuals is valuable. His research has produced a cohesive examination of the empirical evidence for the negative impact of minority stress on LGB individuals' well-being. Overall, 
he found that LGB individuals reported a higher prevalence of mental disorders than heterosexual individuals (Meyer, 2003). Meyer proposed some alternative explanations to the minority stress theory for these findings. He observed that a small LGB sample size in many of the included studies could have skewed the results, but most likely in a way that would have minimized the detection of LGB mental illness. He also noted that it is possible that LGB individuals were more open about reporting mental health issues due to the fact that LGB individuals were more likely to have received mental health services than heterosexual individuals (Cochran, Mays, \& Sullivan 2003; Meyer, 2003). Later research has supported this trend of LGB individuals seeking out mental health services at higher rates than heterosexual individuals (Cochran \& Mays, 2009; Grella, Greenwell, Mays, \& Cochran, 2009). One study which utilized the California Quality of Life Survey found lesbian and bisexual women were the most likely to seek mental health services, while heterosexual men were the least likely to seek mental health services. Additionally, a large number of sexual orientation minorities sought mental health services without having a diagnosable disorder (Grella, Greenwell, Mays, \& Cochran, 2009). Meyer hypothesized that the introspection and disclosure required by LGB individuals in exploring and eventually revealing their sexual identity could help counteract some of the stigma attached to accessing mental health services. The reduction of stigma could then make LGB individuals more likely to accept and report mental health diagnosis. While this explanation seems plausible, seeking mental health services in the past has not been shown to significantly relate to current mental disorder 
diagnosis (Link \& Dohrenwend, 1980; Meyer, 2003). The results of Meyer's meta-analysis therefore seem to support the idea that LGB individuals do experience higher levels of mental illness for reasons related to minority stress and discrimination.

\section{Overt Discrimination}

Meyer's study has become a benchmark work in LGB minority stress research, and many researchers since have utilized this conceptualization in further examining the relationship between sexual orientation minority stress and distress. A significant portion of this research has examined the relationship between hostile environments for LGB individuals and psychological distress utilizing the more overt construct of heterosexist events to represent an individual's perception of environmental hostility to LGB identities. Some researchers such as Szymanski \& Kashubeck-West (2008) have defined heterosexist events as the experiencing of events via family, friends, work, school or society that are perceived to be discriminatory towards the LGBT individual. This construct is useful in assessing more direct discrimination such as job loss and peer and family rejection and has been used by multiple researchers (Lehavot \& Simoni, 2011; Smith \& Ingram, 2004). The results of these studies aligned with results from Meyer's (2003) meta-analysis, as Smith and Ingram (2004) found that exposure to heterosexist events and unsupportive social interactions were linked to depression. In a sample with intersecting minority identities, the same relationship between heterosexist event and mental distress was observed. Lehavot and Simoni (2011) recently examined the direct and indirect impact of 
minority stress on lesbian women of color's psychological distress and substance abuse. They obtained a large sample $(n=1,381)$ of sexual minority women via snowball sampling and targeted sampling methods. The researchers then tested a model that hypothesized higher levels of minority stress would have a direct effect on the outcome variables and predict higher levels of substance abuse and psychological distress. Acceptable model fit was found, and minority stress explained $56 \%$ of the variance in mental health outcomes.

\section{Subtle Discrimination}

The studies included in Meyer's meta-analysis are now over a decade old, and focus heavily on overt discrimination. Even 10 years prior, Meyer (2003) acknowledged that there could be cohort effects within the LGB minority stress literature he reviewed, as societal attitudes towards LGB identities shift over time. Specifically, he stated that some younger LGB individuals experienced more acceptance and less sexual orientation based discrimination than earlier generations due to societal attitude changes. Despite these changes, Meyer also noted that these changes mainly applied to liberal urban and suburban areas. Outside of these "islands" of acceptance, LGB youth may face greater amounts of prejudice and discrimination. While the recognition of potential cohort effects is an important consideration, Meyer still found that the results of the meta-analysis support the validity of the minority stress theory in explaining LGB psychological distress. This finding could be because legislation changes and urban attitude changes do not tell the entire story of U.S. cultural attitudes towards LGB individuals. Overt discrimination, violence and harassment of LGBT individuals 
are still significant societal issues systemically (CDC, 2011). Additionally, marriage equality, job, housing and adoption discrimination are some of the many barriers LGB individuals face in accessing equivalent rights to heterosexual individuals. Despite the continued existence of overt discrimination there have been some recent changes for LGB individuals. Specifically, legislation such as the repeal of Don't Ask Don't Tell, the passing of the Defense of Marriage Act, and the increase of state protective laws for LGBT individuals illustrate a shift away from some types of overt discrimination in certain contexts (Human Rights Campaign, 2013). Unfortunately, changes in overt discrimination do not change societal bias and prejudice. As a result, sexual minority individuals may increasingly face subtle heterosexist discrimination. In recognition of the coexistence of overt and subtle discrimination there is a growing body of research examining the relationship between subtle LGB minority stress (such as microaggressions) and negative physical and mental health outcomes such as substance abuse, stomachaches and headaches (Nadal, Rivera, \& Corpus, 2010; Nadal, Wong, Issa, Meterko, Leon, \& Wideman, 2011; Silverschanz et al., 2008; Woodford, Howell, Silverschanz, \& Yu, 2012; Wright \& Wegner, 2012).

\section{Microaggressions}

As defined earlier, distal minority stress is the overt external environmental prejudice, discrimination, or violence experienced by a minority individual because of their identity (Meyer, 2003). The concept of overt environmental prejudice becomes more complicated to define, as "socially acceptable" discriminatory behavior alters over time. For example, while in most 
social settings it is now unacceptable to make an overtly racist comment, prejudice can still be expressed through more subtle means such as racial jokes, condensation ("You are so articulate!"), or othering (“can I touch your hair?") (Sue, 2010).

More subtle types of identity based discrimination, prejudice and heterosexism, are increasingly referred to as "microaggressions" in the literature. Microaggressions are the "everyday verbal, nonverbal, and environmental slights, snubs, or insults, whether intentional or unintentional, that communicate hostile, derogatory, or negative messages to target persons based solely upon their marginalized group membership" (Sue, 2010, p. 3) The term microaggression was originally coined to describe the subtle aggressions experienced by racial minorities in predominately white environments. The term has recently expanded to include discrimination experienced by sexual and gender identity minorities, religious minorities, women, and the elderly. Microaggressions can be further broken down into three subtypes: micro-assaults, micro-insults and microinvalidations (Nadal, et al., 2011). A micro-assault is a direct, aggressive identity based attack, such as using slurs. A micro-insult is a more subtle conveyance of a negative message towards a minority individual, such as pulling a child away from a gay man. A micro-invalidation is any action or statement that communicates a minimization of a minority individual's experience with oppression, such as telling a bisexual woman that she can't take a joke after she complains when her sexual identity is eroticized by others. Microaggressions can also be enacted by groups and organizations as well as individuals. Being barred 
from donating blood, being exposed to statements from religious organizations that homosexuality is a sin and, being given the right to domestic partnership instead of marriage are all examples of institutional microaggressions.

In developing this study, much thought was given to the exclusion of gender identity microaggression when defining the predictor variable. While the LGBT umbrella is useful for unifying individuals marginalized due to their gender and sexual orientation, research has shown that experiences of microaggression and subtle discrimination can widely vary when comparing gender and sexual orientation identity. While some researchers state that transgender individuals experience discrimination, violence and microaggressions that are unique to gender identity and expression there has been some discrepancy in the research regarding the combining or separating of LGB and transgender microaggression. In 2010, Nadal, Rivera, and Corpus created a combined taxonomy of 8 categories of LGBT microaggressions. These categories included: The use of transphobic or heterosexist language; heteronormative or gender normative culture/behaviors; assumption of a universal LGBT experience; exoticization; discomfort/disapproval of LGBT experience; denial of societal heterosexism and transphobia; assumption of sexual pathology or abnormality; and denial of individual heterosexism/transphobia.

Conversely, more recent qualitative research has identified as many as 12 unique forms of subtle transgender discrimination. These categories include unique microaggression such as transphobic language and/or misgendering (using the incorrect pronouns or name), assuming there is one universal transgender 
experience, exoticization or fetishizing, support of binary gender norms, cultures or behaviors, denial of systemic or individual transphobia, assumption of sexual pathology/abnormality, denial of bodily privacy (questioning an transgender person about their body) (Nadal, Skolnik, \& Wong, 2012). While some of these categories can apply to lesbian, gay and bisexual targeted microaggression, many of the experiences of gender minority groups are unique. For example, it is likely that few LGB individuals have been asked directly about the state of their genitals, which is a common microaggression experience for transgender individuals. Conversely, if a transgender individual is able to "pass" as their identified gender in public and also identifies as straight, they may face minimal overt discrimination for holding their partner's hand in public; a privilege that many LGB individuals don't have. Due to these differences between sexual and gender identity based discrimination, it seems useful to separate the experiences of lesbian, gay, bisexual and transgender individuals when researching homonegative microaggressions. For this reason, this study is focusing on the sexual orientation microaggression experience of individuals of all genders and is not including gender identity microaggression into the model. The intent of this exclusion is not to further marginalize transgender individuals, or to discount gender specific microaggression. The inclusion of only focusing on sexual minority identities of Christian college students is instead to acknowledge the uniqueness of experiences of gender identity minority individuals within the LGBT umbrella. 
Recent efforts have been made to define and categorize how the experience of microaggressions vary in impact. While all marginalized groups experience microaggressions, there can be variation in the ways marginalized individuals identify and experience them. Woodford, Han, Craig, Lim \& Matney (2014) broke homonegative microaggressions into three categories (1) experiencing and witnessing hostility (2) incivility and (3) heterosexist harassment. Results showed that all three categories partially mediate the relationship between sexual minority identity and anxiety. Interestingly enough, only incivility and heterosexist harassment partially mediated the relationship between sexual minority identity and depression. A study by Nadal and colleagues (2011) took a qualitative approach to this question by utilizing a focus group of 26 participants to gather information about LGB individuals' experiences with sexual orientation microaggressions. Specifically, these researchers wanted to determine how LGB college students identify, react to, and cope with microaggressions. The results indicated that participants utilized a variety of coping styles. Some respondents used passive coping, others were more "confrontational" and "aggressive" when targeted by discriminatory behavior. Finally, some participants expressed valuing safety and engaged in protective coping styles. When observing cognitive reactions to microaggression, researchers found that participants either gravitated toward resiliency and empowerment or towards conformity and acceptance. Observed emotional reactions ranged from discomfort/feeling unsafe; anger/frustration; and sadness. Finally, participants acknowledged the connection between experiencing 
microaggression and psychological distress, specifically depression. A rationale proposed by the authors regarding passive acceptance of sexual orientation based microaggression was that higher levels of internalized homophobia may prevent the acknowledgement of sexual orientation based microaggression in LGB individuals. The present study examines both internalized homophobia and sexual orientation based microaggressions in a population (LGB Christian college students) who may have higher levels of internalized heterosexism than nonreligious LGB students. The results of Nadal's research could mean that participants with higher levels of internalized heterosexism may under-report or under-perceive the true amount of heterosexist/homonegative microaggressions in the environment.

\section{Microaggressions on Campus}

While traditionally viewed as more liberal and accepting settings, college campuses are unfortunately no safe haven from sexual orientation based discrimination. Rankin in 2001 conducted a nationwide survey of 1,669 students, faculty, and administration to assess the current campus climate for LGBT students. The results showed that $36 \%$ of LGBT college students surveyed have experienced discrimination in the past year. The most common type of discrimination was derogatory comments, which were reported by $89 \%$ of the students who reported harassment. The prevalence of homophobic slurs and gay jokes usage in college settings has been further supported by later research, among heterosexual men (Woodford, Howell, Kulick, \& Silverschanz, 2012a). 
A recent study conducted with 114 LGB college students found positive associations between hearing "that's so gay" and feeling left out on campus, the frequency physical health issues such as headaches and stomach problems (Woodford et al., 2012b). In that same study $65 \%$ of students surveyed had said, “that's so gay" within the past month, while $90 \%$ of students reported that they heard the phrase "that's so gay" within the past 12 months. One study by Silverschanz et al. (2008) found that experiencing heterosexist harassment not only predicted a negative association of social and academic engagement for LGB individuals, but that merely witnessing heterosexist harassment had similar results. Another study explored the characteristics of those who used sexual orientation micro-aggressive language. Woodford et al., (2012a) found that using the phrase "that's so gay" was positively related to belonging to peer groups that used the same language, and having negative feelings towards more feminine men. On a more positive note it was found that students with LGB acquaintances were more likely to refrain from using heterosexist language, but this sample was limited to only heterosexual men at a large midwestern university (Woodford et al., 2012 a). This study illustrated that communication and integration between LGB and heterosexual individuals could help reduce microaggression language on a campus environment and produce more positive social outcomes.

Heterosexist comments create a hostile environment for LGB individuals, but more subtle forms of discrimination on campuses are often overlooked or minimized despite evidence showing that heterosexist behaviors can negatively impact LGB college students (Silverschanz, Cortina, Konik, \& Magley, 2008; 
Woodford, Howell, Silverschanz, \& Yu, 2012) Additionally, more subtle messages like the omission of LGB history from college course and textbooks, assuming, only using heterosexual imagery when advertising for campus services and events, and using heterosexist language can all send the message that LGB students are outside of the "normal college experience" (Nadal, Rivera, \& Corpus, 2010). Rankin (2001) found that $43 \%$ of LGBT students surveyed did not feel that the curriculum at their institutions recognized the contributions made by LGBT individuals.

In addition to the well-established relationship between heterosexist discrimination and poor well-being in sexual minority college students, recent research has shown that a heterosexist environment can be damaging to college students of all sexual orientations. A study by Silverchanz et al. in 2008 utilized a large sample of college students $(\mathrm{N}=3,128)$ and found that $40 \%$ reported heterosexist harassment, despite only $11 \%$ of the sample identifying as LGB. Additionally, those who reported experiencing heterosexist harassment also reported lower academic and psychological well-being. It should be noted that this study was able to obtain a larger percentage of LGB students than past studies assessing a similar population. The researchers posited that the inclusion of a "between heterosexual and bisexual" option allowed for a larger number of LGB individuals to participate using a label that felt accurate. For this reason, the present study utilized a similar option when collecting demographic information about sexual orientation (Silverschanz et al., 2008). 
Despite the clear evidence that LGB students face discrimination on college campuses, the experience of subtle discrimination is often invalidated, ignored, or overlooked by those who are not directly impacted. The invisibility of subtle discrimination may be explained by research that has shown a difference in perception of microaggressions between those targeted by LGB microaggression and those who merely observe it. Brown, Clarke, Gortmaker, \& Robinson-Keilig (2004) assessed the campus climate for LGBT students by surveying multiple sources to see how they perceived LGBT attitudes on campus. LGBT students, general students, RAs, faculty, and student affairs staff were all asked to rate their perception of anti-LGBT attitudes on campus. Not surprisingly, LGBT students observed higher levels of anti-LGBT attitudes than all other groups (Brown, Clarke, Gortmaker, \& Robinson-Keilig, 2004). Individuals who had higher levels of power (faculty, student affairs staff and RAs) perceived higher levels of antiLGBT attitudes than the general student population, but they perceived less discrimination than LGBT students. Similarly, Silverchanz et al. (2008) found that only $36 \%$ of heterosexual students reported witnessing ambient heterosexist harassment compared to 53\% of sexual minority students. Personal heterosexual harassment was observed at a much lower rate, but there still was a discrepancy between heterosexual (3\%) and sexual minority (19\%) students.

Additionally, heterosexual men were more likely to report personal heterosexism harassment than heterosexual women, supporting the Woodford, Howell, Kulick, \& Silverschanz (2012) theory that heterosexual undergraduate 
men utilized more heterosexist language in interacting with one another than other groups of emerging adults.

These findings reflect an unfortunate truth in campus culture. Specifically, the experience of minority stress is often overlooked or minimized by individuals who are not directly affected. Additionally, even professionals who are trained to recognize social injustice can overlook the occurrence and impact of microaggression. McCabe, Dragowski, \& Rubinson (2013) surveyed one set of school psychologists about the prevalence of harassment and bias in their schools, and their observance of homophobic language used by students and staff. The results found that while only $16 \%$ of those surveyed reported observing significant levels of discrimination, $43 \%$ reported hearing students using homophobic language and $45 \%$ reported hearing staff utilize homophobic language (McCabe et al., 2013). This means that while the participants explicitly observed reported discriminatory events, they overlooked how this behavior creates an environment of discrimination. Unfortunately, these results reflect the minimization of distal stress and microaggressions that many LGB individuals face.

\section{Internalized Heterosexism}

Some researchers have explored the proximal distress factor of internalized heterosexism to partially explain the relationship between a hostile environment for LGB individuals and psychological distress. A source of potential confusion in LGB research is the often-interchangeable use of the terms “internalized homophobia" and "internalized heterosexism." Internalized 
homophobia was at one point the most common term used in research and clinical work (Szymanski, Kashubeck-West, \& Meyer, 2008). In the words of Meyer and Dean (1998, p. 161) it is defined as "the gay person's direction of negative social attitudes toward the self, leading to a devaluation of the self and resultant internal conflicts and poor self-regard." Despite the term's initial popularity, "phobia" means fear, a term that does not fully reflect the complex internal process of an LGB individual in a heterosexist world. To better represent that the source of internal conflict starts from the external context of a heterosexual focused world, the term "internalized heterosexism" is now more commonly utilized in LGB positive research in an effort to have the language reflect the current conceptualization (Szymanski, Kashubeck-West, \& Meyer, 2008). Despite the change in language, both terms in past and current research refer to the internalization of outward hostility towards one's sexual identity. For the purpose of matching current language in this area of research, the term "internalized heterosexism" will be used when describing the present study.

A significant body of research has connected internalized heterosexism with a wide range of psychological distress outcomes. Studies exploring the two variables have found significant relationships between internalized heterosexism and psychological stress factors including depression (Herek et al., 1999; Szymanski et al., 2001), general distress in lesbian women with breast cancer (McGregor et al., 2001) psychological distress in lesbian women (Szymanski, 2005), suicidality (Meyer, 1995), risky sex (Meyer \& Dean, 1998), and fewer preventative health measures (McGregor et al., 2001). Herek and colleagues 
found that women reported lower rates of internalized homophobia than men, but that both men and women with the highest internalized homophobia scores reported significantly more depressive symptoms.

While research on internalized heterosexism can be an integral to understanding sexual identity minority stress, some research on internalized heterosexism can inadvertently highlight LGB stereotypes. An example of this is risky sex behaviors, a variable that has been frequently researched alongside of internalized homophobia (Meyer \& Dean, 1998). According to Mustanski, Newcomb and Garofalo (2011) the methodology used in many of these studies has been flawed due to the lack of consistency in defining "risky sex." These researchers conducted a meta-analysis of 16 studies examining the relationship between internalized homophobia and risky sexual behavior, and found a small effect. This discrepancy between the meta-analysis results and the predicted findings of the examined studies illustrates that research focusing on LGB minority distress can at times rely on assumptions, exaggerate stereotypes, and utilize a pathologizing lens. For this reason, this study focuses on protective factors such social support and identity integration in an attempt to provide a strengths-based approach to minority stress.

The research explored above illustrates a portion of the minority stress model by supporting the relationship between proximal stress and psychological distress. Meyer's model maintains that internalized heterosexism is an internal stressor that is created through experiencing distal stress. In order to better understand internalized heterosexism's relationship to psychological distress, it is 
important to accurately model its theoretical role as a mediator. A mediating variable explains some or all of a relationship between two other variables. In Meyer's model, distal stress has a direct relationship with proximal stress and psychological distress, and proximal stress may be a unique product of distal stress. The proximal stress (internalized heterosexism) then explains some of the impact of distal stress (microaggression) on psychological distress. For reasons supported in past theory and research this study will use internalized heterosexism as a mediating variable.

\section{Concealment and Internalized Heterosexism}

In the minority stress model, the act of concealing one's sexual orientation is separated out as a distinct proximal stress factor from internalized heterosexism. Despite this distinction, the internalized heterosexism measure used in this study (Lesbian Internalized Heterosexism Scale, Szymanski; 2001) includes a concealment subscale labeled Public Identification as Lesbian/Gay/Bisexual. Despite the typical separation of these concepts in past literature it is clear that these factors are related due to the significant $(\mathrm{p}<.001)$ correlations between internalized heterosexism subscales in this study (see Table

2.) This aligns with past research that has shown that higher levels of internalized heterosexism have been found to correlate with concealing one's sexual identity (Lehavot, \& Simoni, 2011; Szymanski, Kashubeck-West, \& Meyer, 2008). This finding is consistent across gender as Herek and colleagues (1999) found that internalized homophobia was associated with less self-disclosure in both lesbian women and gay men. Concealment of one's identity is typically used as a means 
of protection against chronic identity based discrimination and prejudice. Sexual orientation identities are fairly easy to conceal, but the act of concealment in itself can cause isolation, negative psychological, health and job related outcomes (Waldo, 1999). Meyer (2003) cited research in his meta-analysis that examined the cognitive and emotional toll the concealment of one's identity can cause (Miller \& Major, 2000; Frable, Platt, \& Hoey, 1998). Specifically, the concealment of an LGB identity can make it difficult to connect with other LGB individuals or potential allies who could offer affirmation and support. Some research has also supported the physical and mental health benefit of being able to express one's identity in a safe and supportive environment (Meyer, 2003). One study showed that college students reported higher self-esteem when they were around others with similar identities and perceived that they were not stigmatized (Frable, Platt, \& Hoey, 1998). Frable and colleagues found that students with concealable stigma such as bulimia, LGB sexual orientation and low SES reported lower self-esteem and more negative affect when compared to students with visible stigma (identifying as African American or as 30 pounds overweight) or with visible characteristics that were not stigmatizing. Furthermore, those with concealable stigma reported a lower instance of being around similar others. Unfortunately, the small sample size $(\mathrm{N}=86)$ resulted in unequal distribution among cells and a small number of participants per cell, making these results difficult to generalize. Another study connected the construct of microaggression or subtle discrimination to the decreased likelihood of coming out, further illustrating the relationship between minority stress and concealment (Burn, 
Kadlec, \& Rexer, 2005). Burn and colleagues gave 125 LGB college students scenarios in which a heterosexual individual said or assumed negative things about an LGB individual. Perceived offensiveness was found to predict a decreased likelihood of coming out. This finding suggested that even if subtle heterosexism is not directed at a specific LGB individual, the likelihood of coming out still decreases. Alternatively, in the McGregor et al. (2001) study, paths modeled with a sample of 57 lesbian women undergoing breast cancer treatment found that internalized heterosexism positively related to higher levels of distress, but found that disclosure of sexual identity did not relate to lower levels of distress.

\section{Building off Earlier Minority Stress Research}

Although Meyer's work has been crucial to minority stress research by compiling a large body of research that supports the relationship between sexual identity minority stress and psychological distress, most of the studies included in his 2003 meta-analysis had fairly simple designs, observing the strength of relationships between minority stress factors and distress. As LGB minority stress research has developed over the past few decades, researchers have been able to model more complex paths that align with the theoretical structure of minority stress, hypothesizing various proximal minority stress variables, risk and protective factors as modifying or explaining the already supported relationship between distal minority stress and distress. Previous research has explored factors such social support, self-esteem, internalized heterosexism as mediating and moderating factors in the relationship between distal minority stress and distress. 
Meyer and Szymanski in particular have independently examined similar moderation models that identify the proximal stress factor of internalized heterosexism as a moderating variable between external heterosexist stressors and psychological distress. The two studies targeted different populations within the LGBT umbrella including gay men (Meyer, 1995) and lesbian and bisexual women (Szymanski, 2006). Despite the similarity in structure, the results of these studies have varied in their ability to support the relevance of internalized heterosexism as a moderating variable for the sample. While Meyer found that his model fit a gay male sample, Szymanski did not find good model fit in a lesbian and bisexual female sample. These varied results could be the result of many factors. There could be gender differences in how LGB individuals experience and cope with minority stress, or there could be design issues in the measurement and sampling procedures. Szymanski proposed that a possible explanation for the discrepancy between the two studies' results is that the populations sampled by Szymanski tended to have low levels of internalized heterosexism and high social connectivity to LGBT support resources. The lack of variance in internalized heterosexism within the sample may be the result of the sampling procedures. In Syzmanski's study, participants were recruited through LGBT community centers, support groups and listserves. Individuals who were recruited through these services may be at a different stage in their sexual identity development that the larger population and therefore may have more protective factors. Additionally, the services that were used to recruit could act as a support system, making the individuals recruited for this study better supported than the general 
lesbian population. Szymanski suggested that future research utilizing an internalized heterosexism moderation model should include samples with a greater amount of variance in several minority stress factors, including internalized heterosexism and heterosexist events. One suggestion she proposed was the inclusion of individuals with additional intersecting identities. Szymanski's explanation seems reasonable, considering Meyer's study utilized a snowball sampling technique to seek out participants who were not affiliated with LGB support organizations. It is also possible that the climate for LGB individuals altered from 1995 to 2006 . This is not to say that minority stress has become less relevant in recent years, but as overt social attitudes become more LGB inclusive, heterosexism may become less overt. Measuring subversive sexual orientation discrimination such as microaggression may become increasingly important in accurately assessing LGB minority stress.

Due to the limitation listed above, the mediation design in this study differs from Meyer's and Szymanski's models in a few key areas. First, instead of testing internalized heterosexism as a moderating variable, this study examines the mediating effects of this construct. The minority stress model supports the role of internalized heterosexism in explaining some of the relationship between microaggression and psychological distress. Meyer's (2003) model supports a direct path between distal minority stress and psychological stress and also hypothesizes a direct path between distal stress and proximal (internalized) stress. It is possible then that for LGB individuals in this study, internalized heterosexism may act as a mediating variable, explaining some of the variance in 
the relationship between homonegative microaggression and psychological distress. Szymanski \& Ikizler (2013) also support this rationale in a study where they utilized internalized heterosexism as a mediator between heterosexist discrimination and depression in gay men. In this study she states, "the nature, degree, type, and frequency of heterosexism in the environment may all affect sexual minority person's experiences with internalized heterosexism.” (p. 213) This means that an individual's internalized heterosexism may explain the degree to which they are impacted by external minority stress. The results of this study did support internalized heterosexism as a mediator between heterosexist events and depression, supporting the use of internalized heterosexism as a mediating variable in this study.

Second, in order to expand upon Meyer and Szymanski's research while also addressing the lack of internalized heterosexism in Szymanski's sample, a population with intersecting Christian and LGB identities was targeted. Past research has shown that high connectivity to religious organizations can relate to higher levels of internalized heterosexism, even if the organization is LGB affirming (Szymanski, Chung, \& Balsam, 2001). In addition to the focus on intersectionality in the population sampled, the conditional indirect effect of the type of the environment was examined. As the role of internalized heterosexism as a mediator in the relationship between microaggression and psychological distress in LGB Christian students was examined, the impact of three difference moderators was modeled: attending a Christian or secular campus (school type), social support, and religious and sexual orientation identity integration. By 
comparing LGB Christian students from secular and religious schools, the unique challenges and needs of LGB Christian college students on religious and secular campuses will be examined. Social support has been explored as a mediating factor in the relationship between internalized heterosexism and psychological distress, but in this study social support is defined as a moderating variable (Szymanski, 2008). Theoretically, it does not seem likely that a causal path could be drawn from experiencing a microaggression to the amount of social support and individual has. It seems more likely that social support would act as a protective factor that could alter the mediating role of internalized heterosexism in the relationship between minority stress and psychological distress. In a similar fashion, identity integration was selected as a factor that could act as a risk or protective factor for LGB Christian students depending on the degree of integration present. These two factors will represent possible moderating factors in helping LGB Christian college students successfully cope with sexual orientation based stressors using Meyer's (2003) conceptualization of moderating factors in minority stress.

The final key change is the replacement of the construct heterosexist events with homonegative microaggressions. Heterosexist event measures, such as the Heterosexist Harassment, Rejection and Discrimination Scale (HHRDS) used by Szymanski in much of her research, tend to be one dimensional in nature. Heterosexist event measures assess the hostility of the environment, but do not tap into additional factors such as recency or personal impact. Additionally, measures like the HHRDS tend to reflect specific events such as being fired from a job due 
to a sexual identity rather than subtle discriminations like assumptions of heterosexuality. A recent measure developed by Wright and Wegner in 2012 allows for a more nuanced assessment of LGB individual's experience in a heterosexist environment. The three factor structure utilized in their measure allows for the assessment not only the amount of microaggressions experienced by an individual, but also the recency and impact of said microaggressions. Additionally, utilizing homonegative microaggression as an independent variable will allow the proposed model to account for more subtle heterosexists events. By definition, microaggressions tend to be subtle in nature. Incorporating more sensitive measures in minority research should be a priority as systemic discrimination becomes more covert. While legislation, work-place and school regulations are increasingly providing protection for LGB individuals from more visible forms of aggression and discrimination, more subtle forms of heterosexism are difficult to regulate. It is therefore important to continually seek out sensitive measures to accurately assess the hostility of an environment.

\section{Protective Factors}

The literature covered in the first portion of this chapter highlighted the existing relationships in the current literature between microaggressions in the environment, internalized heterosexism and psychological and physical wellbeing. These variables have clearly been well researched in the past, but never in a LGB Christian college student population or in conjunction with social support and identity integration. 
Previous research on minority stress in LGB individuals tends to focus on negative factors and psychological distress outcomes. Research examining the minority stress effects on LGB individuals has historically focused on the negative impact of violence or aggressive crimes on LGB individuals' physical, emotional, and psychological well-being (Meyer, 2003). While these studies are important, recent efforts have been made to examine the subtle minority stress created by a culture that values heterosexism and devalues sexual orientation variance. In kind, this study focuses on an acknowledgement and exploration of protective and resiliency factors shown by LGB individuals in hostile environments. In additional to the uniqueness of the population targeted in this study the scope of past research has been expanded with the inclusion of moderating variables that could potentially act as protective factors. In this study, I hypothesize that environment, social support and identity integration will reflect potential strategies or protective factors that LGB Christian individuals may be able to access in order to offset the impact of proximal and distal minority stress on psychological well-being.

A moderator is a quantitative or qualitative variable that alters the direction or strength of the relationship between an independent variable and dependent variable (Baron \& Kenny, 1986). One of the moderators selected in this study, social support, has previously been shown to correlate with internalized heterosexism and microaggression. Social support, specifically, has been used as both a moderator and a mediator in models including internalized heterosexism and microaggression in past studies with mixed results (McGregor 
et. al 2001; Szymanski, 2009; Szymanski \& Carr, 2008; Szymanski \& Kashubeck-West, 2008). In light of the lack of social support and outright opposition to LGBT students' attempts to seek social-support on Christian campuses, the hypothesis is that this factor could play key roles in explaining the experience of LGB Christian college students in experience with microaggressions. In addition to social-support, the role of religious and sexual identity integration as a protective factor was also examined. Specifically, religious and sexual identity integration was modeled as a moderator of the path between homonegative microaggression and internalized heterosexism.

\section{School Type}

Researching the experiences of LGB Christian college students at Christian campuses is becoming increasingly relevant. A recent survey of undergraduate students at 19 Christian colleges found that while $96.4 \%$ of the students surveyed identified as heterosexual, $12.6 \%$ reported experiencing same sex attraction at some time. This finding illustrates that a significant percentage of students who choose to attend faith based colleges have some sort of sexual minority identity (Stratton, Dean, Yarhouse, \& Lastoria, 2013). A large percentage of this population tends to remain concealed, with $93.7 \%$ of sexual minority students at Christian colleges publicly claming a heterosexual identity, but some members of identifying as a sexual minority group are becoming more vocal (Stratton et al., 2013). Several Christian campuses have recently made headlines for denying LGB students the right to assemble, seek social support or express their sexual identity. In recent years, several Christian campuses have 
received open requests from LGB students for LGBT social support groups on campus. Many of the Christian campuses have denied these requests. Campus administrations have cited concerns regarding the appearance of condoning LGB behavior. Concerns have also been raised regarding students potentially using the support groups to find LGB partners as a rationale for denying the LGB student's request (Althoff, 2012). In addition to systemic heterosexism faced by LGB Christian students attending faith based institutions, some research has shown that sexual minority students at Christian colleges who report experiencing a negative campus environment perceive peer aggression to be more distressing than administrative aggression (Yarhouse, Stratton, Dean, \& Brooke, 2009).

One might wonder why a LGB Christian youth would choose to attend college at a campus that may publicly condemn their sexual identity. LGB Christian college students are not a homogenous group, and there is variability in the reasons for why a sexual minority individual would attend a conservative faith-based college. In a Christian college environment, campus administration may require allegiance to honor and conduct codes. On more conservative religious campuses, these codes typically forbid "sexual immorality" which can include the expression of LGB sexual identities along with pre-marital sex, pornography use and masturbation. Conversely while these environments often restrict sexual expression, they can also create a rich context for spiritual and religious development. LGB Christian college students at Christian colleges may value an environment where their spiritual identity is encouraged and celebrated at the cost of their sexual identities. Additionally, LGB Christian students may not 
have had space to fully process and accept their sexual identity before choosing a religious college, or they may have experienced family pressure to attend a college that aligned with their family of origin's religious tradition.

Alternatively, secular campuses typically have infrastructures in place to support LGB students. For LGB college students who were raised in a conservative Christian environment and are now attending a secular university, the secular college experience may be the first time that they are able to truly explore their sexual identity. Similar to the identity trade-off found at Christian colleges, there may be fewer opportunities for religious identity support and development while at secular college. Although it could be argued that many secular campuses have at least some resources and support groups for religious students, it should be noted that there are typically few supports for students struggling with the intersection of religious and sexually minority identities in either secular or Christian college environments.

Minority stress theory states that LGB individuals are exposed to higher levels of stigma and will therefore will experiences higher levels of psychological distress. Following this line of thought, LGB Christians who are in less affirming environments (Christian campuses with a code forbidding LGB sexual identity expression) will experience higher levels of stigma and therefore greater amounts of psychological distress. The environmental differences between religious and secular campuses for LGB Christian have not been previously explored. A unique piece of this study is the exploration of how affiliation with a Christian or religious campus could moderate the mediation role of internalized heterosexism 
in the relationship between homonegative microaggression and psychological distress.

\section{Social Support}

A significant component of any environment when viewed through the framework of well-being is the presence of social support. Minority stress theory posits that social support can aid in the alleviation of the negative effects of minority stress. Social support is therefore frequently conceptualized as a protective factor that reflects the level of social engagement and encouragement an individual has access to. Research examining the relationship between internalized heterosexism and social support has found negative significant relationships between these variables in both sexual minority women and men. Internalized heterosexism consistently has been found to significantly relate to fewer social supports, less satisfaction with social support, and a lack of integration into the LGB community (McGregor et al., 2001; Szymanski et al., 2001; Szymanski et al., 2008).

A recent study acknowledged the well-researched relationship between minority stress and psychological distress in LGB individuals, but recognized that social support may impact this direct relationship. Fingerhut, Peplau, \& Gable (2010) examined individuals' sense of belongingness to the LGB community as predictor of both exposure to sexual orientation based discrimination and reactivity to LGB minority stress. The results indicated that individuals who reported a higher level of connectivity to the LGB community reported higher levels of discrimination, but lower levels of perceived stigma than individuals 
with lower levels of connectivity. Additionally, the researchers found that those with higher levels of gay identity reported were better protected against the negative effects of perceived stigma, as those participants reported lower levels of depression than individuals with lower gay identity (Fingerhut et al., 2010). Similarly, Lehavot and Simoni (2011) predicted that psychosocial resources (such as social and religious support) would mediate the relationship between minority stress and negative mental health outcomes in sexual minority women. Acceptable model fit was found for the entire model, and psychosocial support accounted for $24 \%$ of the variance in negative mental health outcomes, supporting its mediating role in the model. Similarly, McGregor et al. (2001) found that for lesbian women with breast cancer a lack of perceived social support did significantly mediate the relationship between internalized heterosexism and distress.

Despite these findings, social support does not always act as a significant protective factor. Szymanski \& Carr (2008) examined the role of internalized heterosexism and gender role conflict in gay and bisexual men's psychological distress. Social support (along with several other factors) was included in the model as a mediator. The results found that while low social support predicted psychological distress, when self-esteem and avoidant coping were included in the model, social support no longer significantly related to psychological distress. Additionally, social support was not found to have a mediating role between selfesteem and psychological distress. The authors noted that the social support measure used did not assess LGB support specifically, which could explain why 
this construct did not significantly mediate the relationship. This explanation is contradicted by another study within the same year by Szymanski \& KashubeckWest that used the same measure for social support (The Social Support Questionnaire). Using this same measure in a sample of lesbian women, social support was found to significantly mediate the relationship between internalized heterosexism and psychological distress. This could be due to the differences in sexual orientation (lesbian and gay) between the populations targeted in this sample. Current gender norms may contribute to beliefs about it being more socially acceptable for women to seek out social support than men. Therefore, it is possible that social support plays a unique role in lesbian women's experience with minority stress that is not found in gay men.

Shidlo (1994) found that in addition to general social support, higher levels of internalized heterosexism were related to lower amounts of gay social support. Connected to the impact of concealment referenced earlier, Wright and Perry (2006) found that sexual identity distress was negatively related to being out to one's peer group in LGB youth. These results suggest that concealment of one's sexual orientation may make it difficult to obtain social support for one's LGB identity. Despite this relative consistency, conflicting results have been found in examining these variables. In a study of LGB youth, it was found that while peer and family support had positive effects of psychological distress, it did not fully offset the negative impact of minority stress (Mustanski, Newcomb, \& Garofalo, 2011). 
Past research examining social support as a successful moderating variable has been limited. Szymanski (2009) found that social support did not moderate the relationship between heterosexist events and psychological distress in gay and bisexual men. As mentioned earlier, this result could in part be due to the limited variance in the sample. The sample used in this study comprised of highly educated, white, high SES (40\% of the participant had an annual income above $\$ 60,000)$ men with a mean age of 36 . These men also did not report high levels of heterosexist events, meaning that social support for this population may not have been as necessary for coping due to low levels of external minority stress. Alternatively, social support was found to act as a mediator between internalized heterosexism and psychological distress in sexual minority women (Szymanski \& Carr, 2008; Szymanski \& Kashubeck-West, 2008). Despite this empirical support for social support acting as a mediator instead of a moderator, using Meyer's (2003) minority stress model, social support seems to act best as a moderator conceptually, since the hypothesis is that this construct will act as a protective factor in moderating the paths between microaggression, internalized heterosexism and psychological distress. Additionally, while the lesbian internalized heterosexism scale does have a factor that reflects the level of LGB community involvement an individual engages in, research has shown that LGB individuals can experience microaggressions from the LGB community (Nadal et al., 2011). For this reason, social support was assessed as a separate construct, so assumptions are not made that LGB community involvement and social support are interchangeable constructs. 


\section{Religious and Sexual Identity Integration}

While social support and internalized heterosexism provide some information about LGB individuals' well-being and adjustment, neither of these constructs reflect the complexity of LGB Christian individuals' experience with identity development. Research examining the relationships between religion, spirituality and sexual identity has found that many LGB individuals value their spiritual and religious identities as well as their sexual identity (Rodriguez \& Ouellette, 2000). According to Erikson's psychosocial model of development, identity development tends to occur in late adolescence and early adulthood, which coincides with the traditional college years. Identity formation can become complex as multiple (and sometimes conflicting) identities can exist within the same individual. The co-existence of multiple identities is often labeled as "intersectionality." Intersectionality has historically been used to describe the compound and unique discriminatory impact multiple minority identities can have on the individual (Macionis \& Gerber, 2011). While Christianity is by no means a marginalized or minority identity within the United States, the concept of intersectionality is a useful lens in conceptualizing that multiple identities can interact, conflict or merge in a way that may differ from individuals aligning with only one minority identity. An individual who identifies with two groups that are unaccepting of one another may be at risk for internal identity conflict. This conflict is often prevalent when an individual is immersed in an environment that supports one identity but rejects another identity with which they align. Identity conflict can manifest among a number of identities including racial identity, 
religious identity and sexual orientation. The process of identity integration can be challenging and painful regardless of the type of identities one possesses, and there are unique challenges faced by those who are attempting to integrate identities that at times feel contradictory or hostile to one another. Despite the potential difficulty of identity integration, Meyer (2003) explained in his minority stress model that "the integration of all identities is an important aspect of the self-acceptance and protection against minority stress" (p. 8).

The integration of religious and sexual identities has been conceptualized in similar ways by several different researchers. Rodriguez and Ouellette (2000) proposed a four-step model of sexual and religious identity integration; (1) rejecting the religious identity, (2) rejecting the sexual identity, (3) compartmentalizing each identity or (4) integrating these identities fully. Another qualitative study examining the experiences of 12 lesbian and gay college students interacting spiritual and sexual identities proposed a model of "reconciliation" rather than integration. Reconciled students are those who have accepted both sexual and religious identities. Despite past pain the struggle between these two identities may have caused, a reconciled student is currently comfortable with both identities (Love, Bock, Jannarone, Richardson, 2005). Recent research by Gold and Stewart (2011) found a similar pattern when examining how LGB undergraduate students integrate their sexual and spiritual identities. The results indicated that students were able to integrate with varying levels of success exhibited by reconciliation; progressive, arrested or completed development and reconciliation. 
Regardless of the model of integration, all of these theories imply that religious and sexual identities may cause conflict due to the exclusive and heterosexist nature of many organized religions. Within the United States, many hostile messages towards LGB individuals originate from religious organizations. Some Protestant denominations view homosexuality as a choice inconsistent with religious beliefs (Buchanan, Dzelme, Harris, \& Hecker, 2001; Rodriguez \& Ouellette, 2000; Wilcox, 2002). The Catholic Church acknowledges that innate variant sexual orientations exist, but holds the position that acting on this orientation is sinful (Buchanan et al, 2001, Wilcox, 2002). Alternatively, some religiously affiliated anti-LGB groups view variant sexual or gender identities as a disorder. Much like the pre-feminist theory conceptualization of LGB stress, these groups will often point to the minority distress LGB individuals can experience as evidence of the "mental illness" aspect of sexual orientation variance (Wilcox, 2002). Despite condemnation of such practices from the APA, this mindset has led to the formation of the conversion or reparative therapies movements where sexual orientation is viewed as something that can be changed or "fixed" with religious and psychological intervention (APA, 2006; Robinson \& Spivey, 2007). This is not to say that all Christian denominations have openly negative attitudes towards the LGB population. Some congregations specifically advertise as being "gay friendly" or "affirming churches". According to gaychurch.org, there are 7,578 of these churches worldwide (retrieved May $31^{\text {st }}, 2016$ ). Additionally, the former Evangelical affiliated conversion therapy organization Exodus International recently issued an apology to the LGBT community for the harm the 
organization has caused (Steffan, 2013). Despite the changes in some religious organizations to move towards inclusion, LGB affirming churches comprise a small percentage of religious organizations, and do not reflect the larger attitudes of most church bodies. LGB individuals who are religious are more likely to be involved in non-LGB affirming religious organizations than in affirming religious organizations (Buchanan, Dzelme, Harris, \& Hecker, 2001). LGB individuals' affiliation with a non-affirming religious organization has been found to relate to higher levels of some minority stress factors such as internalized homophobia, although it does not significantly relate to negative mental health (Barnes \& Meyer, 2012). Furthermore, Rodriguez and Ouellette (2000) found in a sample of 101 gay men and lesbian women that $25 \%$ of participants who belonged to a gay affirming religious organization still had not fully integrated their religious and sexual identities as there was no significant difference between this sample and a community sample of gay Catholic men's level of internalized homophobia. This result indicates that even in an environment designed to be supportive of religious and sexual identities; the relationship between these two identities remains complex.

Understanding the intolerant attitudes and mixed messages LGB Christian individuals can receive from religious organizations highlights the confusing arena a religious LGB individual must navigate. When authority figures related to one important aspect of a person's identity denounce another important identity component, identity confusion and conflict seem unavoidable. Overcoming internalized heterosexism is considered by some to be a key aspect of positive 
identity formation in LGB individuals (Frost \& Meyer 2009). One theological researcher posited that spirituality is a concept that encompasses the entire individual, including sexuality. In order to be an integrated human being, one must reconcile the spiritual and sexual aspects of the self into one identity (Helminiak, 1995). Research has shown that this task of identity integration can be challenging for some LGB Christians. One study found that religious wellbeing in LGB individuals positively correlated with greater levels of shame and guilt. Individuals who experienced less shame and internalized homophobia tended to view religious doubts as positive occurrences (Sherry, Adelman, Whilde, \& Quick, 2010). Another study by Lease, Horne, and Noffsinger-Frazier (2005) found a positive predictive relationship between high levels of religious conflict and internalized heterosexism.

Identity conflict can be especially prevalent for LGB individuals in the process of discovering one's sexual orientation or gender identity within a religious environment or belief system, but it is not an unavoidable certainty. As Meyer elaborates in his minority stress model, other identities (including religious identity) can interact with an LGB minority identity in a protective or maladaptive manner. An older qualitative interview of gay men by Yip (1997) gathered information about individuals' ability to integrate their religious and sexual identity. The men cited positive personal experiences, beliefs that their Christian principles and values enriched and supported their same-sex relationships as the catalyst for integration (Yip, 1997). A study by Lapinski \& McKirnan (2013) found that no significant differences between past and current LGB Christians in 
their attitudes towards their own sexual identities, indicating that LGB Christians are fully capable of integrating their sexual and religious identities in a positive way. Despite these positive findings, it should be noted that the population sampled were targeted through LGB-affirming churches and organizations. As stated in earlier work by Meyer (2003) and Szymanski (2001), it is possible that internalized heterosexism and identity conflict were not as prevalent for individuals who were immersed in LGB affirming environments. This potential environmental factor has been highlighted as a limitation of past LGB research. Szymanski, Kashubeck-West \& Meyer (2008) pointed out that the majority of the research conducted on the relationship between sexual minority stress (specifically internalized heterosexism) has utilized samples from LGB affirming religious organizations. This means there has been little variability in LGB religious individuals' experiences represented in the current literature. There is the possibility that the experiences of LGB individuals who do not belong to LGB affirming churches have very different experiences in negotiating minority stress.

Research further supports this by suggesting that identity conflict is more salient for more conservatively religious individuals. One study found LGB individuals reported greater amounts of internalized homophobia when aligned with a more conservative religious belief system (Sherry, et al., 2010). While little quantitative research has been conducted to this effect, a qualitative study of gay men raised in fundamental Christian environments observed participants reporting that their faith had contributed to feelings of isolation and guilt (Loon, 2003). Some research has further supported the complexity of religiously by finding that 
Christianity differs as a protective or risk factor, based on the level of religious guidance reported. In 2013, Longo, Walls, and Wisenki found that Christians with low religious guidance exhibited the least risk for non-suicidal self-injury, with secular participants exhibiting a moderate risk and Christians with high religious guidance exhibiting the most risk. This research as a whole seems to indicate that well-being for LGB Christians may be influenced by complex interactions between environmental and individual identity factors.

\section{Current Study}

The purpose of this study is to target a population that has not been well represented in either homonegative microaggression or internalized heterosexism literature, sexual minority Christian college students. The previous focus on individuals with low levels of internalized heterosexism in LGB minority stress research has potentially robbed several studies of the necessary variance to explore the potentially complex relationships among these variables. By comparing a mediation model of internalized heterosexism in LGB Christian college students across the conditions of several moderators, we will examine rich information about the relationships between potentially conflicting identities. This study is based on Meyer's (2003) model of minority stress by examining the impact of a source of distal minority stress (microaggression) on psychological distress and exploring how a type of proximal minority distress (internalized heterosexism) mediates this impact across context. Using a moderated mediation model, the moderating roles of campus type, social support, and identity integration on the path between homonegative microaggression and internalized 
heteorsexism, embedded within a mediation model of minority stress will be examined (Preacher, Rucker, \& Hayes, 2007). These latter two moderating variables of social support and identity integration will mimic the function of protective factors embedded within Meyer's model (2003). Finally, two aspects of identity salience (Christian and LGB identity) will be modeled as control variables.

\section{Hypotheses}

Based on both past research and minority stress theory, this study hypothesizes that:

1. Internalized heterosexism will partially mediate the relationship between homonegative microaggression and psychological distress in LGB Christian college students.

2. The mediating role of internalized heterosexism will vary between LGB Christian college students at Christian campuses and secular campuses. Specifically, internalized heterosexism will account for more of the relationship between homonegative microaggression and psychological distress in LGB Christian students on Christian campuses, meaning that the indirect effect of internalized heterosexism will be moderated by campus type.

3. The internalized heterosexism mediated path between microaggression and psychological distress will vary based on the level of social support. Specifically, the relationship between heterosexism microaggression and 
internalized heterosexism will be less in students with higher levels of social support.

4. The internalized heterosexism mediated path between microaggression and psychological distress will vary based on the level of identity integration participants report. 


\section{CHAPTER 2: METHOD}

\section{Sample}

The focus of this research study is sexual minority Christian individuals in a college setting. Prior to the 2000s, much of the LGB minority stress research focused on samples of either lesbian or gay individuals, but within the past decade bisexual individuals have been increasingly included in studies. This study continued this inclusionary approach by targeting all sexual orientation minority identities but excluded including individuals who identity as transgender individual with no sexual minority identity (i.e., transwoman, heterosexual) due to discrepancies in how microaggression and internalized stigma are experienced within the LGBT umbrella. Participants of all genders were encouraged to participate. The instructions for the survey stated that all individuals who identified as a sexual identity minority were welcome to participate, but that language in the surveys may not be inclusive of all individuals preferred labels for their sexual identity. College students from ages 18-25 were included, while individuals outside of this age range were not included in the final analysis. Although the traditional college age is $18-22$, by expanding the age range to 25 this study was able to capture data from individuals who may have started college later but are still developmentally within a time of identity exploration and integration. This age range is consistent with previous research exploring college undergraduates' experience with sexual orientation minority stress (Woodford et al., 2012a; Woodford et al., 2012b). Participants were recruited through 
respondent driven sampling. Contact was made for the first round of participants via Facebook groups, campus affiliated LGBT support groups, campus listserves, and university counseling centers. Participants were encouraged to recruit additional participants who fit the inclusion criteria of this study, which will be LGB college students who identify as Christian. This study targeted populations from both Christian and secular colleges. Secular and Christian liberal arts schools were defined by how the college websites "about the college" section defined the university. Specifically, to be included in this study, the university needed to include in the mission statement a reference to (1) identifying as a college or university (2) an affiliation with Christianity (for the Christian campus subgroup) or (3) a lack of stated affiliation with any religious group. For example A College's "about the college" section states that A College is a four-year, private liberal arts institution founded in 18XX and affiliated with the United Methodist Church, and therefore A College would be coded as being a Christian campus. College B's "about the college" section states that College B is a fouryear, highly selective liberal arts college and conservatory of music. College B does not state any affiliation with any type of religious framework and therefore College B would be coded as a secular campus.

LGB Christian students on some Christian campuses are a vulnerable population, with the risk of expulsion, harassment, or violence if their participation in a LGB identity survey was discovered. Contact was also made with leaders of both underground and campus-sanctioned LGB support groups within various Christian campuses nationwide. Several of these leaders expressed 
concern over the safety and privacy of students who chose to participate. In an effort to conduct ethical research and protect anonymity, social media was used for both recruitment and participation. Past research has shown that internet surveys are a useful tool for reaching sexual minority populations who may not be out (Riggle, Rostosky, \& Reedy, 2005). A digital survey was distributed with a link to Qualtrics that was distributed via various LGBT groups through e-mails to students, postings on Facebook, Reddit message boards and newsletters. Entry into a drawing for a $\$ 100$ gift card was offered for every time an individual either a) participates in taking the survey or b) someone else takes a survey and enters the e-mail address of the individual who forwarded it to them. This process is called snowball sampling, a method that can facilitate more access to a small population than traditional sampling methods. Traditional recruitment methods can result in surveys only being distributed to individuals connected to the researchers. By incentivizing the distribution of the survey through participants, it is more likely that a broader network of the targeted population was accessed.

Networking, incentives, and respondent-driven sampling were used to increase participation. Snowball sampling procedures were utilized to target LGB Christians in secular universities and colleges. As suggested by Kline (2010), at least 200 participants should be sampled for each group (Christian and secular campuses). Taking into account the number of latent (5) and observed variables (23), an online A-priori sample size calculator (http://www.danielsoper.com/statcalc3/calc.aspx?id=89) was used to conduct a power analysis. The results suggest that 45 participants will be needed to detect a 
moderate effect. It was also recommended by the calculator that a minimum of 88 participants are sampled for the model structure. Despite the small number of participants needed for analysis, thus study aligns with Kline's (2010) recommendation to exceed 200 participants and a final sample of 207 was obtained. Post hoc power analysis was not conducted due support in the literature for the lack of valid statistical meaning for the concept of "observed power" (Hoenig \& Heisey (2001). Institutional Review Board approval was granted through the University of Louisville and recertification of approval was maintained in alignment with IRB regulations.

\section{Demographics}

Of the 207 participants, all disclosed gender identity with 106 identifying under the category of cisfemale (e.g. "women" or "female"), 79 identifying under the category of cismale (e.g. "man" or "male"), and 22 identifying within the category of transgender (e.g. transman, genderless). $85 \%$ of respondents identified as White/Caucasian, $8.2 \%$ as African American, $7.2 \%$ as Hispanic, 5.8\% as Asian, $2.9 \%$ as Native American, $1.4 \%$ as Pacific Islander, and $1.9 \%$ as "Other." The majority of participants (79.2\%) were between the ages of 18 and 22 with only $16 \%$ identifying as being between the ages of 23 and $25.4 .8 \%$ of respondents elected not to report their age, but all participants were required to confirm that they were between the ages of 18-25 to participate in this study. Fewer total participants reported school type $(n=200)$ with 109 reporting that they attended a secular college (coded as 0 ) and 91 (coded as 1) reporting they attended a Christian college. 62 different universities were represented in the 
sample. The range of participants based on school was 1-8, with 8 participants being the largest number to attend the same university. The average GPA for participants was 3.4 .

The majority of participants $(81.2 \%)$ stated that their college or university had a support group for LGBT students, while $10.1 \%$ were not certain if their campus had such a group, and $8.7 \%$ stated that their campus did not have an LGBT support group. All participants provided their sexual orientation label with 33 identifying as lesbian, 72 identifying as gay, 50 identifying as bisexual, 19 identifying as queer, 25 as pansexual, 4 as same sex attracted, 2 as mostly heterosexual and 4 as "other." The most popular Christian religious identities listed were nondenominational $(n=64)$, Catholic $(n=30)$, Baptist $(n=18)$, Methodist (12), Episcopalian ( $\mathrm{n}=10)$, Lutheran $(\mathrm{n}=11)$ and Seventh Day Adventist $(n=10)$. The remaining religious identities had less than 10 participants represented, included Anglican, Brethren, Christian, Church of Christ, Disciples of Christ, Eastern Orthodox, Evangelical, LDS, Mennonite, Messianic, and Wesleyan. The majority of participants $(52.1 \%)$ reported that they at least attended church a couple of times per month. Only $7.2 \%$ stated that they did not attend church at all. When asked if the church they attended was an LGBT affirming church, the majority of participants stated no (68\%), while $28 \%$ of the participants stated yes, and $3.9 \%$ chose not to answer. The majority of respondents (94.2\%) stated that they were "raised in a Christian household" meaning that at least one adult guardian identified as Christian.

\section{Measures}




\section{Homonegative Microaggression}

The Homonegative Microaggressions Scale (HMS) is a 45-item measure that uses a 5-point Likert scale (Wright \& Wegner, 2012). Although there are 11 categories of microaggression embedded within the scale, Wright and Wegner state that the three subscales within this measure are the current frequency, past frequency and impact of microaggressions. The internal consistency for these three subscales in the literature ranges from .94-.96. Using this study's data, the internal consistency was Recent Frequency of Microaggression $\alpha=0.93,95 \%$ CI [0.921, 0.931]; Past Frequency of Microaggression $\alpha=0.94,95 \%$ CI [0.936, 0.944], Impact of Microaggression $\alpha=0.924,95 \%$ CI [0.919, 0.928]. The 11 theoretical microaggression factors within this scale are based on the Sue et al. (2007) categorization of racial microinvalidations, microinsults, microassaults. An example of questions on this measure is "Has anyone ever assumed you had HIV/AIDS because of your sexual orientation?" This scale has been found to exhibit good content, construct, and criterion validity (Wright \& Wagner, 2012). A few items in this measure focus on the gay male/female lesbian experience, at times expressing gender as a dichotomy. In an effort to correct this limitation, with the permission of the author, I reworded a few items to be more gender inclusive for participants who do not identify using traditional gendered language. Depending on the method of analysis, missing data were replaced at the item level by using multiple imputation or pulled using listwise deletion and the subscales were be calculated by summing the relevant items for each construct.

\section{Internalized Homophobia}


A short-form modified version of the Lesbian Internalized Homophobia Scale (LIH; Szymanski \& Chung, 2001) was used to assess the presence of an individual's negative attitudes towards their own sexual orientation. The original full length LIHS lesbian and bisexual version provided by Szymanski and Chung (2001) was created to be used to only assess lesbian and female identified bisexual individuals. A few years later, a 39-item short-form version of the original survey was created by Piggot (2004). This version was adapted to be more gender inclusive with permission from the authors. Participants completed the modified short-form, gender inclusive version of this scale, consisting of 39 items rated on a 7-point Likert scale. For example; the original LIHS version read "I have respect and admiration for other lesbian woman." and the modified version now reads "I have respect and admiration for other lesbian/gay/bisexual individuals." The short form was validated by the measure's author for sexual minority women but needed to be checked for validity when the measure was adapted to be gender inclusive. In the original scale internal consistency was analyzed using a sample of lesbian women $(\alpha=.94)$ and construct validity, using the same sample, was supported by significant correlations between found between the LIHS and self-esteem and loneliness measures (Szymanski \& Chung, 2001). Internal consistency for these data varied from the "acceptable" to "good" range across the four subscales; Attitudes Towards Other Lesbian/Gay/Bisexual $\alpha=0756,95 \%$ CI $[0.736,0.772]$, Personal Feelings About Being Gay/Lesbian/Bisexual $\alpha=0.823,95 \%$ CI [0.811,0.835], Personal Identification as Lesbian/Gay/Bisexual $\alpha=0.88695 \%$ CI $[0.878,0.893]$, and Connection with the 
Lesbian/Gay/Bisexual Community $\alpha=0.85,95 \%$ CI [0.84, 0.859]. Depending on the method of analysis, missing data were replaced at the item level by using multiple imputation or pulled using listwise deletion, and the subscales were calculated by summing the relevant items for each construct.

\section{Psychological Distress}

The 34-item Counseling Center Assessment of Psychological Symptoms (CCAPS-34; 2001) is a measure of psychological distress in college students. Internal consistency for this data varied from the "acceptable" to "good" range across the seven subscales: Depression $\alpha=0.858,95 \%$ CI [0.849, 0.867], Generalized Anxiety $\alpha=0.837,95 \%$ CI [0.827, 0.848], Social Anxiety $\alpha=0.802$, 95\% CI [0.788, 0.816], Academic Distress $\alpha=0.759,95 \%$ CI [0.74, 0.776], Eating Concerns $\alpha=0.837,95 \%$ CI [0.825, 0.848], Hostility $\alpha=0.774,95 \%$ CI [0.759, 0.788], and Alcohol Use $\alpha=0.798,95 \%$ CI [0.784, 0.811], which all load onto a Distress Index $\alpha=0.782,95 \%$ CI $[0.767,0.796]$ The measure also includes a Suicidal/Homicidal Ideation checklist. This measure was normed on a United States college student population but has not been normed on a Christian LGB population. Although understandable that a general psychological symptom measure would not include such a specialized population in the norming sample, this exclusion may be a limitation considering the unique aspects of psychological distress in individuals with these intersecting identities. Specifically, alcohol use may have a floor effect due to the number of participants who may attend a dry campus or abstain from alcohol use for religious reasons. This possible limitation is explored in the discussion section and the analysis of an alternative model in 
the results section. The CCAPS-34 exhibited acceptable test-retest reliability $(.74$ - .87) in a sample of non-clinical college students at one and two week intervals. Test developers have found that the internal consistency for this measure ranged from $.89-.82$. Convergent validity of the CCAPS-34 has been assessed by examining correlations between the 8 subscales and similar measures including the AUDIT (.78), BAI (.68), BDI (.70), Social Phobia Diagnostic Questionnaire (.76), EAT (.52), the Marlow-Crown Social Desirability Scale (.44-.26), the State Trait Anger Expression Inventory (.69), and Student Adaptation to College Questionnaire (-.68) (Locke et al., 2012). Depending on the method of analysis, missing data were replaced at the item level by using multiple imputation or pulled using listwise deletion, and the subscales were be calculated by summing the relevant items for each construct.

\section{Identity Salience}

At this time there appears to be no existing measure of either Christian or sexual orientation identity salience. In order to assess these constructs a new measure was created that is based on the African American Racial Identity Scale subscale of centrality. Four items from the centrality subscale were pulled from the original 56-item inventory and adapted to measure the centrality or salience of both spiritual and sexual identity for the participants in this study. A sample question from the Christian identity salience is "Being a Christian is an important reflection of who I am.” A sample question from the sexual minority identity salience is "Being a LGB/SSA individual is an important reflection of who I am." Sexual and religious identity salience were then used as control variables within 
all three models. Internal consistency for this data varied from the "acceptable" to "good" range for the two constructs, Christian Identity Salience $\alpha=0.889,95 \%$ CI $[0.881,0.897]$ Sexual Orientation Identity Salience $\alpha=0.825,95 \%$ CI [0.812, 0.837]. Depending on the method of analysis, missing data were replaced at the item level by using multiple imputation or pulled using listwise deletion, and the subscales were be calculated by summing the relevant items for each construct.

\section{Social Support}

The 12-item Multidimensional Scale of Perceived Social Support (MSPSS; 1988) measures how the participant views the availability of social support resources through friends, family, or significant others. All items utilize a 7-point Likert scale. Sample questions include "I can talk about my problems with my friends" and "I have a special person who is a real source of comfort to me." Internal consistency for all three subscales in this data set was excellent; Family $\alpha=0.89195 \%$ CI $[0.884,0.898]$, Significant Other $\alpha=0.938,95 \%$ CI [0.933, 0.942] Friends $\alpha=0.901,95 \%$ CI [0.894, 0.907]. Test developers stated that re-test

reliability with a 2-3 months interval was .85 . Construct validity was supported by significant correlations between the MSPSS and the anxiety and depression subscales of HSCL (Zimet, Dahlem, Zimet \& Farley, 1988). Depending on the method of analysis, missing data were replaced at the item level by using multiple imputation or pulled using listwise deletion, and the subscales were be calculated by summing the relevant items for each construct.

\section{Spiritual and Sexual Identity Integration}


This three-item scale is a composite measure combining several items used by previous researchers to assess conflict between sexual and spiritual identities (Dahl \& Galliher, 2009; Hamblin \& Gross, 2011). An example of questions on this measure is "To what extent have you combined your sexual orientation and your religious beliefs?" The items are rated on 5-point Likert scale, with a higher rating reflecting higher levels of spiritual and sexual identity integration. This measure is constructed by the researcher utilizing items used to measure sexual and spiritual identity integration in two previous studies (Dahl \& Galliher, 2009; Hamblin \& Gross, 2011). As a result, there is no current reliability and validity information on this measure. Internal consistency for this item was borderline questionable $\alpha=.0681,95 \%$ CI $[0.657,0.705]$. Depending on the method of analysis, missing data were replaced at the item level by using multiple imputation or pulled using listwise deletion, and the subscales were be calculated by summing the relevant items for each construct.

\section{Demographic Questionnaire}

A series of demographic question was administered at the beginning of the survey. Questions about the participant's age, race/ethnicity, same sex attraction, sexual orientation, gender identity, religious identity, and school type were also assessed.

\section{Model Fit}

A strength of SEM is the ability to assess for model fit and obtain information about how well the constructs in this study are being measured. 
Assessment of model fit is accomplished by creating a measurement model and examining fit indices. For acceptable model fit, a non-significant chi square test is desirable but not always obtainable. If a model has a significant chi-square test, additional indices can be examined. If the model has a TLI at or above the .90 acceptable range, a CFI value at or above the acceptable range of .93, a RMSEA value lower than the .08 cut-off with the high end of the $90 \%$ confidence interval below the 0.1 cut-off, one could claim acceptable model fit (Bentler, 1990;

Browne \& Cudeck, 1993; Marsh et al., 2004). Without acceptable model fit, the ability to make accurate conclusions from the structural model becomes compromised. 


\section{CHAPTER 3: RESULTS}

The purpose of this research was not to create a comprehensive model that combines all identified moderators into one model. Instead the analyses comprise three separate moderated mediation models. In each model, the moderating effects of school type, social support, or identity integration on the mediating role of internalized heterosexism between homonegative microaggression and psychological distress were explored.

As such, the primary model in this study is predicting that the mediation effects of internalized heterosexism between homonegative microaggression and psychological distress will vary based on the context of the level of school type (secular vs Christian). Two other potential moderators that could have an impact (identity integration and social support) on the mediating role of internalized heterosexism were included as separate moderated mediation models. This inclusion was made due to interest in how these variables may influence in the path between external minority stress and internalized minority stress. Although the religiosity of the environment (as represented by school type) may be a significant moderator, it is possible that other environmental (social support) or internal (identity integration) factors could have an impact on the strength and/or direction of the mediating role of internalized heterosexism. Furthermore, because secular or Christian colleges have not been included as a variable in previous sexual orientation minority stress research, it seemed prudent to include other better-developed variables in the model to act as a comparison. 
Including a mediator and several moderators into one model necessitates comparing indirect effects across context or analyzing conditional indirect effects (Preacher, Rucker, \& Hayes, 2007). There are several suggested methods for how to successfully observe the conditional indirect effect in moderated mediation models.

1. Piecemeal approach (Edwards \& Lambert, 2007): The mediators and moderators are analyzed separately.

2. The subgroup approach (Edwards \& Lambert, 2007): The sample is split based on the moderator (i.e., secular and Christian colleges) and the mediation effects of internalized heterosexism are tested within each subgroup.

3. Moderated causal steps approach (Edwards \& Lambert, 2007) moderation (of school type, social support, and integrated identities) is tested before and after controlling for mediator (internalized heterosexism).

4. Interaction approach (Preacher, Rucker \& Hayes, 2007) - the interaction between the predictor variable (microaggression) and moderator (school type, social support, or identity integration) is included in the model as loading onto the relationship between the predictor and mediator (internalized heterosexism).

The primary hypothesis (the mediation role of internalized heterosexism between microaggression and psychological distress differs across school type) seems at first to align the best with the division of groups based on the primary moderator (school type). Using the subgroup approach, two separate mediation models divided by school type could be run, and the indirect effects compared to see if they differ when grouped by the level of moderator. Although this analysis 
at first appears to be the best approach for school type, there are a few limitations to this approach. The first is that by analyzing the moderators of social support and identity integration in this manner, the continuous variables in models 2 and 3 would need to be transformed into dichotomous variables, which could reduce the variance in these constructs. The second limitation is the loss of power, or the lowering of the models' ability to detect genuine effects, from dividing the sample into two separate models. If multiple models were compared at different levels of the moderator, a sample size of 200 would need to be collected for each level to obtain a sufficient sample size for the analysis. Because 200 participants were not collected from each group of the primary moderating variables (school type, social support, and identity integration) a different method of analysis (i.e., the interaction approach) was needed.

Two methods were utilized to analyze the moderated mediation model (Hayes' PROCESS approach in SPSS and SEM in SPSS Amos) to address limitations in both approaches. The PROCESS method allows for the analysis of a smaller sample size but cannot support a dataset in which multiple imputation or maximum likelihood has been used to address missing data. For the PROCESS method, listwise deletion was used to account for missing data, which resulted in a smaller sample size of 134. Additionally, although the PROCESS approach provides information about the significance of paths among variables, it does not provide information about the goodness of fit of the proposed measurement model, include measurement error, or allow for the use of latent variables. Therefore, to obtain information about the fit of the model and to utilize the full 
dataset, SEM was also run in Amos. To address the missing data and run the analysis with at least a minimum of 200 participants, multiple imputation was necessary. Further details about this process can be found in the missing data section below. In Amos 23, the hybrid moderated mediation model was run for all three models. Using Bollen's two-step rule (1989), the hybrid model was assessed by assessing the model fit of the measurement model and then the structural model.

\section{Assumptions}

\section{Directionality}

SEM specifies the direction of causal paths. This means that predictor variables should have temporal precedence over outcome variables. The one-time observation nature of this study prevents a true mediation analysis because technically, the direction of the paths in the proposed model will not be known for certain. This also means that there are likely many alternative models that could be constructed using the targeted variables. Despite this limitation, there is a precedence set by multiple researchers for utilizing a mediation model in the prescribed order with these variables (internalized heterosexism, homonegative microaggression, psychological distress, and social support) during one-time observation analysis (Meyer, 1995; Szymanski, 2009).

\section{Collinearity}

Although the process of SEM necessitates an association among explanatory variables, there should not be a perfect relationship among any of the variables utilized in this model. This assumption was checked by viewing the 
correlations among all variables used in this analysis and ensuring that said correlations did not approach too strong of an either positive or negative correlation (Table 1). 
Table 1

Correlations Among Measures

\begin{tabular}{|c|c|c|c|c|c|c|c|c|c|c|c|c|c|}
\hline Measure & 1 & 2 & 3 & 4 & 5 & 6 & 7 & 8 & 9 & 10 & 11 & 12 & 13 \\
\hline 1 School & 1 & & & & & & & & & & & & \\
\hline $2 \mathrm{MAr}$ & .001 & 1 & & & & & & & & & & & \\
\hline 3 MAp & .067 & $.530 * *$ & 1 & & & & & & & & & & \\
\hline $4 \mathrm{MAi}$ & .103 & $.661 * *$ & $.559 * *$ & 1 & & & & & & & & & \\
\hline 5 IDint & $-.145^{*}$ & $-.271 * *$ & .058 & -.100 & 1 & & & & & & & & \\
\hline 6 LGBID &.--62 & .006 & -.091 & $-.214 * *$ & $-.230 * *$ & 1 & & & & & & & \\
\hline 7 XID & .012 & .017 & -.089 & $-.196 * *$ & $-.260 * *$ & $.590 * *$ & 1 & & & & & & \\
\hline 8 IHComm & .037 & .055 & -.047 & -.024 & $-.165^{*}$ & $.271 * *$ & -.076 & 1 & & & & & \\
\hline 9 IHOut & .081 & $.430 * *$ & .131 & $.247 * *$ & $-.481 * *$ & $.158^{*}$ & -.028 & $.464 * *$ & 1 & & & & \\
\hline 10 IHSelf & .041 & $.295 * *$ & .049 & .125 & $-.400 * *$ & .081 & -.134 & $.392^{* *}$ & $.616^{* *}$ & 1 & & & \\
\hline 11 IHOthers & -.043 & $.216^{*}$ & .042 & .064 & $-.192 * *$ & $.239 * *$ & .040 & $.510 * *$ & $.366 * *$ & $.494 * *$ & 1 & & \\
\hline $12 \mathrm{SS}$ & -.013 & $-.300 * *$ & .009 & $-.262 * *$ & $.249 * *$ & -.103 & .025 & $-.223 * *$ & $-.438 * *$ & $-.257 * *$ & $-.284 * *$ & 1 & \\
\hline 13 CCAPS & .082 & $.204 *$ & .011 & .043 & $-.251 * *$ & .004 & $.172 *$ & .056 & $.345^{* *}$ & $.372^{* *}$. & $.161^{*}$ & $-.266^{* *}$ & 1 \\
\hline
\end{tabular}

Note. $* \mathrm{p}<.01, * * \mathrm{p}<$ 


\section{Normality, Linearity, and Homoscedasticity}

SEM also assumes that the data observed follow a normal distribution. This assumption was checked by viewing histograms of all explanatory variables to determine if the data follow a normal curve distribution. Review of histograms illustrated that the data were acceptable and followed a normal curve.

SEM also assumes that the relationships between variables is linear and does not curve. To check for linearity, scatterplots were created to assess for a bivariate linearity or curvilinear relationships to ensure there is a linear relationship between explanatory variables using the factor scores. Acceptable linear relationships were observed for all variables.

Finally, SEM also assumes that the error variance between data points is similar across variables. To check for heteroscedasticity among errors, the normality of all explanatory variables should be established, with any outliers addressed. Error variances were plotted and observed to follow an acceptable linear distribution.

\section{Representativeness of Sample}

Bootstrapping is a resampling method that estimates the sampling distribution of the parameter estimates to obtain approximate standard errors. As recommended by Preacher et al. (2007), when assessing indirect effects, bootstrapping was conducted so that the shape of the data was assumed to fit a normal curve before analysis. This process is especially useful in instances where it is unknown if the sample accurately represents the targeted population. Despite utilizing respondent-driven sampling to increase the likelihood of a representative 
sample, bootstrapping this study provided another method of tapping into the true distribution of the data and allowed for the assessment of the statistical significance of the indirect effects.

\section{Measurement Error}

An additional assumption, and strength, of SEM is the assumption that latent constructs are not measured perfectly. Error in measurement is included in all measurement models that were tested, allowing for unreliability of measures to be included in the analysis.

\section{Missing Data}

Two methods of addressing missing data were utilized. PROCESS using SPSS will not run a dataset in which multiple imputation has been used. Because PROCESS does not have as stringent of requirements for sample size, listwise deletion was conducted when using this method resulting in a sample size of 134. Addressing missing data in Amos was a more complex issue. Listwise deletion would have resulted in a sample size below the recommended n of 200. Although there are several methods for addressing missing data, best practice suggests that multiple imputation be used to replace missing data (Osborne, 2012). Multiple imputation does not require that the missing data be missing completely at random and can produce more robust estimates and confidence intervals than older methods (such as listwise deletion or maximum likelihood; Osborne, 2012). Additionally, the use of maximum likelihood in Amos prevents the obtainment of modification indices and makes it more difficult to conduct the bootstrapping necessary to test for indirect effects. Although multiple imputation appeared to be 
the best method, this process did not come without its own challenges, as a dataset with multiple imputations in SPSS cannot be supported in Amos without modifications.

In order to use a multiple imputated dataset in Amos, multiple imputation was run in SPSS and the multiple datasets were compiled into one set using the process outlined in the Amos 21 user's guide (Arbuckle, 2012. The original dataset was first imputated 10 times. Wayman (2003) stated that most researchers use 3-10 datasets for multiple imputations, so 10 data sets were well within the limits of common practice. The resulting data sets were then compiled by combining and averaging variables across the 10 data sets. Unfortunately, this process reduces the variance in the data. According to the Amos manual (Arbuckle, 1995), to account for this loss of variance, error terms must be manually calculated. A regression analysis was conducted on each of the 10 data sets to obtain estimates and standard errors. The following values were then calculated: multiple imputation estimate of regression weight (18.92), average within-imputation variance (7.96), between-imputation variance (1.01), total variance (7.97), and multiple group standard error (2.82). After these steps were completed, a measurement and structural model using the full data set of over 200 participants $(n=207)$ was able to run in AMOS.

\section{Analysis}

\section{Data}

Table 1 contains the correlation matrix for the variables that were used for all three models. Table 2 depicts the descriptive data for both samples that were 
used within SPSS and PROCESS. The first data set depicted utilized multiple imputation to replace missing data resulted in a full data set of 207 participants.

The second data set used listwise deletion to pull out participants with incomplete responses. This process resulted in an incomplete dataset of 134 participants.

Table 2

Descriptive Statistics for Multiple Imputation and Listwise Deletion

\begin{tabular}{|c|c|c|c|c|c|}
\hline \multicolumn{3}{|c|}{ Multiple Imputation $(n=207)$} & \multicolumn{3}{|c|}{ Listwise Deletion $(\mathrm{n}=134)$} \\
\hline Variable & Mean & $\underline{\mathrm{SD}}$ & Mean & $\underline{\mathrm{SD}}$ & Sig \\
\hline$\overline{\text { School Type }}$ & 0.46 & $\overline{0.49}$ & 0.44 & $\overline{0.49}$ & .014 \\
\hline MA Recent & 2.67 & 1.13 & 2.55 & 0.84 & .015 \\
\hline MA Past & 3.38 & 0.97 & 3.28 & 1.18 & .01 \\
\hline MA Impact & 3.1 & 1.44 & 2.95 & 0.99 & .016 \\
\hline ID Integration & 4.32 & 1.31 & 4.35 & 1.46 & .002 \\
\hline LGB ID & 3.27 & 1.48 & 3.33 & 1.41 & .006 \\
\hline Christian ID & 3.54 & 1.06 & 3.58 & 1.59 & .004 \\
\hline IH Attitudes & 3.22 & 1.23 & 1.96 & 0.89 & .152 \\
\hline IH Feeling & 3.26 & 1.3 & 2.45 & 1.38 & .090 \\
\hline IH Public & 2.02 & 0.85 & 3.2 & 1.29 & .142 \\
\hline IH Conn & 3.27 & 1.12 & 3.22 & 1.12 & .005 \\
\hline Social Supp & 5.18 & 1.2 & 5.3 & 1.17 & .007 \\
\hline Psych Distress & 2.48 & 0.67 & 2.46 & 0.64 & .003 \\
\hline
\end{tabular}

A t-test was conducted in SPPS to compare means and determine if there were significant differences between the two data sets. Results indicated that for several of the variables, there were significant differences between the two sets of data. The only variables that did not have significant differences between the two data sets were in three internalize heterosexism subscales (attitudes towards other LGB individuals, feelings towards one's own identity, and public identification as LGB). This information necessitates caution when directly comparing the results of PROCESS in SPSS and SEM in Amos due to the significant differences between data sets. 


\section{School Type Moderated Mediation Model}

School type measurement model. The first step in analyzing the school type moderated mediation model was to create a measurement model to determine model fit. In this model, homonegative microaggression is depicted as a latent variable with the frequency of recent microaggression, frequency of past microaggression, and impact of microaggression acting as indicators. Frequency of recent of microaggression was selected as the marker variable. While all three subscales have an equivalent number of items, frequency of recent microaggressions is the most theoretical similar to the latent variable heterosexist microaggression. Internalized heterosexism is depicted as latent variable with the four subscales of the LIHS acting as indicators, with personal feelings about being gay/lesbian/bisexual acting as the marker variable. The personal feelings subscale comprised of the most items and is the most theoretical similarity to the latent variable internalized homophobia. Finally, psychological distress (CCAPS) is depicted as latent variable, with Depression acting as a marker variable. This subscale comprised of the most items and is the most theoretical similarity to the latent variable of psychological distress. School type, the interaction between school type and homonegative microaggression, and the control variables of LGB identity salience and Christian identity salience are also included in the model as observed variables. Figure 2 on the subsequent page shows the measurement model after all modifications have been made.

Table 3 illustrates the modifications to the measurement model and the corresponding fit indices. The original model had poor over-all fit based on the 
significant chi square test $\left(\chi^{2}=311.07, \mathrm{DF}=118, p<.001\right)$, a TLI value of .79 (below the .90 acceptable range), and a CFI value of .841 (below the acceptable range of .93; Bentler, 1990; Marsh et al., 2004). In addition, the RMSEA value was larger than the preferred .08 cut-off at .089 , and the high end of the $90 \%$ confidence interval 0.1 just meets the desired 11 cut-off (Browne \& Cudeck, 1993). Several modifications were made based on theory and obtained modification indices. Two sets of error terms were correlated. The first pair were two similar error terms loading on subscales of Connection to LGB Community and Negative Attitudes Towards other LGB Individuals $[\mathrm{MI}]=12.13$, standardized residual 0.05 which loaded onto the latent construct of Internalized Heterosexism. This correlation is believed to be theoretically appropriate based on past research that has shown college students who have friendships with LGBT individuals have positive attitudes towards LGBT individuals (Woodford et al., 2012). Specifically, it seems logical that an individual's negative attitudes towards a community and their level of connection to a community would have a strong positive relationship above and beyond the correlation between the constructs.

The second set of error terms reflected a correlation between the internalized heterosexism subscale of "outness" with the psychological distress subscale of social anxiety $[\mathrm{MI}]=10.06$, standardized residual $=0.05$. This correlation is believed to be theoretically appropriate as past research by Meyer (2003) has highlighted the emotional toll concealment of identity can cause (Frable, Platt, \& Hoey, 1998; Miller \& Major, 2000), supporting the observation in this model that level of "Outness" and a psychological distress sub scale of 
"Social Anxiety" would have a strong negative relationship, above and beyond the correlation between the constructs.

The modifications resulted in improved but relatively poor model fit, as indicated by the significant chi square test $\left(\chi^{2}=280.67, \mathrm{DF}=116, \mathrm{p}>.001\right)$ as well CFI (.821) and TLI values (.865) below the acceptable cutoff. The RMSEA value in the adapted measurement model was slightly larger than the preferred .08 cutoff at .083 and the high end of the CI90 range (.095) did not exceed 0.1. Results of a chi-square difference test after each modification support the retention of the more constrained final model as having superior fit when compared to the original model.

Table 3

School Type Measurement Model Modifications

\begin{tabular}{llllllll}
\hline & $\mathrm{X}^{2}$ & $d f$ & $p$ & TLI & CFI & RMSEA & CI90 \\
\hline Model 1 & 311.07 & 118 & $<.001$ & .794 & .841 & .089 & $.077-.101$ \\
E4 <-> E7 & 291.37 & 117 & $<.001$ & .812 & .857 & .085 & $.073-097$ \\
E4 <-> E7 & 280.67 & 116 & $<.001$ & .821 & .865 & .083 & $.071-.095$ \\
\& E5 <-> E11 & & & & & & & \\
\hline
\end{tabular}

Although additional potential modifications were highlighted in the modifications indices, the changes were deemed not theoretically appropriate. Despite acceptable model fit not being obtained, analysis of the structural model proceeded. Limitations of poor model fit will be addressed in the discussion of results. 
Figure 2

School Type Measurement Model Post-modification

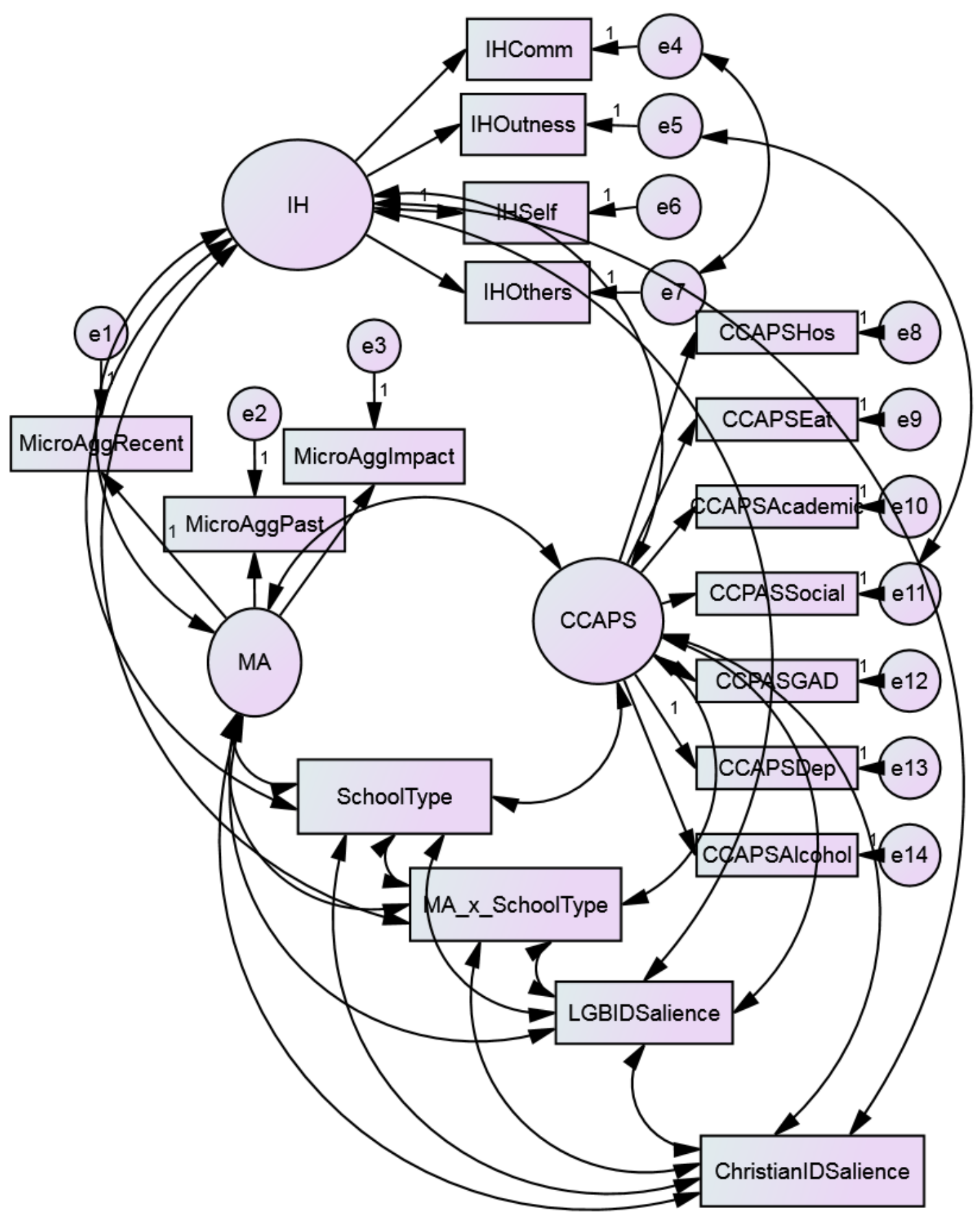


School type structural model. The second step in the analysis of a hybrid model using SEM is to test the direct paths of the moderated mediation model (see Figure 3). The correlation paths in the measurement model were deleted and direct paths were drawn from homonegative microaggression to internalized heterosexism and psychological distress. A direct path was drawn from internalized heterosexism to psychological distress, completing the mediation portion of the model. Direct paths were drawn from the moderator (school type) and the interaction between the moderator and predictor variable onto internalized heterosexism, following Hayes (2012) model of mediated moderation. Paths were also drawn from the control variables to the outcome variable. Error terms were added to internalized heterosexism and psychological distress, and all of the exogenous variables were correlated. Data were bootstrapped 200 times. 
Figure 3

School Type Structural Model

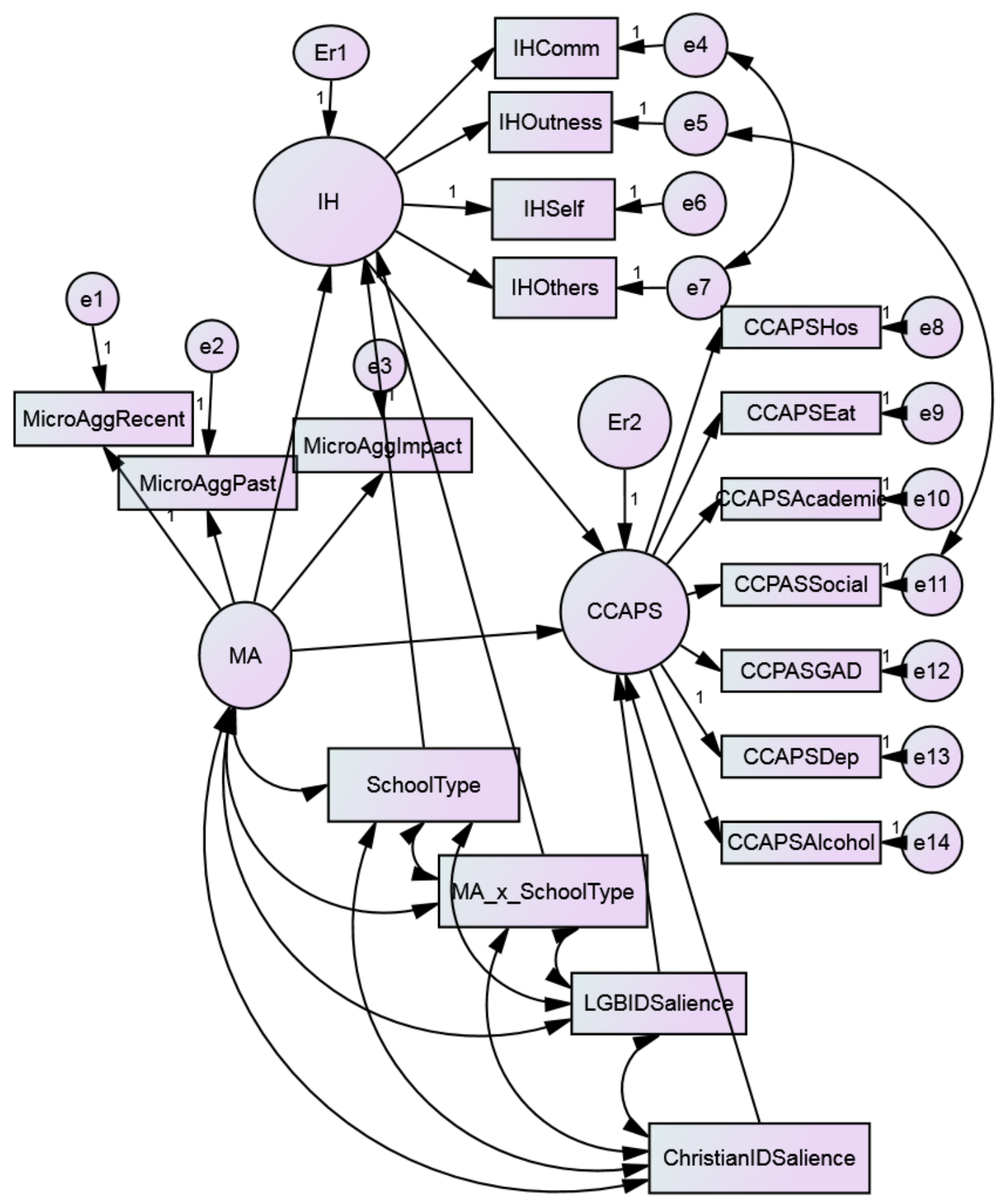


Table 4 depicts the bootstrapped regression weights for the school type moderated mediation model. The paths between homonegative microaggression and internalized heterosexism and internalized heterosexism and psychological distress were found to be significant. The interaction between homonegative microaggression and school type was not significant. The paths from the control variables were statistically significant.

Table 4

Bootstrapped Regression Weights School Type

\begin{tabular}{lcllll}
\hline & Estimate & & S.E. & C.R. & p \\
Internalized Heterosexism <- Microaggression & 0.49 & & 0.13 & 3.84 & $* * *$ \\
Psychological Distress <-Microaggression & 0.03 & & 0.1 & 0.31 & .741 \\
Psychological Distress <- Internalized Hetero & 0.52 & & 0.08 & 6.91 & $* * *$ \\
IH <-Ma x School Type & -0.06 & 0.1 & -0.65 & .513 \\
Psychological Distress <-LGBID Salience & -0.18 & 0.06 & -3.19 & .001 \\
Psychological Distress <-Christian ID & 0.21 & 0.05 & 4.17 & $* * *$ \\
\hline
\end{tabular}

Note. $* * *=\mathrm{p}<.001$

Table 5

Bootstrapped Direct, Indirect, Total Effects

\begin{tabular}{|c|c|c|c|c|c|c|c|c|}
\hline & \multicolumn{3}{|c|}{ Direct Effects } & \multicolumn{3}{|c|}{ Indirect Effect } & \multicolumn{2}{|c|}{ Total Effects } \\
\hline & Est & S.E. & $p$ & Est & $\underline{p}$ & Est & S.E. & $\underline{p}$ \\
\hline $\mathrm{MA}>\mathrm{IH}$ & 0.49 & 0.13 & **** & 0.00 & -- & 0.49 & 0.13 & **** \\
\hline $\mathrm{MA}>\mathrm{PD}$ & 0.03 & 0.1 & .741 & 0.26 & .014 & 0.29 & --- & --- \\
\hline $\mathrm{IH}>\mathrm{PD}$ & 0.52 & 0.08 & $* * *$ & 0.00 & -- & 0.59 & 0.08 & $* * *$ \\
\hline MAxS > IH & -0.06 & 0.1 & .513 & 0.00 & --- & -0.06 & 0.1 & .513 \\
\hline LGB $>$ PD & -.018 & 0.06 & .002 & 0.00 & --- & -.018 & 0.06 & .002 \\
\hline XID > PD & 0.2 & 0.05 & $* * *$ & 0.00 & --- & 0.2 & 0.05 & $* * *$ \\
\hline
\end{tabular}

Note. $* * *=\mathrm{p}<.001$

As Table 5 depicts above, there is partial indirect effect of internalized heterosexism that accounts for $7 \%$ of the variance between microaggression and psychological distress $($ Estimate $=0.255,95 \mathrm{CI} .081-.436)$. The direct effect of homonegative microaggression on psychological distress is not significant; while the indirect effect was found to be significant, indicating that indirect only 
mediation was found. All paths in the mediation model were positive, indicating that complimentary mediation occurred. The lack of a significant relationship between the interaction of microaggression and school type indicates that school type does not act as a moderator for the mediation model. This is unsurprising considering that the variable of school type did not have a significant relationship with any of the variables included in the model, with the exception of a negative significant correlation with sexual and religious identity integration. As expected, given the poor fit of the measurement model, the model fit for the combined hybrid has poor over-all fit based on the significant chi square test $\left(\chi^{2}=302.49\right.$, $\mathrm{DF}=120, p<.001$ ), TLI value of .8 , and CFI value of .85 . The RMSEA value in the original model was larger than the preferred .08 cut-off at 0.086 , and the high end of the $90 \%$ confidence interval .098 was acceptable. The comparison of indirect effect across school type shows that the mediation role of internalized heterosexism between the direct path of homonegative microaggressions and psychological distress is not moderated by school type. Considering the poor model fit in the measurement model, poor model fit in the structural model is to be expected. As stated in the measurement model section above, these relationships should be interpreted with caution due to the poor model fit observed.

School Type PROCESS. As mentioned in the missing data section, PROCESS analysis was run in SPSS to compare the results of moderated mediation with two different approaches. Data were bootstrapped in SPSS to produce 1000 samples. Listwise deletion was used to address missing data, as a 
multiple imputation data set cannot be run in PROCESS. Model 7 (see Figure 4) was selected to best represent the hypothesis that the mediating role of internalized heterosexist between homonegative microaggression and psychological distress varies conditionally based on school type. Specifically the top model 7 depicts the conceptual representation of predicting that school type will modify the path between experiencing homonegative microaggression and internalized heterosexism. The bottom figure represents the statistical model, depicting how in PROCESS the interaction between school type and homonegative microaggression is utilized as the moderating variable.

Figure 4

School Type Moderated Mediation Model in PROCESS (Model 7)

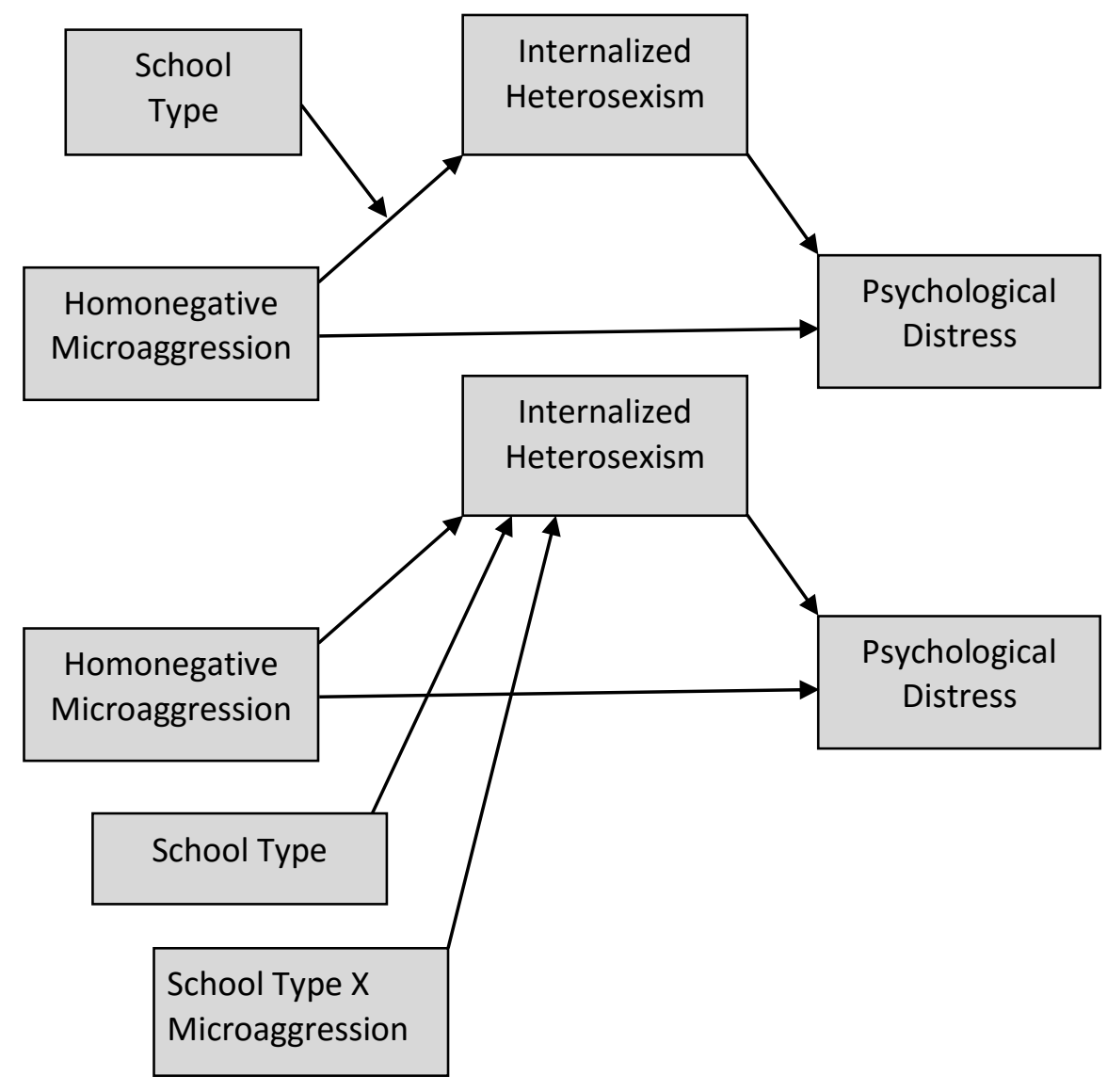


Table 6 depicts the model summary for the school type moderated mediation model. The direct effect of microaggression on psychological distress was not found to be significant (effect=0.02, $\mathrm{SE}=0.14, \mathrm{p}=.91$ ). This aligns with the results of the SEM model Amos, which also indicated that the direct path between homonegative microaggression and psychological distress was not significant and was, in fact, mediated by internalized heterosexism. In PROCESS, the indirect effect of internalized heterosexism did have a significant relationship with the psychological distress outcome variable (coeff $=0.57,95 \%$ CI $[0.37$, 0.78], $\mathrm{p}<.001)$ which again supports internalized heterosexism role as mediating the homonegative microaggression's impact on psychological distress.

Table 6

PROCESS Model Summary School Type

\begin{tabular}{lllllll}
\hline & Effect & S.E. & $\mathrm{t}$ & $p$ & LLCI & ULCI \\
\hline Direct Effect & 0.02 & 0.14 & 0.12 & .9 & -0.27 & 0.3 \\
Constant & 10.58 & 1.89 & 5.6 & $* * *$ & 6.84 & 14.33 \\
IH & 0.57 & 0.1 & 5.5 & $* * *$ & 0.37 & 0.78 \\
MA & 0.02 & 0.14 & 0.12 & .9034 & -0.27 & 0.3 \\
LGBI & -1.16 & 0.34 & -3.42 & .0008 & -1.82 & -0.49 \\
ChristID & 1.15 & 0.29 & 3.91 & .0001 & 0.57 & 1.73 \\
\hline
\end{tabular}

A conditional indirect effect of microaggression on psychological distress was observed across one level of the moderator (Secular School) as the constraints on each end of the confidence internal 95\% CI [0.1, 0.44] do not include 0 (Table 7). When the conditional direct effects of the interaction between microaggression and school type were observed, results were not statistically significant (coeff $-0.45,95 \%$ CI $[0.92,0.03], \mathrm{p}=.06$ ). This means that one 
category of the moderator (secular school type) moderated the path between homonegative microaggression and internalized heterosexism. The control variables (LGB identity salience and Christian identity salience) were both significant $(\mathrm{p}<.001$ and $\mathrm{p}<.001)$, which indicate that they were appropriately included in this model.

Table 7

School Type Conditional Indirect Effects

\begin{tabular}{lllll}
\hline Variable & Effect & Boot SE & BootLLCI & BootULCI \\
\hline Secular & 0.26 & 0.1 & 0.1 & 0.44 \\
Religious & 0.00 & 0.16 & -0.37 & 0.27 \\
ModMed Index & -0.26 & 0.2 & -0.72 & 0.06 \\
\hline
\end{tabular}

\section{Social Support Moderated Mediation Model}

Social support measurement model. Similar to Model 1, the testing of Model 2 began with examining the fit of the measurement model using social support as the moderator. As in model one, homonegative microaggression, internalized heterosexism and psychological distress (CCAPS) are latent variables with the same indicators used in Model 1 acting as marker variables. Social support and the interaction between social support and homonegative microaggression and the control variables of LGB identity salience and Christian identity salience were also included in the model as observed variables. Figure 5 on the subsequent page shows the measurement model after all modifications have been made to improve model fit.

Table 8 illustrates the modifications to the measurement model and the corresponding fit indices. The original model had poor over-all fit based on the significant chi square test $\left(\chi^{2}=340.284, \mathrm{DF}=118, p<.001\right)$, a TLI value of .78 
(below the .90 acceptable range), and a CFI value of .83 (below the acceptable range of .93). In addition, the RMSEA value was larger than the preferred .08 cutoff at .096 , and the high end of the $90 \%$ confidence interval 0.11 exceeded the desired cut-off. One modification was made based on theory and obtained modification indices. Consistent with Model 1, the error terms E4 and E7 were correlated $[\mathrm{MI}]=17.45$, standardized residual $=0.05$ ). The modification resulted in improved but still relatively poor model fit, as indicated by the significant chi square test $\left(\chi^{2}=321.026, \mathrm{DF}=117, \mathrm{p}<.001\right)$ as well as unacceptable CFI (.79) and TLI values (.85). The RMSEA value in the adapted measurement model was slightly larger than the preferred .08 cut-off at .083 and the high end of the CI90 range (.104) exceeded 0.1. Results of a chi-square difference test after each modification support the retention of the more constrained final model as a superior fit to the original model. After this modification, no other modifications highlighted in the modification indices were made due to the lack of theoretical support. While analysis of the structural model proceeded, results should be interpreted with caution due to the poor resulting fit.

Table 8

Social Support Measurement Model Modifications

\begin{tabular}{lllccccc}
\hline & $\mathrm{X}^{2}$ & $d f$ & $p$ & TLI & CFI & RMSEA & CI90 \\
\hline Model 1 & 340.28 & 118 & $<.001$ & .781 & .841 & .096 & $.077-.101$ \\
E4 <-> E7 & 321.03 & 117 & $<.001$ & .797 & .857 & .092 & $.073-097$ \\
\hline
\end{tabular}

Although additional potential modifications were highlighted in the modifications indices, the changes were deemed not theoretically appropriate. 
Despite acceptable model fit not being obtained, analysis proceeded. Limitations of poor model fit will be addressed in the discussion of results.

Figure 5

Social Support Measurement Model Post-modification

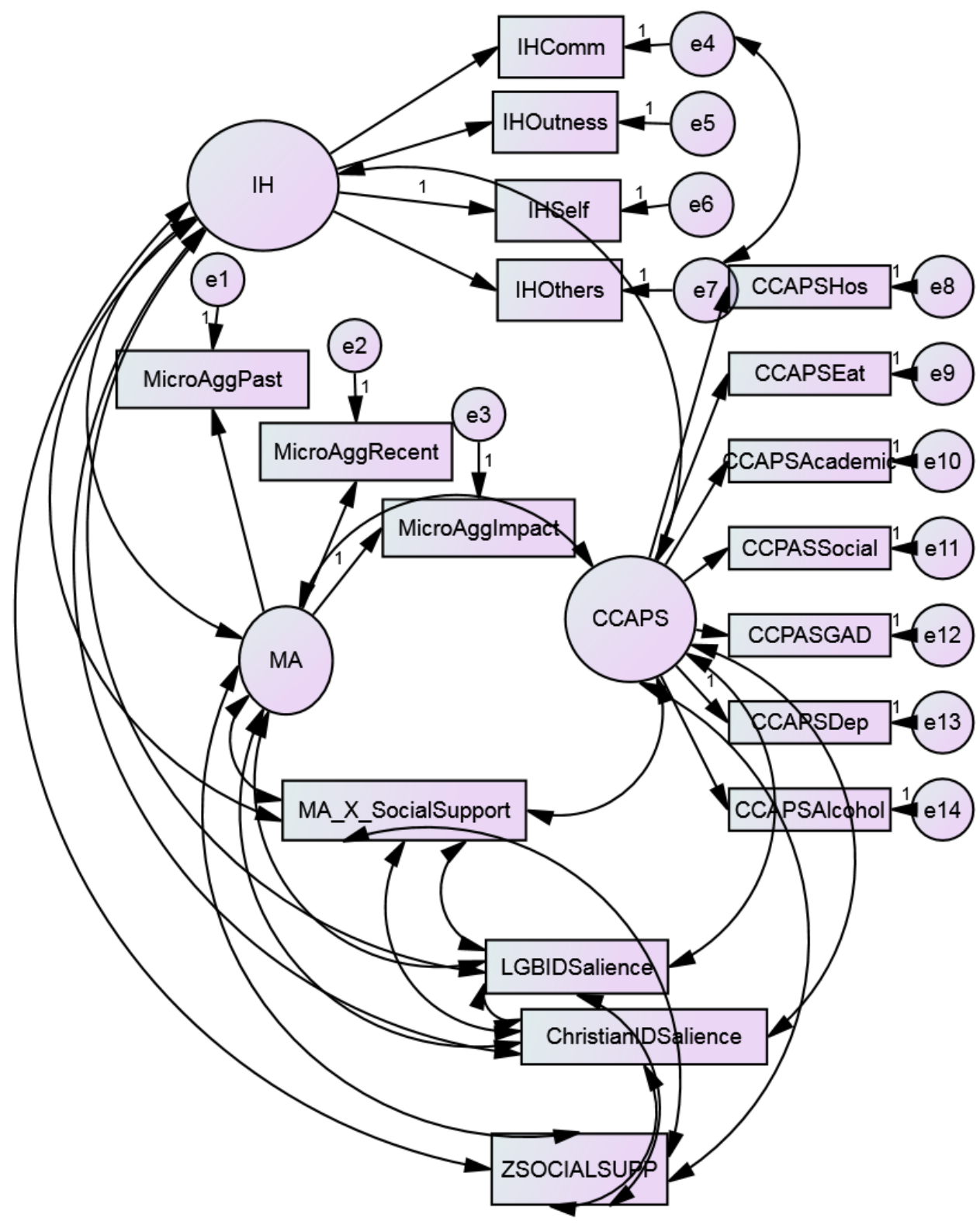


Social support structural model analysis. The second step in the hybrid analysis process is to test the direct paths of the moderated mediation model (see Figure 6). The correlation paths in the measurement model were deleted and direct paths were drawn from homonegative microaggression to internalized heterosexism and psychological distress. A direct path was drawn from internalized heterosexism to psychological distress completing the mediation portion of the model. Direct paths were drawn from the moderator (social support) and the interaction between the moderator and predictor variable onto internalized Heterosexism, following Hayes model of mediated moderation. Paths were also drawn from the control variables onto the outcome variable. Error terms were added to internalized heterosexism and psychological distress and all exogenous variables were correlated. Data were bootstrapped 200 times. 
Figure 6

Social Support Structural Model Post-modification

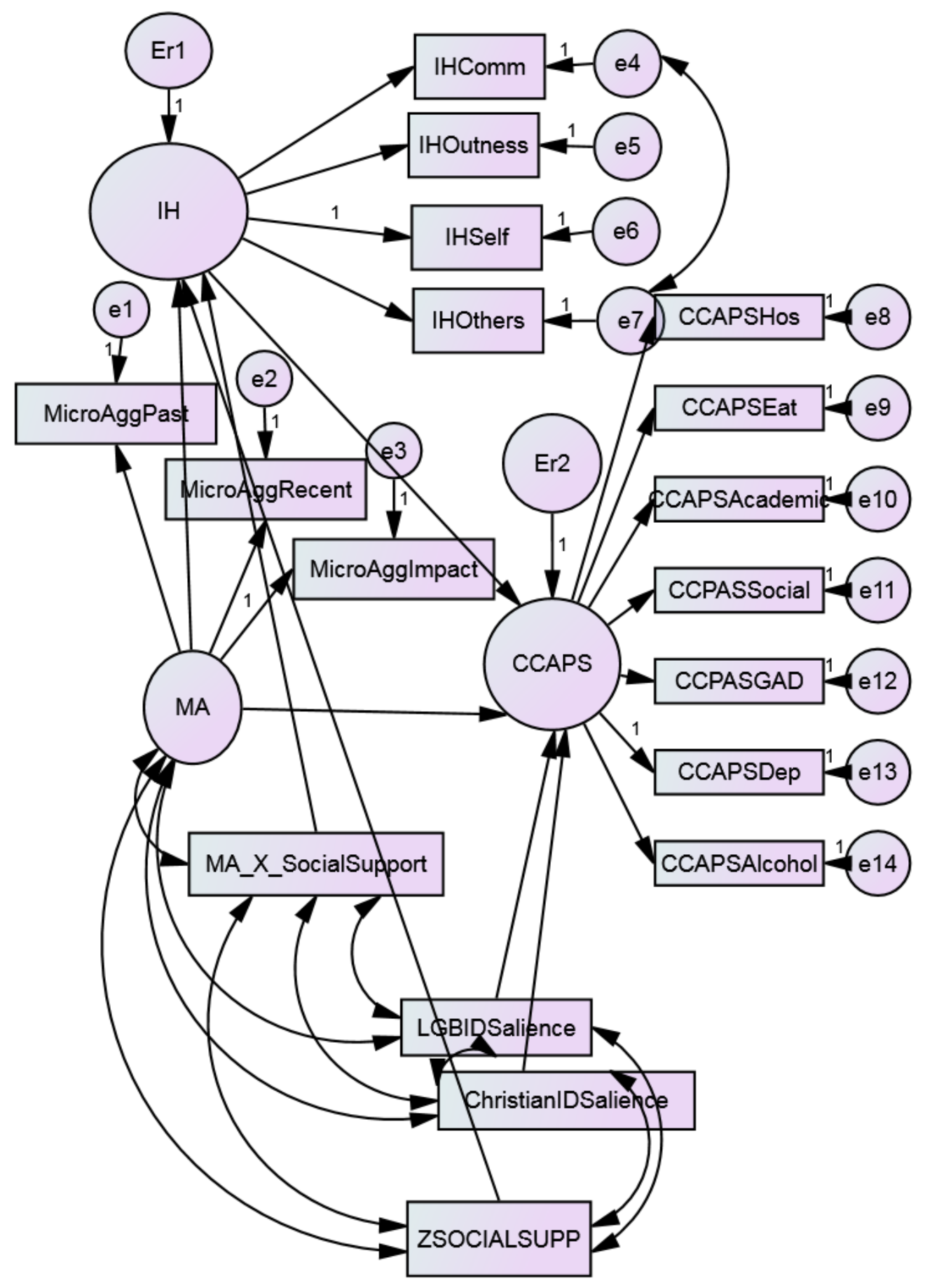


Table 9 depicts the bootstrapped regression weights for the social support moderated mediation model. The paths between homonegative microaggression and internalized heterosexism and internalized heterosexism and psychological distress were found to be significant. The direct path between homonegative microaggression and psychological distress was not significant. The interaction between homonegative microaggression and school type was not significant. The control variables were observed to be significant.

Table 9

Bootstrapped Regression Weights Social Support

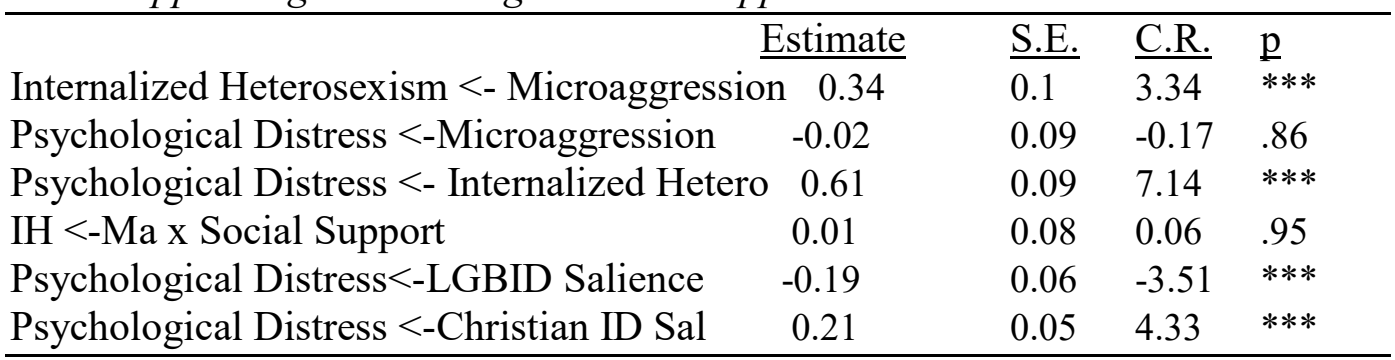

Note. $* * *=\mathrm{p}<.001$

Table 10

Bootstrapped Direct, Indirect, Total Effects

\begin{tabular}{|c|c|c|c|c|c|c|c|c|}
\hline & \multicolumn{3}{|c|}{ Direct Effects } & \multicolumn{3}{|c|}{ Indirect Effect } & \multicolumn{2}{|c|}{ Total Effects } \\
\hline & Est & S.E. & $\underline{p}$ & Est & $\underline{p}$ & Est & S.E. & $\underline{p}$ \\
\hline MA->IH & 0.34 & 0.1 & *** & 0.00 & - & 0.34 & 0.103 & $* * *$ \\
\hline MA->PD & -0.02 & 0.09 & .863 & 0.21 & .083 & 0.19 & --- & --- \\
\hline $\mathrm{IH}>\mathrm{PD}$ & 0.61 & 0.09 & $* * *$ & 0.00 & --- & 0.61 & 0.09 & $* * *$ \\
\hline MAxSS->IH & 0.01 & 0.07 & .952 & 0.00 & --- & 0.01 & 0.07 & .952 \\
\hline LGB->PD & -.019 & 0.06 & .002 & 0.00 & --- & -.019 & 0.06 & .002 \\
\hline XID->PD & 0.21 & 0.05 & $* * *$ & 0.00 & --. & 0.21 & 0.05 & $* * *$ \\
\hline
\end{tabular}

Based on the above analysis while there is partial indirect effect in the mediation model from Figure 3, the indirect effect is not significant therefore not supporting the mediating role of internalize heterosexism in this model. However due to the poor overall fit of the measurement and structural model, these results 
should be interpreted with caution. The model fit for the combined hybrid model is poor, with a significant chi square $\left(\left(\chi^{2}=356.24, \mathrm{DF}=121, p<.001\right)\right.$, and a below .9 TLI value (TLI $=.774)$. The CFI is at .821, below the preferred cutoff. The RMSEA is at .097, which is higher than ideal and the CI90 range is between .086 and .109 , which exceeds the desire .1 cut-off point. There is no significant mediation to be moderated in this model, but it should be noted that there lack of a significance in the path between the interaction between Social Support and Internalized Heterosexism.

Social support PROCESS. Model 7 (see Figure 7) was again selected to best represent the hypothesis that the mediating role of internalized heterosexist between homonegative microaggression and psychological distress varies conditionally across amount of social support individuals self-report. Specifically model 7 predicts that amount of social support will modify the path between experiencing homonegative microaggression and internalized heterosexism. In the figure below the top model depicts the conceptual representation of predicting that social support will modify the path between experiencing homonegative microaggression and internalized heterosexism. The bottom figure represents the statistical model, depicting how in PROCESS the interaction between social support and homonegative microaggression is utilized as the moderating variable. 
Figure 7

Social Support Moderated Mediation Model in PROCESS (Model 7)
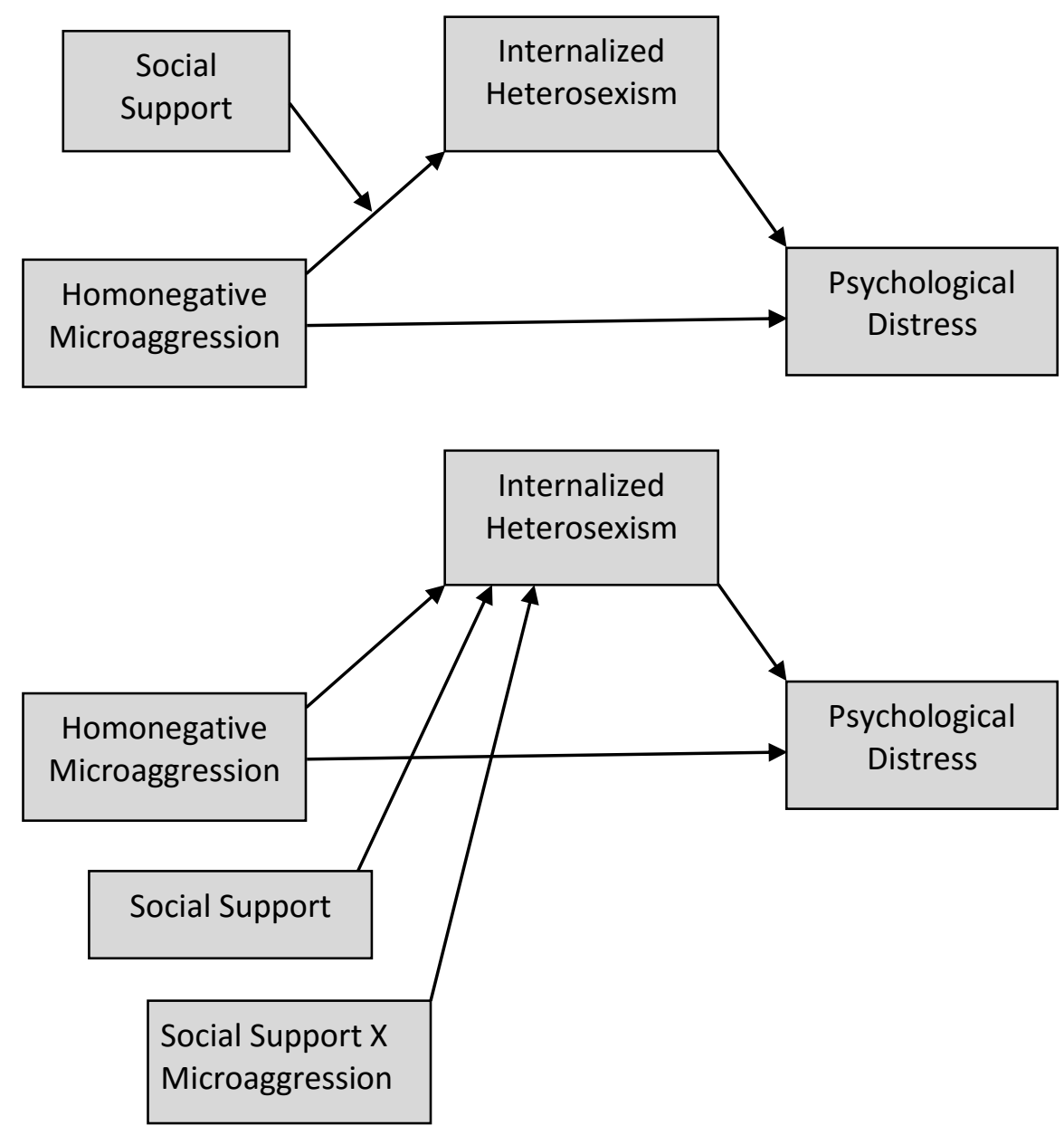

Table 11 depicts the social support model summary. The direct effect of microaggression on psychological distress was not found to be significant (Effect $=0.02,95 \%$ CI $[-0.27,0.3], p=.9)$. This aligns with the results of the SEM model Amos which also indicated that the direct path between microaggression and psychological distress was not significant. Unlike the SEM model, the mediating role of internalized heterosexism in PROCESS was found to be significant. The 
indirect effect of internalized heterosexism did have a significant relationship on the psychological distress outcome variable $(\operatorname{coeff}=0.57,95 \% \mathrm{CI}[0.37,0.78]$, $p<.001)$ which again supports internalized heterosexism role as mediating the homonegative microaggression's impact on psychological distress. It should be noted that the values in Table 11 are identical to Table 6 in the results section for the first model. This is due to process analysis providing results for the mediation model first and then taking into account the role of the moderator. This is difference from the SEM approach of including all variables into the analysis of model. The control variables (LGB identity salience and Christian identity salience) were both significant $(p<.001$ and $p<.001)$ which indicate that they were appropriately included in this model.

Table 11

PROCESS Model Summary Social Support

\begin{tabular}{llllcll}
\hline & Effect & S.E. & $\mathrm{t}$ & $p$ & LLCI & ULCI \\
\hline Direct Effect & 0.02 & 0.14 & 0.12 & .9 & -0.27 & 0.3 \\
Constant & 10.58 & 1.89 & 5.6 & $* * *$ & 6.84 & 14.33 \\
IH & 0.57 & 0.1 & 5.5 & $* * *$ & 0.37 & 0.78 \\
MA & 0.02 & 0.14 & 0.12 & .9 & -0.27 & 0.3 \\
LGBI & -1.16 & 0.34 & -3.42 & .0008 & -1.82 & -0.49 \\
ChristID & 1.15 & 0.29 & 3.91 & .0001 & 0.57 & 1.73 \\
\hline
\end{tabular}

Table 12 depicts the conditional indirect effect of internalized heterosexism mediating microaggression's relationship on psychological distress. The mediation model was tested across the 5 levels of the social support using the $10^{\text {th }}, 25^{\text {th }}, 50^{\text {th }}, 75^{\text {th }}$ and $90^{\text {th }}$ percentiles. At each level of the moderator the lower and upper limits of the confidence intervals included zero, indicating the lack of a significant conditional indirect effect. 
Table 12

Social Support Conditional Indirect Effects

\begin{tabular}{lllll}
\hline Social Support & Effect & Boot SE & BootLLCI & BootULCI \\
\hline 10.75 & 0.014 & 0.15 & -0.2 & 0.41 \\
14.00 & 0.01 & 0.09 & -0.01 & 0.26 \\
16.25 & 0.07 & 0.07 & -0.06 & 0.2 \\
18.50 & 0.04 & 0.08 & -0.013 & 0.2 \\
20.00 & 0.02 & 0.11 & -.02 & 0.23 \\
\hline
\end{tabular}

\section{Identity Integration Moderated Mediation Model}

Identity integration measurement model. The testing of model 3 again

began with examining the fit of the measurement model using identity integration as the moderator. As in model one, homonegative microaggression, internalized heterosexism, and psychological distress (CCAPS) are latent variables with the same indicators acting as marker variables. Identity integration and the interaction between identity Integration and homonegative microaggression and the control variables of LGB identity salience and Christian identity salience are also included in the model as observed variables Figure 8 on the subsequent page shows the measurement model after all modifications have been made to improve model fit.

Table 13 illustrates the modifications to the measurement model and the corresponding fit indices. The original model had poor over-all fit based on the significant chi square test $\left(\chi^{2}=314.62, \mathrm{DF}=118, p<.001\right)$, a TLI value of .803 (below the .90 acceptable range), and a CFI value of .85 (below the acceptable range of .93. In addition, the RMSEA value was larger than the preferred .08 cutoff at .09 , and the high end of the $90 \%$ confidence interval 0.101 exceeded the desired cut-off. 
Two modifications was made based on theory and obtained modification indices. Similar to the first two models, the error terms E4 and E7 were correlated $[\mathrm{MI}]=22.56$, standardized residual $=0.05)$. The theoretical rational for this modification is outlined in the model description of modifications.

The second modification was between two indicators within the internalized heterosexism scale $(\mathrm{E} 6$ and $\mathrm{E} 7,[\mathrm{MI}]=12.74$, standardized residual $=$ 0.05). Theoretically, it fits that two indicators in the same model, specifically attitudes towards other's and one's own sexual orientation would related. Past research supports the theory that an individual's negative attitudes towards other LGB individuals and their own sexual orientation would have a strong positive relationship above and beyond the correlation between the constructs. (Syzmanski \& Chung, 2001).

These modifications resulted in improved fit that is still poor at best. This is indicated by the significant chi square test $\left(\chi^{2}=275.76, \mathrm{DF}=116, p<.001\right)$ as well as the below acceptable CFI (.84) and TLI values (.88). The RMSEA value in the adapted measurement model was slightly larger than the preferred .08 cutoff at .082 and the high end of the CI90 range (.094) did not exceeded 0.1. Results of a chi-square difference test after each modification support the retention of the more constrained final model as a superior fit to the original model. While analysis of the structural model proceeded, results should be interpreted with caution due to the poor model fit. 
Table 13

Identity Integration Measurement Model Modifications

\begin{tabular}{lllccccc}
\hline & $\mathrm{X}^{2}$ & $d f$ & $p$ & TLI & CFI & RMSE & CI90 \\
\hline Model 1 & 314.62 & 118 & $<.001$ & .803 & .848 & .090 & $.078-.102$ \\
E4 <-> E7 & 290.3 & 117 & $<.001$ & .825 & .866 & .085 & $.073-.097$ \\
E4 <-> E7 & 275.77 & 116 & $<.001$ & .837 & .877 & .082 & $.069-.094$ \\
$\&$ E6 <-> E7 & & & & & & & \\
\hline
\end{tabular}

Although additional potential modifications were highlighted in the modifications indices (correlating the connection to LGB community subscale and the alcohol use subscale), the changes were deemed not theoretically appropriate. Despite acceptable model fit not being obtained, analysis of the structural model proceeded. Limitations of poor model fit will be addressed in the discussion of results. 
Figure 8

Identity Integration Measurement Model Post-modification

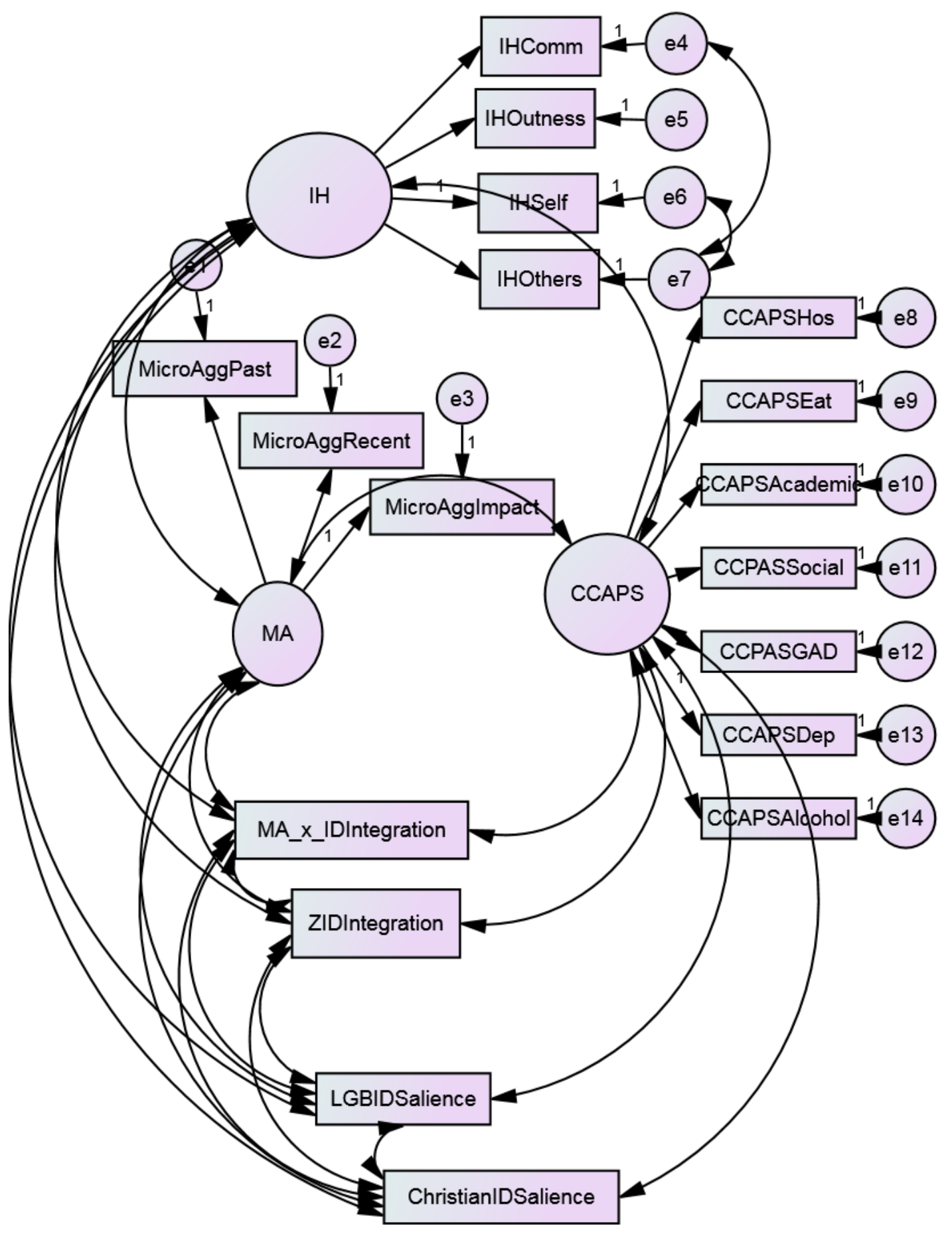


Identity integration structural model analysis. The second step in the hybrid analysis process is to again test the direct paths of the moderated mediation model (See Figure 9). The correlation paths in the measurement model were deleted and direct paths were drawn to complete the same mediation model from models 1 and 2. Direct paths were drawn from the moderator (identity integration) and the interaction between the moderator and predictor variable onto internalized heterosexism, following Hayes model of mediated moderation. Paths were also drawn from the control variables onto the outcome variable. Error terms were added to internalized heterosexism and psychological distress and all exogenous variables were correlated. Data were bootstrapped 200 times. 
Figure 9

Identity Integration Structural Model Post-Modification

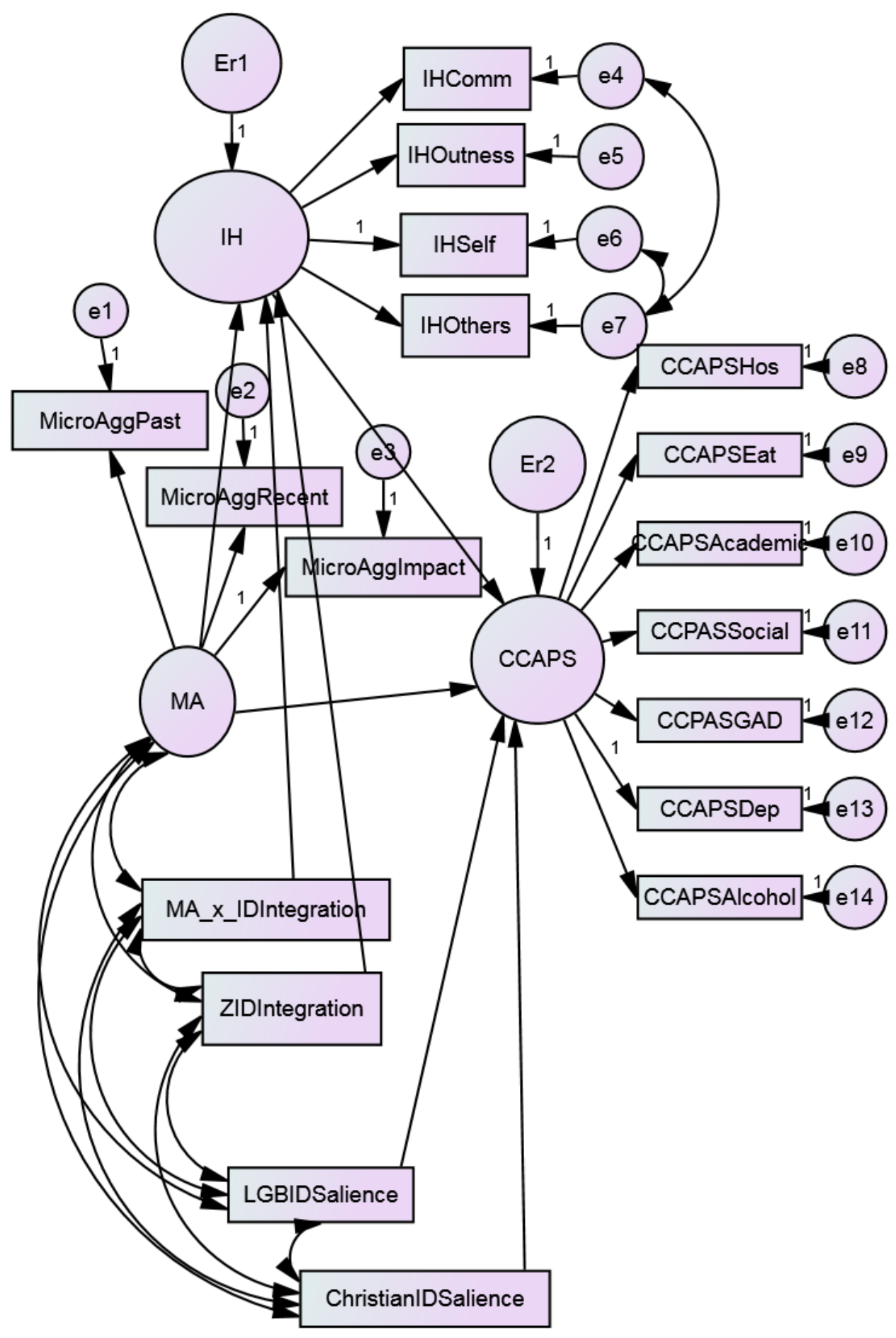


Table 14 depicts the bootstrapped regression weights for the school type moderated mediation model. The paths between homonegative microaggression and internalized heterosexism and internalized heterosexism and psychological distress were found to be significant. The path between homonegative microaggression and psychological distress was not significant. The interaction between homonegative microaggression and school type was not significant. The control variables were observed to be significant.

Table 14

Bootstrapped Regression Weights Identity Integration

\begin{tabular}{|c|c|c|c|c|}
\hline & Estimate & S.E. & C.R. & $\underline{p}$ \\
\hline Internalized Heterosexism $<-$ Micro & 0.37 & $\overline{0.09}$ & 3.9 & $* * *$ \\
\hline Psychological Distress <-Microaggression & 0.02 & 0.1 & 0.16 & .875 \\
\hline Psychological Distress <- Internalized Heter & o 0.56 & 0.09 & 6.3 & $* * *$ \\
\hline IH <-Ma x Social Support & 0.02 & 0.07 & 0.23 & .821 \\
\hline Psychological Distress $<-$ LGBID Salience & -0.17 & 0.06 & -3.0 & .003 \\
\hline Psychological Distress <-Christian ID Sal & 0.18 & 0.05 & 3.67 & $* * *$ \\
\hline
\end{tabular}

Note. $* * *=p<.001$

Table 15

Bootstrapped Direct, Indirect, Total Effects

\begin{tabular}{lllllllll}
\hline & \multicolumn{3}{c}{ Direct Effects } & \multicolumn{4}{c}{ Indirect Effect } & \multicolumn{3}{c}{ Total Effects } \\
\hline & $\underline{\text { Est }}$ & $\underline{\text { S.E. }}$ & $\underline{p}$ & $\underline{\text { Est }}$ & $\underline{p}$ & $\underline{\text { Est }}$ & $\underline{\underline{\text { S.E. }}}$ & $\underline{p}$ \\
$\mathrm{MA}>\mathrm{IH}$ & 0.37 & 0.09 & $* * *$ & 0.00 & --- & 0.37 & 0.09 & $* * *$ \\
$\mathrm{MA}>\mathrm{PD}$ & 0.22 & 0.1 & .875 & 0.2 & .007 & 0.22 & 0.1 & .875 \\
$\mathrm{IH}>\mathrm{PD}$ & 0.56 & 0.07 & $* * *$ & 0.00 & --- & 0.56 & 0.07 & $* * *$ \\
$\mathrm{MAxID}>\mathrm{IH}$ & 0.02 & 0.06 & .821 & 0.00 & --- & 0.02 & 0.06 & .003 \\
LGB > PD & -.017 & 0.05 & .003 & 0.00 & --- & -.017 & 0.05 & .003 \\
XID > PD & 0.18 & 0.09 & $* * *$ & 0.00 & --- & 0.18 & 0.09 & $* * *$ \\
\hline
\end{tabular}

Note. $* * *=\mathrm{p}<.001$

As Table 15 depicts above, there is partial indirect effect of internalized heterosexism that accounts for $4 \%$ of the variance between microaggression and 
psychological distress (Estimate $=0.204,95 \mathrm{CI} .090-.370)$. The direct effect of homonegative microaggression on psychological distress is not significant, while the indirect effect was found to be significant, indicating that indirect only mediation was found. All paths in the mediation model were positive, indicating that complimentary mediation occurred. The model fit for the combined hybrid model is poor, with a significant chi square $\left(\chi^{2}=03.97, \mathrm{DF}=120, p<.001\right)$, and a below .9 TLI value (TLI=.82). The CFI is at .86, slightly below the preferred cutoff. The RMSEA is at .086, which is slightly higher than ideal and the CI90 range is between .074 and .098 , which does not exceed the desired .1 cut-off point. Similar to the results of model 1 , there is a significant partial mediation, but there lack of a significance in the path between the interaction between social support and internalized heterosexism. This means that while internalized heterosexism is partially mediating the relationship between microaggressions and psychological distress, internalized heterosexism does not significantly change as a mediator across any of the levels of identity integration.

Identity integration PROCESS. Model 7 (see figure 10) was again selected to best represent the hypothesis that the mediating role of internalized heterosexism between homonegative microaggression and psychological distress varies conditionally across amount of identity integration individuals self-report. Specifically model 7 predicts that amount of identity integration will modify the path between experiencing homonegative microaggression and internalized heterosexism. As in the previous figures, the top model depicts the conceptual model and the bottom the statistical model. 
Figure 10

Identity Integration Moderated Mediation Model in PROCESS (Model 7)
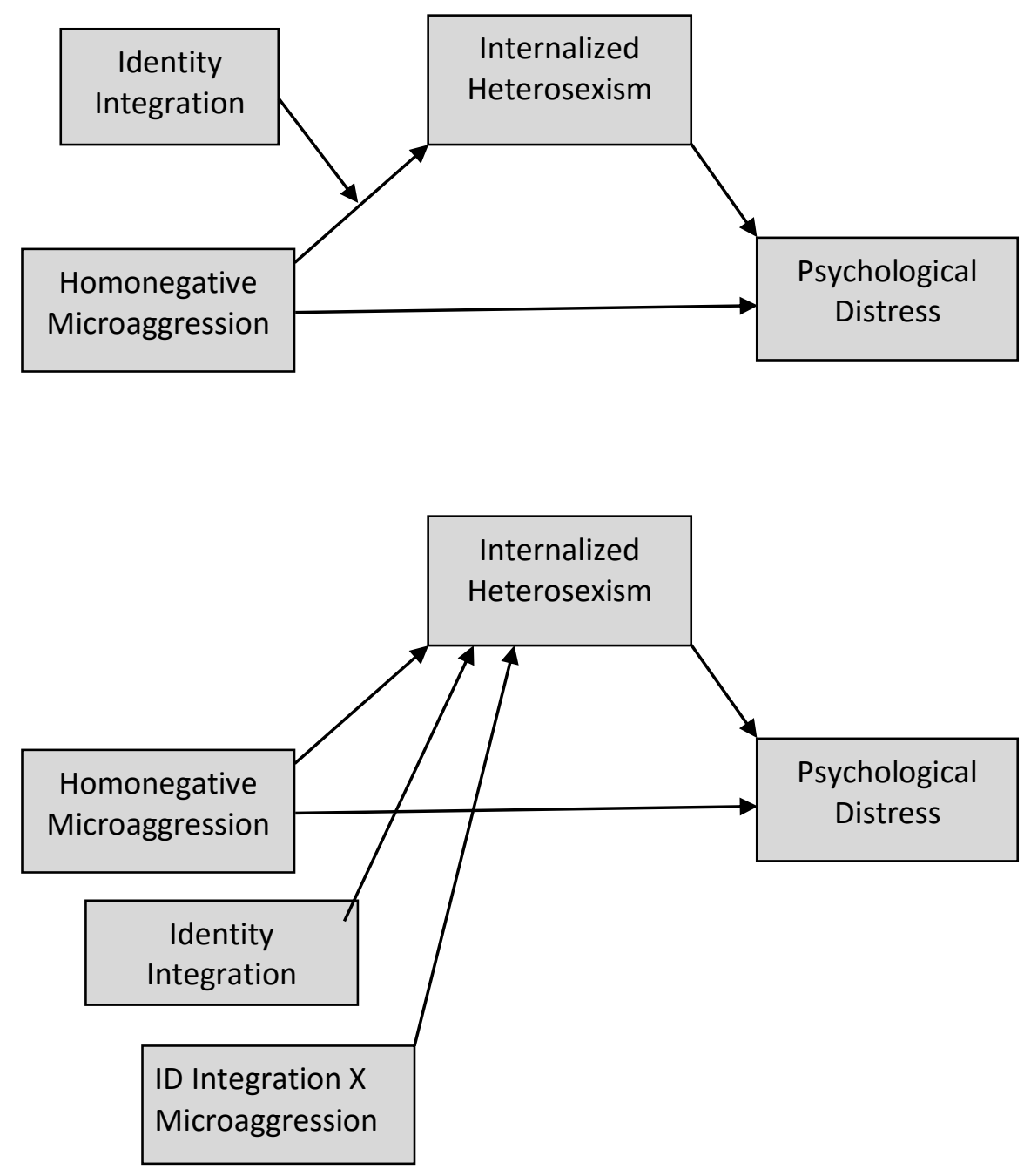

Table 16

PROCESS Model Summary Identity Integration

\begin{tabular}{llllcll}
\hline & Effect & S.E. & $\mathrm{t}$ & $p$ & LLCI & ULCI \\
\hline Direct Effect & 0.02 & 0.14 & 0.12 & .9 & -0.27 & 0.3 \\
Constant & 10.58 & 1.89 & 5.6 & $* * *$ & 6.84 & 14.33 \\
IH & 0.57 & 0.1 & 5.5 & $* * *$ & 0.37 & 0.78 \\
MA & 0.02 & 0.14 & 0.12 & .9 & -0.27 & 0.3 \\
LGBI & -1.16 & 0.34 & -3.42 & .0008 & -1.82 & -0.49 \\
ChristID & 1.15 & 0.29 & 3.91 & .0001 & 0.57 & 1.73 \\
\hline
\end{tabular}


As Table 16 depicts in the model summary, the direct effect of microaggression on psychological distress was not found to be significant (Effect $=0.02,95 \%$ CI $[-0.27,0.3], p=.9034)$. This aligns with the results of the SEM model AMOS which also observed that the direct path between microaggression and psychological distress was not significant and was in fact mediated by internalized heterosexism. Like the previous model, the indirect effect of internalized heterosexism did have a significant relationship on the psychological distress outcome variable $($ coeff $=0.57,95 \%$ CI $[0.37,0.78], p<.001)$ which again supports internalized heterosexism role as mediating the homonegative microaggression's impact on psychological distress. A conditional indirect effect of internalized heterosexism mediating microaggression's impact on psychological distress was tested across the 5 levels of the identity integration using the $10^{\text {th }}, 25^{\text {th }}, 50^{\text {th }}, 75^{\text {th }}$ and $90^{\text {th }}$ percentiles (see table 17 ). The upper and lower confidence intervals across all five levels included zero in within the limits, indicating that there was not a significant chance that the conditional indirect effects were not zero. When the conditional direct effects of the interaction between microaggression and identity integration were observed, results were found to be insignificant (coeff $-.0311,95 \%$ CI $[-0.1741,0.1119] p=.66$ ). The control variables (LGB identity salience and Christian identity salience) were both significant $(\mathrm{p}<.001$ and $\mathrm{p}<.001)$ which indicate that they were appropriately included in this model. 
Table 17

Identity Integration Conditional Indirect Effects

\begin{tabular}{lllll} 
ID Integration & Effect & Boot SE & BootLLCI & BootULCI \\
\hline 2.33 & 0.12 & 0.14 & -0.15 & 0.4 \\
3.33 & 0.1 & 0.09 & -0.08 & 0.3 \\
4.33 & 0.08 & 0.07 & -0.04 & 0.21 \\
5.33 & 0.06 & 0.07 & -0.07 & 0.2 \\
6.33 & 0.05 & 0.1 & -.15 & 0.25 \\
\hline
\end{tabular}

Alternative Model: Removal of Alcohol Subscale from Psychological Distress

An important step of SEM analysis in the consideration of alternative

models. Since adequate model fit was not obtained in any of the models, modifications to the measurement model seemed the most logical direction. One question that arose when examining the first measurement model was the possible issues with the subscale of alcohol use being included into the psychological distress measure. Literature on the CCAPS has pointed out measurement concerns with the alcohol use subscale due to a floor effect. Since numerous college students abstain from alcohol, the alcohol use scale can appear inflated despite only reflecting mild alcohol use. It is possible that the subscale has more limitations when used with a religious population. Some of the religious colleges participants attended were dry campuses, meaning that for students who attended a Christian college, alcohol use may not be an appropriate index of psychological distress. Conversely, the study by Rostosky et al, 2007 indicated that religiosity is only a protective factor against substance use for non-sexual minority individuals. These factors indicate that alcohol use may be a confounding indicator in the 
psychological distress subscale. For this reason, the School Type moderation mediation model was run again with the alcohol use subscale removed as an indicator from the psychological distress subscale to see if model fit could be improved.

Alternative Measurement Model. Improved model fit was obtained by making theoretically appropriate modifications. Table 18 illustrates the final modification to the measurement model and the corresponding fit indices. Similar to the original model two sets of error terms were correlated (E4 and E7 and E5 and E11). The alcohol subscale was also removed from the psychological distress latent variable. Final model fit was improved but borderline acceptable, as indicated by the significant chi square test $\left(\chi^{2}=239.706, \mathrm{DF}=100, p<.001\right)$ as well as unacceptable CFI (.883) and TLI values (.840). The RMSEA value in the adapted measurement model was slightly larger than the preferred .08 cut-off at .082 , and the CI90 range (.096) did not exceed 0.1. Similar to the initial school type model results of a chi-square difference test after each modification support the retention of the more constrained final model as a superior fit to the original model. Figure 11 on the subsequent page shows the measurement model after all modifications have been made.

Table 18

Alternative Measurement Model Modifications

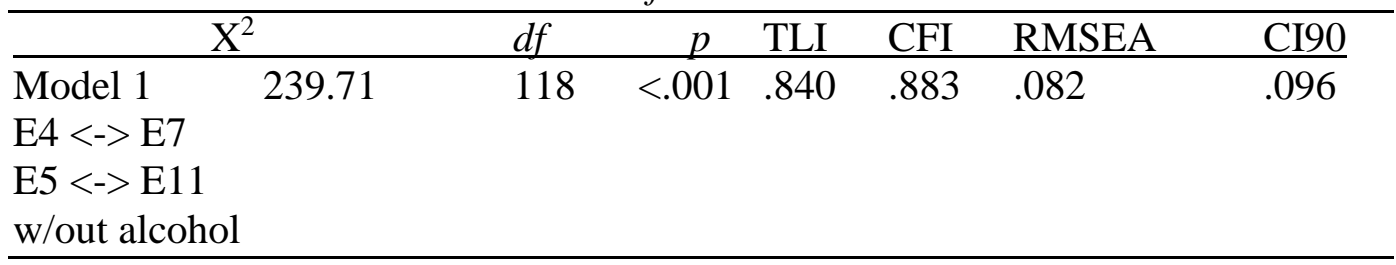


Figure 11

Alternative Measurement Model Post-modification

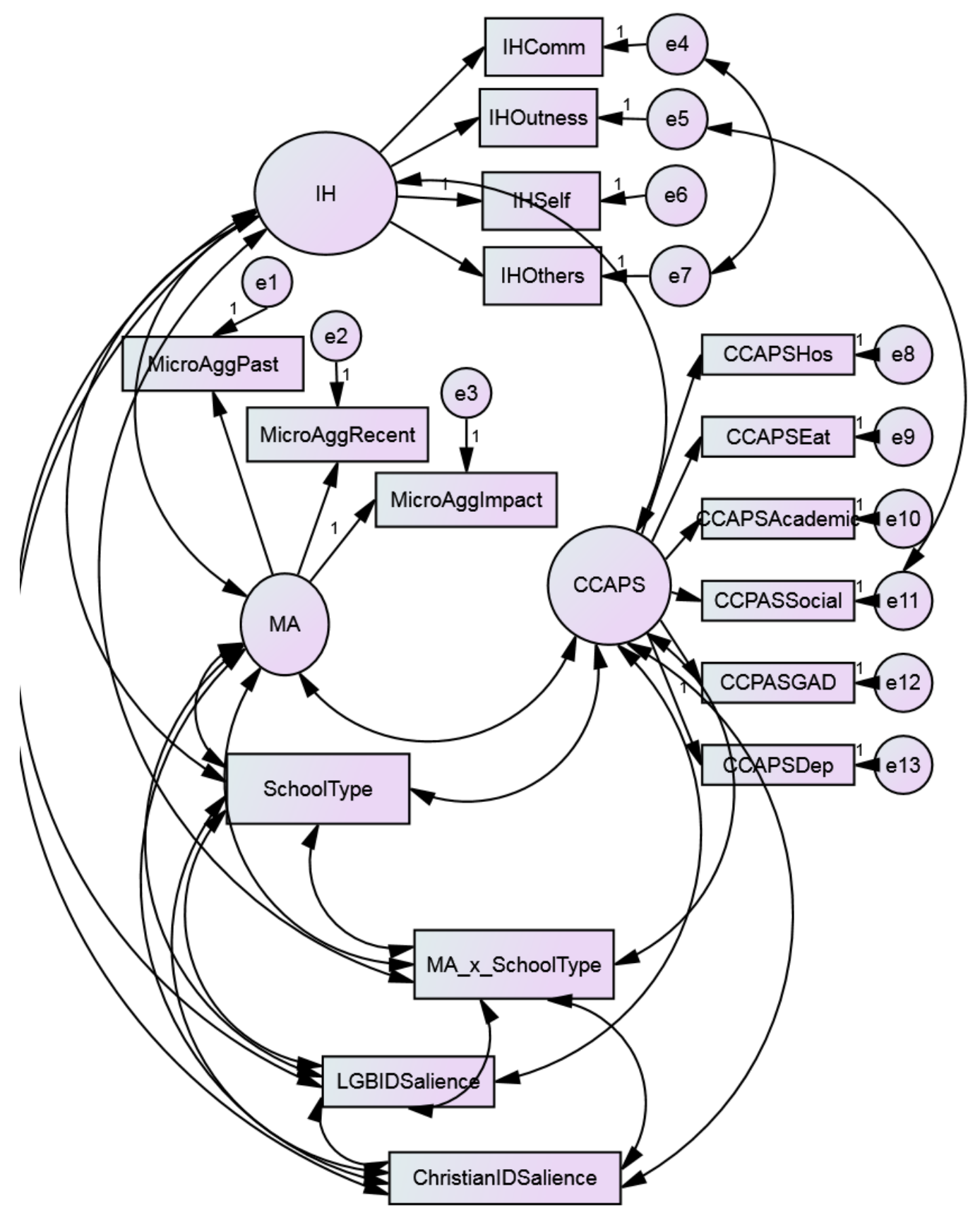


Alternative structural model analysis. The second step in the hybrid analysis process is to again test the direct paths of the moderated mediation model (See figure 12). The goal of exploring this alternative model was to explore if model fit could be improved. Unfortunately, despite the removal of the alcohol use subscale and use of theoretically appropriate modifications, acceptable model fit was not obtained. Despite the lack of acceptable model fit, analysis of the structural model proceeded to observe if different results could be gathered. 
Figure 12

\section{Alternative Structural Model}

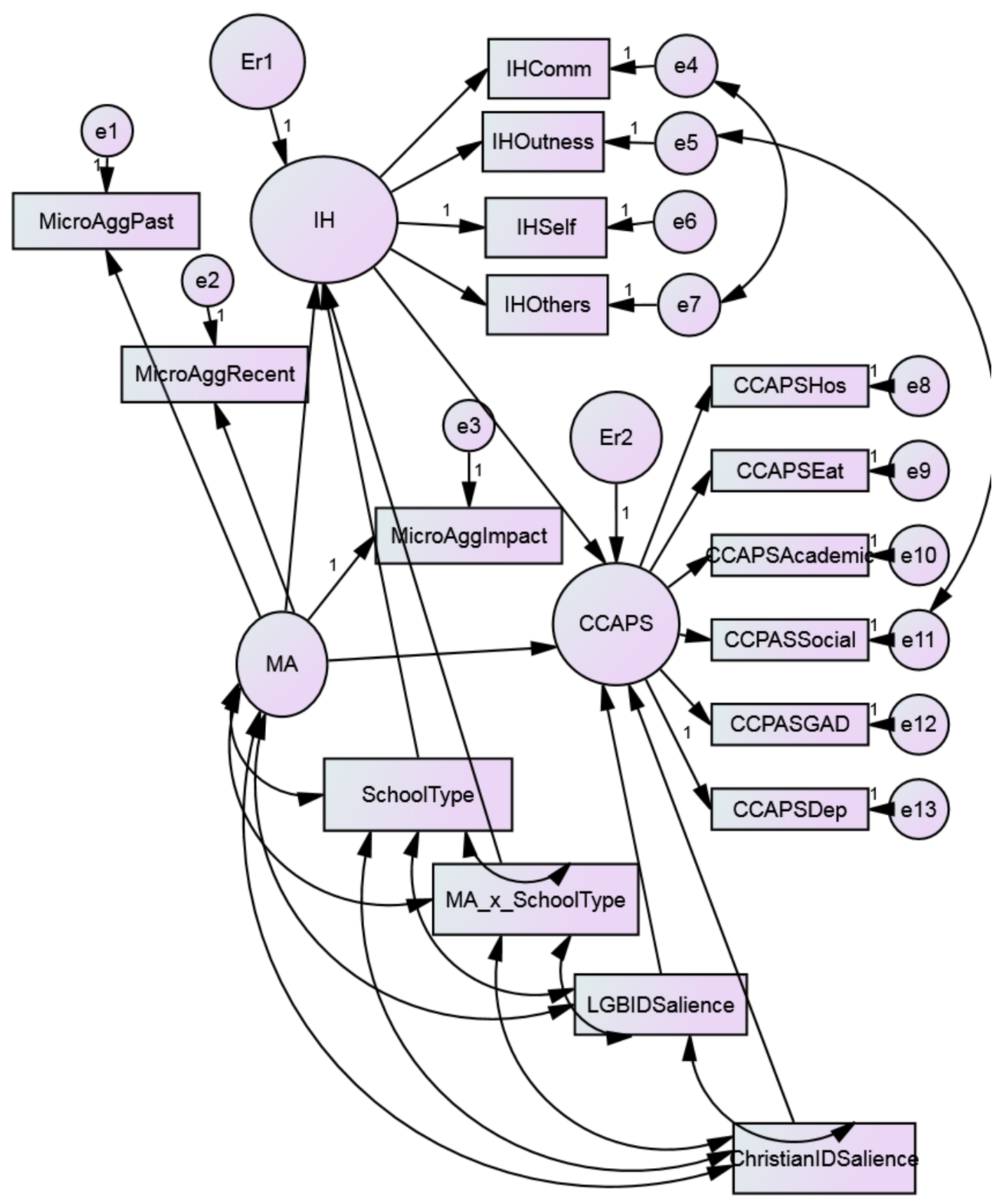


Table 19 depicts the bootstrapped regression weights for the social support moderated mediation model. The paths between homonegative microaggression and internalized heterosexism and internalized heterosexism and psychological distress were found to be significant. The direct path between homonegative microaggression and psychological distress was not significant. The interaction between homonegative microaggression and school type was not significant. The control variables were observed to be significant.

Table 19

Bootstrapped Regression Weights Alternative Model

\begin{tabular}{|c|c|c|c|c|}
\hline & Estimate & S.E. & C.R. & $\underline{p}$ \\
\hline Internalized Heterosexism <- MA & 0.45 & 0.12 & 3.84 & $* * *$ \\
\hline Psychological Distress <-Microaggression & 0.03 & 0.09 & 0.35 & .729 \\
\hline Psychological Distress <- IH & 0.52 & 0.08 & 6.91 & $* * *$ \\
\hline IH $<$-Ma x Social Support & -0.06 & 0.1 & -0.65 & .514 \\
\hline Psychological Distress $<$-LGBID Salience & -0.18 & 0.06 & -3.16 & .002 \\
\hline Psychological Distress <-Christian ID Sal & 0.2 & 0.05 & 4.14 & $* * *$ \\
\hline
\end{tabular}

Note. $* * *=\mathrm{p}<.001$

Table 20

Bootstrapped Direct, Indirect, Total Effects

\begin{tabular}{llllllllll}
\hline & \multicolumn{3}{l}{ Direct Effects } & \multicolumn{4}{l}{ Indirect Effect } & \multicolumn{3}{l}{ Total Effects } \\
\hline & $\underline{\text { Est }}$ & $\underline{\text { S.E. }}$ & $\underline{p}$ & $\underline{\text { Est }}$ & $\underline{p}$ & $\underline{\text { Est }}$ & $\underline{\text { S.E. }}$ & $\underline{p}$ \\
MA>IH & 0.44 & 0.12 & $* * *$ & 0.00 & --- & 0.44 & 0.12 & $* * *$ \\
MA>PD & 0.03 & 0.09 & .729 & 0.23 & .018 & 0.26 & -- & -- \\
IH>PD & 0.00 & 0.08 & $* * *$ & 0.00 & --- & 0.00 & 0.08 & $* * *$ \\
MAxID>IH & 0.06 & 0.1 & .514 & 0.00 & --- & 0.06 & 0.1 & .514 \\
LGB>PD & -.018 & 0.06 & .002 & 0.00 & --- & -.018 & 0.06 & .002 \\
XID $>$ PD & 0.2 & 0.05 & $* * *$ & 0.00 & --- & 0.2 & 0.05 & $* * *$ \\
\hline
\end{tabular}

Note. $* * *=p<.001$

Based on the above analysis there is partial indirect effect between microaggression and psychological distress indicating that internalized heterosexism acted as a mediator. The direct effect of homonegative microaggression on psychological distress is not significant; while the indirect 
effect was found to be significant, indicating that indirect only mediation was found. All paths in the mediation model were positive, indicating that complimentary mediation occurred. The lack of a significant relationship between the interaction of microaggression and school type indicates that school type does not act as a moderator for the mediation model when alcohol use is removed from the measurement model. This is unsurprising considering that the variable of school type did not have a significant relationship with any of the variables included in the model, with the exception of sexual and religious identity integration. The model fit for the combined hybrid has borderline over-all fit based on the significant chi square test $\left(\mathrm{X}^{2}=261.54, \mathrm{DF}=104, p<.001\right)$, TLI value of .827, and CFI value of .868 (Bentler, 1990; Marsh et al., 2004), The RMSEA value in the original model was larger than the preferred .08 cut-off at 0.086 , and the high end of the $90 \%$ confidence interval .099 smaller than the desired .1 cutoff (Browne \& Cudeck, 1993. The comparison of indirect effect across school type shows that the mediational role of internalized heterosexism between the direct path of homonegative microaggressions and psychological distress is not moderated by school type. Again these relationships should be interpreted with caution, as acceptable model fit was not obtained. Overall, this indicates that the removal of the alcohol use subscale did not significantly improve model fit or alter the findings in the structural model. 


\section{CHAPTER 4: DISCUSSION}

Minority stress research has consistently shown that sexual minority individuals face inordinate discrimination (Center for Disease Control, 2011; Herek, 2009; Mays \& Cochran, 2001) and subsequent negative mental health outcomes (Cochran \& Mays, 2009; Cochran, Sullivan, \& Mays, 2003; Meyer, 2003) when compared to heterosexual individuals. Recent research shown that violence towards LGBT individuals is only worsening. A recent survey found that murders of transgender individuals has increased by $13 \%$ and murders of LGBT and HIV positive individuals increased by $11 \%$ between 2013 and 2014 in the United States (National Coalition of Anti-Violence Programs, 2015). Additionally there has been at least one high profile hate crime in 2016 that specifically targeted a safe space for LGBT individuals (Stack, 2016).

In a cultural climate that is increasingly hostile towards individuals with sexual orientation and gender diversity, research about minority stress and resiliency factors can provide more information about ways to support and protect individuals who are impacted by sexual orientation discrimination. In an effort to add to this body of knowledge, this study focused on sexual minority Christian college students' experiences with subtle on-campus discrimination at Christian and secular colleges and the impact of relevant protective factors. The purpose of this study was to examine if three separate moderators (school type, social support and religious and sexual identity integration) 
would modify internalized heterosexism's role as a mediator between homonegative microaggression and psychological distress. These three models were analyzed using two statistical methods (SEM and PROCESS) as a way to compare two different methods of examining conditional indirect effects.

Christian and sexual orientation minority identity salience were also included in these models as control variables. Unfortunately, in the SEM analysis all three moderation mediation models had poor model fit, indicating that the constructs used were not accurately measured. Possible explanations for poor fit of the models will be further explored below. The lack of acceptable model fit across models warrants cautious interpretation of the findings in this study. While the results indicated that internalized heterosexism may explain a portion of the variance between homonegative microaggression and psychological distress, conclusive statements about this result would be inappropriate. Similarly, the lack of a significant moderating role of any of the three moderators should be viewed through a conservative lens.

\section{Uniqueness}

\section{Population}

While similar factors in alignment with Meyer's minority stress model have been explored in previous research, this study's core mediation model has a few unique aspects to offer the current body of research. The first unique aspect is the focus on an emerging adult population with the intersecting identities of LGB sexual orientation and Christianity. In a similar past study, Szymanski (2006) stated that the absence of significant effects when utilizing internalized 
heterosexism as a moderator could be attributed to a lack of identity diversity in her sample. Her hypothesis proposed that the populations she surveyed comprised of older Caucasian lesbian women who were more connected to community support, further along in their sexual identity development, and did not have other marginalized identities. Szymanski specifically proposed that the homogeneity in her sample may have contributed to the lack of variance she observed in factors such as internalized heterosexism. Considering that significant results were observed in a similar model using a gay male population (Meyer 1995), it was also proposed that there may have been gender differences in how sexual orientation minority individuals experience discrimination. These past limitations were taken into consideration when designing this study. Sampling procedures in this study therefore used snowball sampling to target individuals who may not be connected to a LGBT community, represent a wider range of gender identities, possess intersecting marginalized identities and are in the early stages of identity development and integration. In this study, it was hypothesized that a wider variability in minority stress related constructs would be observed in a religious sexual minority population. As mentioned in the review of past literature, religious and sexual identities can intersect and conflict in interesting ways. Connection to a religious organization can connect to higher levels of internalized minority stress or be a resiliency factor (Szymanski, Chung, \& Balsam, 2001). In seeking out a sexual orientation minority Christian college student population, some diversity was obtained in the above categories. While the majority of participants (81.2\%) were aware of an LGBT support group on their campus, less 
than a third $(28 \%)$ of the sample reported that they attended a church that was LGBT affirming. The sample also included representation of masculine, feminine, and non-binary gender identities. Some racial diversity was observed in this sample, but a large majority ( $85 \%$ ) of participants identified as White/Caucasian. Finally, by targeting the 18-25 age range, participants were in the appropriate "emerging adulthood" age range that aligns with an identity exploration stage. While this sample may have more diversity than earlier minority stress research studies, the population overall was not as varied as desired. Limitation of the lack of variance will be explored further.

\section{Microaggression}

A second unique component in this study is the shift away from overt heterosexist events to the more subtle and multi-dimension construct of homonegative microaggression. Szymanski (2006) noted another possible reason for the lack of observed significant results, despite the results found by Meyer in 1995. She hypothesized that generational changes may impact how minority stress is expressed and experienced by LGB individuals and may have created inconsistent results between cohorts. Specifically, it's possible that younger generations of LGB individuals experience of discrimination were not adequately measured using an "event based" assessment. Taking this possible shift into account, subtle discrimination (homonegative microaggression) was utilized in this study as a predictor instead of overt, event based discrimination. The measure used to assess this variable includes not only the frequency of recent and past microaggressions but also allows for the assessment of impact. This construct 
therefore allows for nuances in the evaluation of personalized and individual experiences and reduces rater bias in determining for participants the impact of their experiences with discrimination. While some recent research has focused on the impact of heterosexist microaggression on sexual minority individuals' wellbeing (Nadal, Wong, Issa, Meterko, Leon, \& Wideman, 2011; Silverschanz et al., 2008; Woodford, Howell, Silverschanz, \& Yu, 2012; Wright \& Wegner, 2012) the significant portion of this research has been qualitative in nature (Nadal, et al., 2011; Nadal, Rivera, \& Corpus, 2010; Woodford, Han, Craig, Lim \& Matney, 2014). Qualitative research is essential for understanding the complex experiences of individuals but does not always allow for a broader look at the experience of larger groups. This study assumed that more robust results could be obtained by utilizing a quantitative subtle discrimination variable as a predictor. The limitations in utilizing a quantitative approach with novel constructs and measures will be outlined below.

\section{Moderated Mediation}

Another unique aspect of this study is the use of complex mediation models in contrast to the simplistic mediation models used in the past (Syzmanski 2006; Meyers, 2005) to examine relationships between minority stress variables. This study built off previous mediation models and hypothesized that internalized heterosexism would mediate the relationship between homonegative microaggression and psychological distress. The complexity of this study lies in the three additional variables that were hypothesized to change the strength or directionality of the mediating role of internalized heterosexism. 
In this study, attendance of a Christian or secular college, self-perception of social support across three domains (family, friends, significant other), and integration of Christian and sexual orientation identity were all predicted to moderate the path between homonegative microaggression and internalized heterosexism. The results of this study show that these complex moderated mediation hypotheses could not be supported through SEM or PROCESS. Additionally, as poor model fit was observed in all three models when SEM analysis was utilized, interpretation of the results should proceed with caution. This caution should apply to results obtained in PROCESS as well, despite the lack of model fit information included in the results.

\section{Discussion of Results}

\section{Model Fit}

An aspect of this study's results that warrants exploration is the consistent poor model fit. The poor fit across all three moderated mediation measurement models indicates that the constructs included in this study are not being measured well. Improvement of fit was attempted in the alternative SEM model, where it was hypothesized that measurement issues with the psychological distress measure (CCAPS) negatively impacted model fit. Specifically it was hypothesized that school type may not have acted as a consistent moderator in model 1 due to issues with the alcohol use subscale included in the psychological distress (CCAPS) variable (see measurement and alternative model subsections for more details.) As depicted in the alternative model, the removal of this subscale did not significantly improve model fit or allow for the observation of 
the conditional indirect effects of school type. Despite the of modification to the CCAPS not improving model fit to the acceptable range, it's possible that there are additional issues with the use of the CCAPS as an outcome measure. Specifically, the measure combines multiple symptom category factors (depression, generalized anxiety, social anxiety, hostility, eating concerns, academic distress and alcohol use) into one distress scale. While this is a useful approach for obtaining diagnostic information in a clinical setting, there may be too many domains that are inapplicable to a general psychological distress construct. The hypothesis that the psychological distress measure is too broad is supported by recent research by Woodford et al (2014). They found that the use of different subcategories of psychological distress as outcome variables, specifically depression and anxiety, produced different results. They found that homonegative microaggression changes its role as a mediator between sexual identity and psychological distress based on the type of psychological distress used. For example while three categories of microaggression used in the study mediated the relationship between the predictor of sexual minority status and the outcome variable of anxiety, only two categories functioned as mediators when the outcome was depression. The results of this study suggest that while the CCAPS is a useful indicator of overall mental health concerns, it may be too broad of a construct to pinpoint the specific outcomes of sexual orientation minority stress.

Another possible explanation is that the measures utilized were not appropriate for the population. It should also be noted that internalized 
heterosexism and homonegative microaggression scales were modified to be gender inclusive. While the internal consistency of these scales was acceptable, it's possible that these modifications reduced the integrity of the measures. Gender identity is a fluid construct and this researcher's interpretation of gender inclusive items may not have aligned with participant's experience of their gender. Additionally, the measures used ranged from 5-10 years old creating possible vulnerability to instrumentation concerns based on generational differences between norming samples and participants. Regardless of the reason for poor model fit, it's clear that there are significant concerns with the measurement of constructs in this study.

It should be noted however, that despite measurement limitations in gleaning meaningful conclusions from the results, the dual analysis approach is a significant strength of this study. If only PROCESS had been used to examine the data, information about poor model fit would not have been obtained and the limitations in this study may have been overlooked. Utilizing the two approaches highlights the strengths of an SEM approach when analyzing complex relationships between variables. It should be noted however that since the missing data was addressed differently between methods of analysis, it is impossible to draw direct comparison between methods. It is possible that discrepancy between the results obtained originated in differences between sample sizes.

Despite the limitation of poor model fit in mind, structural analysis proceeded in order to examine differences in results across the two methods and explore the strengths and limitations of each approach. 


\section{Hypothesis One}

Keeping in mind the limitations in being able to confirm or deny the hypothesis based on poor model fit, internalized heterosexism was observed to partially mediate the relationship between homonegative microaggression and psychological distress in LGB Christian college students in the majority of the moderated mediation models.

Specifically the proximal distress construct (internalized heterosexism) was found to partially explain the relationship between distal distress (homonegative microaggression) and distress (psychological distress) in two out of the three SEM models (model 1: school type and model 3: identity integration) and all three of the PROCESS models. This supports the hypothesis that internalized heterosexism partially explains the relationship between homonegative microaggression and psychological distress. These results can be cautiously interpreted to mean that when Christian sexual minority college students are in a heterosexist environment, the amount of psychological distress they experience may be partially explained by the amount of internalized heterosexism they report. It is possible that the unique additions of using subtle discrimination as a predictor with a population with intersecting identities allowed for the observation of significant results for the first hypothesis, in contrast to Szymanski's findings in 2006. However, it should be noted that in the social support SEM moderated mediation model, internalized heterosexism was not found to act as a significant partial mediator. In a sense, the discrepancy between the significance found across the mediation models in the SEM analysis supports 
the conceptualization that the role of internalized heterosexism would differ as a mediator across moderators. Unfortunately, none of the mediation models differed across different levels of the moderator, nor was good enough model fit achieved to drawn conclusive results from these discrepancies.

In the PROCESS analysis, the findings across all three models supported internalized heterosexism's role as a significant mediator between the predictor of homonegative microaggression and psychological distress. In the process approach, the mediation model is analyzed first and then the moderator is included into the analysis. This is reflected in the consistent values across the mediation model summary tables for all three models (see Tables $6,11,16$ ). The model is then analyzed across levels of the interaction between the predictor and moderator. The three models therefore only differ when the three separate moderators are included into the PROCESS analysis. While this method obtained significant results supporting the first hypothesis, the discrepancy between these results and the SEM results highlight limitations of the PROCESS method. There was no indication in using this approach that there were concerning measurement issues with the models. If both methods had not been utilized in this study, important information about significant limitations would not have been obtained. These results indicate that while it may be more difficult to obtain significant results while using SEM to analyze complex models, the results may provide a more accurate view the data's ability to support meaningful interpretations than the PROCESS method. 
Despite the measurement limitations, results for the first hypothesis align consistently with past research on the topic and therefore should not be discarded based on poor model fit alone. At least one past study has specifically supported that the relationship between external minority stress and psychological distress is partially mediated by the internalization of external stress or internalized heterosexism (Szymanski \& Ikizler, 2013). In fact, the basis of the current study assumed this relationship between proximal stress, distal stress, and distress would hold true and predicted a number of additional factors would moderate this model. Specifically, since it was assumed that internalized minority stress would account for some of the variance in the mediation model, this study was designed to explore what variables could conditionally affect the assumed mediating role of internalized heterosexism. This study's inability to observe this relationship within the confines of good model fit does not disprove this relationship exists.

\section{Hypothesis Two}

The mediating role of internalized heterosexism did not vary between LGB Christian college students at Christian campuses and secular campuses. Specifically, the partial indirect effect of internalized heterosexism was not moderated by campus type.

When a lack of significant results are observed in a complex model, the first assumption to check is to ensure enough power was available to avoid a Type II error. In this case an appropriate sample size was obtained for the analysis used ( $\mathrm{n}=134$ for PROCESS and $\mathrm{n}=207$ for SEM) meaning that there was likely acceptable power to observe conditional indirect effects if present. Additionally 
the first moderator of school type had fairly equal representation of both Christian and secular colleges making it appropriate to attempt comparison across levels of the school type moderator. However, considering the complex nature of the moderated mediation model, it is possible that the inclusion of a conditional interaction effect necessitates more power than was obtained.

It is also possible that a common issue in minority stress research emerged in this study considering that low amounts of minority stress were found in the sample. While the data for all the variables was observed to fit the normal curve, means skewed towards the lower end of the scale for distress measures and towards higher amounts of protective factors (see Table 1). This means that the sample size is skewed towards lower amounts of psychological distress, internalized heterosexism, and experiences with microaggression and towards higher amounts of social support and identity integration. Additionally, the normalness of the data and the lack of "extreme" data points may have limited the model's ability to observe conditional indirect effects in a complex moderated mediation model.This hypothesis aligns with the rationale given by Meyers (2001) and Szymanski (2006) in past research for the lack of significant effects in predicted minority stress models. They suggested that it may be difficult to observe significant complex relationships between minority stress factors in populations that skew towards having lower amounts of minority stress and higher amounts of protective factors. This applies to the lack of significant results in the second hypothesis in that there may have been less variance between 
school type groups and higher variance within the two groups across multiple variables than initially predicted.

An issue with attributing the lack of significant results in the school type moderated mediation model to sample concerns arises when one considers that all of these variables work as expected and predicted in the mediation model. If no issues were observed in predicting that internalized heterosexism would mediate the relation between homonegative microaggression and psychological distress, it would not follow that sample concerns were spontaneously arise in a manner that impacts the models ability to detect conditional indirect effects alone.

It is possible though, that the assessment and use of moderator alone (secular and Christian school type) is problematic. Despite this limitation, the results for this first model when compared across analysis types are some of the most interesting within this study. While SEM analysis did not support a moderated mediation model, the PROCESS results indicated a possible unconditional indirect effect for one level of school type (secular school). This result means that attending a secular school strengthens the role of internalized heterosexism as a mediator between internalized heterosexism and psychological distress. Again, any interpretation made from this result should be cautious considering the poor model fit observed in the SEM analysis and the lack of significant conditional indirect effects when observing both levels of the moderator. Keeping this limitation in mind, there are some interesting relationships to consider e based off of this data. Specifically, attending a secular school as a sexual minority Christian may uniquely impact the role of internalized 
heterosexism as a mediator. Unfortunately, significant relationships between school type and any of the variables included in model 1 were not found, making it unlikely that this result is meaningful. Specifically, as depicted in Table 1, school type had no significant correlations with homonegative microaggressions, internalized heterosexism or psychological distress. In fact the only variable that significantly correlated with school type was not included in the first moderated mediation model. School type was observed to have a negative significant relationship with identity integration. This relationship means that those who attended secular schools may rate themselves as being less likely to have integrated their sexual orientation and religious identity. Unfortunately, since these variables were not analyzed together within the same model, interpretation of the true relationship between these factors is limited. Future research might take into consideration that attending a secular college campus may uniquely impact sexual orientation minority religious college students' experience with identity integration and minority stress.

\section{Hypothesis Three}

The internalized heterosexism mediated path between microaggression and psychological distress did not vary based on the level of social support. Specifically, the impact of heterosexism microaggression on internalized heterosexism did not change in strength or directionality in students with higher levels of social support.

Results observed in the second moderated mediation model (social support) also had some interesting components. Model 2 was the only model 
analyzed in SEM that did not support the first hypothesis, and also had the poorest final model fit. Conversely, the mediation model was supported in the PROCESS results, but conditional indirect effects of social support were not significant. This discrepancy again highlights the limitations of the PROCESS approach. Despite modeling identical relationships and controlling for the same variables the PROCESS results indicate that valid significant results were obtained for the mediation model, but social support did not act as moderator.

As highlighted when discussing model one, this study should have ample power to detect results so it is unlikely that a Type II error occurred. Unlike the school type variable, social support was observed to have significant negative relationships with internalized heterosexism, psychological distress, and the frequency and impact of recent homonegative microaggressions. Social support was also not a novel variable like school type. In fact, social support is well supported in the literature as being a relevant variable in minority stress models (Otis and Skinner, 1996, Szymanski, 2008). Despite the repeated inclusion of this variable, it is rarely modeled as a moderator and instead often serves as a predictor (Fingerhut, Peplau, \& Gable, 2010), outcome (McGregor et al., 2001; Shidlo, 1994; Szymanski et al., 2001; Szymanski et al., 2008), or mediation variable (McGregor et al., 2001; Lehavot \& Simoni, 2011; Szymanski \& Kashubeck-West, 2008) In fact, when social support has been modeled as a moderator in the past, results aligned with the findings of this study. Szymanski (2009) found that social support did not moderate the relationship between heterosexist events and psychological distress in gay and bisexual men. It was 
again hypothesized by Szymanski that this was due to limitations in the variance of the sample.

A lack of variance in levels of social support is one possible explanation for the lack of significant results in this model. Despite a little less than half of the participants being enrolled in a Christian college, the majority of respondents identified that their campus has some sort of sexual orientation support group. While it is not clear if all of these groups are affirming of all sexual orientations, it is likely that the majority of respondents know where they could obtain some identity related support, regardless of school type. It is possible that despite the researcher's best efforts, the use of online survey and snowball sampling did not allow for the inclusion of sexual minority Christians who are not connected to some sort of sexual orientation support system. Additionally, most participants self-rated as "mildly" to "very strongly agreeing" to having multidimensional social support. With the majority of participants having access to both sexual orientation specific support and general social support, it is likely that a lack of variance in this construct is a significant limitation.

Another possible explanation for the lack of significant moderating mediation is that despite social support's significant negative relationship with the minority stress variables in this data set, social support simply does not relate to these variables in the way that was hypothesized. Consistent with previous research (e.g.McGregor et al., 2001; Lehavot \& Simoni, 2011; Szymanski \& Kashubeck-West, 2008), social support may function better as a mediator when examining the relationship between external and internal distress factors. 
However there are significant limitations in conceptualizing social support as a variable that explains part of the variance between homonegative microaggression and psychological distress. Theoretically, it does not make sense that experiencing homonegative microaggression would predict social support, therefore drawing a direct path from homonegative microaggression to social support would not be conceptually sound. Additionally, a true mediation model indicates a temporal order of variables. Similar to concerns with prediction, it there is no theoretical rational for why experiencing homonegative microaggressions would temporally precede constructs such as family, friend and significant other social support.

\section{Hypothesis Four}

The internalized heterosexism mediated path between microaggression and psychological distress did not vary based on the level of identity integration participants reported.

The final moderated mediation model observed similar results to the previous two hypotheses. In both the PROCESS and SEM analyses, internalized heterosexism acted as a partial mediator, however Christian and sexual identity integration was not found to alter the strength or direction the mediator. The model fit was better than the previous two models, but the fit indices were still poor. Similar to the previous two models this model is not underpowered due to sample size and therefore the occurrence of a Type II error is unlikely.

Integration of sexual orientation and religious identity is a construct that is similar to school type. It had not been included in previous research specifically focused on Meyer's minority stress model or used as a moderator or mediator in 
past research. Despite its absence in this particular area of literature, it seemed useful to include due to this study's focus on emerging adulthood in a population with intersecting and potentially conflicting identities. In a similar fashion to the previous moderators explored in this study, identity integration was selected as a factor that could act as a risk or protective factor for LGB Christian students. Past research has shown that religious identity in sexual minority individuals can relate to both positive (Gold, \& Stewart, 2011; Kocet, Longo, Walls, \& Wisenki, 2013)Sanabria, \& Smith, 2011; Rodriguez \& Oullette, 2000; Yip, 1997) and negative outcomes (Loon, 2003; Sherry, Adelman, Whilde, \& Quick, 2010). In this study it was hypothesized that the ability of individuals to integrate religious identity and sexual orientation could be a significant factor in religious sexual orientation minority individuals' ability to maintain well-being in a discriminatory environment.

The uniqueness of adding identity integration as a variable also created a possible limitation. Sexual identity and religious identity integration was assessed by adapting a scale used within a previous study and may not have accurately measured the desired construct. Specifically, this measure was constructed with items used to measure sexual and spiritual identity integration in two previous studies (Dahl \& Galliher, 2009; Hamblin \& Gross, 2011). Using the data collected in this study, the internal consistency for this variable was questionable $(\alpha=.69)$. However, it should be noted that there were very few items included in the scales which may have falsely lowered the Cronbach's alpha. 
Despite possible limitations in the measurement of this construct, identity integration was the only other variable that school type had a significant (negative) correlation with school type, meaning that those who attended secular colleges also reported lower amounts of religious and sexual identity integration. While these constructs were never included within the same model at the same time, exploration of this relationship could be an interesting future direction. It could be that LGB Christian individual who choose to attend a secular school initially felt less internal or external pressure to integrate their faith and sexual orientation. Alternatively, perhaps LGB Christian individuals have a difficult time finding community support for both identities while on campus. Identity integration also had negative significant relationships with internalized heterosexism, psychological distress and frequency of recent homonegative microaggressions and may act as a variable that explains variance between proximal and distal distress. Specifically and alternative model could explore if identity integration mediates the relationship between selection of homonegative microaggression and psychological distress. Regardless of identity integration's true role in the minority stress model, the strong relationship it has with other it is a potentially important factor in LGB Christian college students' well-being and is possibly related to college environment. However due to the poor model fit observed in this study, alternative methods for assessing these constructs may be necessary for obtaining meaningful results.

\section{Conclusion \& Future Directions}


Overall, due to the lack of any significant conditional indirect effects observed across moderators, one wonders if the issue lies in the hypotheses or in the analysis. Poor model fit was clearly a significant limitation in obtaining meaningful results. Sufficient power and normality of data were observed and theoretically appropriate modifications were made. Further changes to improve model fit would damage the integrity of the study and therefore were not pursued. Despite a poor foundation for drawing meaning from the data a few interesting pieces were observed in this study. By comparing two methods of analysis the strengths and limitations of SEM and PROCESS analysis for examining moderated mediation models were explored. While the PROCESS approach allows for the use of a smaller sample size the lack of information about model fit would have been a serious limitation in this study if this information had not been obtained by alternative analysis. It should be noted however that since the missing data were addressed differently between methods of analysis, comparison between methods should keep this in mind.

Another surprising finding was that the hypothesis of social support acting as a moderator was not supported. Due to the theoretical basis for social support acting as a significant protective factor against minority stress, this hypothesis was regarded as one with the strongest support in the literature. This finding is further complicated by the strong relationships observed between social support and several other factors included in the model (See Table 1). One possible explanation is that social support acts as a factor in the perception of microaggressions and therefore may theoretically act as a mediator. The factors of 
school type and identity integration are novel constructs and therefore the lack of observed moderation does not elicit the same confusion. However, considering identity integration's strong negative relationship with several of the minority stress variables, it seems likely that these factors relate in a complex manner, just not as hypothesized. The more plausible explanation for the lack of statistically significant support for this hypothesis is the poor model fit. Without a solid measurement basis for this model, it is difficult to interpret the lack of findings with certainty.

A final limitation in this study that should be acknowledged is the issues that arise in any endeavor that treats a diverse group of individuals as one homogenous group. Additionally, this study was conceptualized by individuals who identify outside of the Christian sexual orientation minority community and cannot avoid the bias this outside perspective creates. Within this study there are certainly important pieces of participants' narratives that may have been overlooked or misunderstood due to the quantitative nature of this study design. For example, students may have experienced specific microaggressions that were not included in the survey, or they may experience internalized heterosexism in a way not completely captured by the measures used.

Related to measurement and construct conceptualization, it also may be useful to move away from a general social support construct and explore a more focused minority social support measure. The use of a multidimensional social support scale may not have allowed for the nuance of individuals being able to differentiate among domains. For example LGB Christian individuals may have 
support from peers but lack support from their families. The multidimensional social support measure may not be appropriate for sexual orientation minority individuals who may not be "out" in all social domains. For example a participant could identify that their family is a great source of support in many areas, but may believe the support would diminish if they were "out." By collapsing these dimensions into one construct, aspects of participants' true experiences may have been overlooked. It is possible that a measure that is has been developed for and validated with sexual orientation minority individuals would collect more meaningful data about social support.

Finally the separation of school type into "secular" and "Christian" assumes similar uniformity. In actuality sexual minority Christian college students may face diverse experiences with acceptance and discrimination in their college environment regardless of "school type." Keeping in mind the variability among Christian campuses in terms of having visible sexual orientation identity support, it would be interesting to learn how the school type moderator might have acted differently if the variable was defined in an alternative manner. For example, instead of examining differences between secular and Christian colleges, it could be interesting to explore the difference among campuses that either had or did not have a LGBT support groups. Additionally, comparing student experiences among campus that had or did not have honor codes specifically condoning acting on sexual minority identities could illicit interesting results.

When one considers the counseling implications of this study, these factors seems particularly relevant. As noted earlier, the distress variables in this 
study skewed towards the lower end. The participants had higher levels of support and lower levels of psychological distress. It is possible that participants felt pressured to respond to survey questions in a manner that challenged the pathologizing conceptualization of sexual orientation minority identities. Specifically, participants may have responded in a manner that reflected inflated levels of well-being due to understandable distrust of psychological research that targets sexual orientation minority individuals. Conversely, participants may be expressing genuine resilience and could be "thriving" despite experiences of discrimination and identity conflict. For individuals working in college counseling and student life services, it may be important to be aware of this potential for resiliency. While LGB Christian college students may be a vulnerable population, the data in this study indicates strength and resolve in the face of discrimination.

Despite the limitations within this study, obtaining an overarching view of the effects of minority stress on LGB Christian individuals has been valuable. To continue adding value to this area of study it is likely that greater access to diverse individuals and more accurate measures are needed to obtain more robust results. While snowball sampling procedure were used to try to obtain more diversity, it is likely that within the more conservative Christian colleges, sexual orientation minority individuals are cut off from individuals with shared identities. Since the sampling procedures relied on accessing individuals with at least one connection to another sexual orientation minority individual, it is likely that this subset of the population was underrepresented in this study.

Finally, while quantitative analysis is a useful step in understanding the 
complex experienced of individuals, it is likely that rich information about the true nature of relationships between the targeted variables in this study could be explored through additional qualitative research targeting sexual orientation minority Christian college studetns. It is possible that some of the qualitative conceptual support for the structure of this study is not applicable for this specific population. Continuing past research, in alignment with Nadal and colleagues (2010) use of focus groups and qualitative interviews, could provide richer information about this population. In short, it is likely that intersecting sexual and religious identities may create complexity that is not adequately captured by the traditional minority stress model. 


\section{REFERENCES}

Althoff, A. J. (December 7, 2012). Hope for the gay undergrad. Christianity Today, 57,17-21. Retrieved from http://www.christianitytoday.com/ct/2013/january-february/hope-forgayundergrad.html

American Psychological Association. (August 10, 2006). Statement of the American Psychological Association, Office of Public Communications.

Aneschenel, C. S. (1992). Social stress: theory and research. Annual Review of Sociology. 18, 15-38. Doi: 10.1146/annurev.so.18.080192.000311

Arbuckle, J. L. (2012). IBM SPSS AMOS 21 a user's guide. IBM, AMOS Development corporation. Chicago, IL.

Barnes, D. M., \& Meyer, I. H. (2012). Religious affiliation, internalized homophobia, and mental health in lesbians, gay men and bisexuals. American Journal ofOrthopsychiatry, 82, 505-515. doi: 10.1111/j.19390025.2012.01185.x.

Baron, R. M., \& Kenny, D. A. (1986). The moderator-mediator variable distinction in social psychological research: Conceptual, strategic, and statistical considerations. Journal of Personality and Social Psychology, 51, 1173-1182. doi: 10.1037/0022-3514.51.6.1173

Bollen, K. A. (1989). Structural equations with latent variables. New York, NY: Wiley Interscience. doi: 10.1002/9781118356258.ch3

Branscombe, N. R., Schmitt, M. T., \& Harvey, R. D. (1999). Perceiving pervasive 
discrimination among African Americans: Implications for group identification and well-being. Journal of Personality and Social Psychology, 77, 135-149. doi: 10.1.1.460.8563

Brown, R. D., Clarke, B., Gortmaker, V., \& Robinson-Keilig, R. (2004). Assessing the campus climate for gay, lesbian, bisexual and transgender (LGBT) students using a multiple perspectives approach. Journal of College Student Development, 45, 8-26. doi: 10.1353/csd.2004.0003

Buchanan, M., Dzelme, K., Harris, D., \& Hecker, L. (2001). Challenges of being simultaneously gay or lesbian and spiritual and/or religious: A narrative perspective. The American Journal of Family Therapy, 29, 435-449. doi: $10.1080 / 01926180127629$

Burn, S. M., Kadlec, K., \& Rexer, R. (2005). Effects of subtle heterosexism on gays, lesbians, and bisexuals. Journal of Homosexuality, 49(2), 23-38. doi: 10.1300/J082v49n02_02

Canty-Mitchell, J. \& Zimet, G.D. (2000). Psychometric properties of the Multidimensional Scale of Perceived Social Support in urban adolescents. American Journal of Community Psychology, 28, 391-400. doi: 10.1023/A:1005109522457

Centers for Disease Control and Prevention. (May 19, 2011). Lesbian Gay and Transgender Health. National Center for Chronic Disease Control and Prevention: Division of Adolescent and School Health. Retrieved from http://www.cdc.gov/lgbthealth/youth.htm

Cochran, S. D., \& Mays, V. M. (2009). Burden of psychiatric morbidity among 
lesbian, gay and bisexual individuals in the California Quality of Life Survey. Journal of Abnormal Psychology, 118, 647-658. doi:

10.1037/a0016501.

Cochran, Mays, \& Sullivan (2003). Prevalence of mental disorders psychological distress and mental health services use among lesbian gay and bisexual adults in the United States. Journal of Consulting Clinical Psychologyl, 53-61. doi: 10.1037/0022-006X.71.1.53

Crocker, J. \& Major, B. (1989). Social stigma and self-esteem: the self-protective properties of stigma. Psychological review, 96, 608-630. doi: 10.1037/0033-295x.96.4.608

Dahl, A., \& Galliher, R. V. (2009). LGBQQ young adult experiences of religious and sexual identity integration. Journal of LGBT Issues in Counseling, 3, 1-21. doi: $10.1080 / 15538600903005268$

Dohrenwend, B. P. (2000). The role of adversity and stress in psychopathology: Some evidence and its implications for theory and research. Journal of Health and Social Behavior, 41, 1-19. doi: 10.2307/2676357

Edwards, J. R. \& Lambert, L. S. (2007). Methods for integrating moderation and mediation: A general analytical framework using moderated path analysis. Psychological Methods, 12, 1-22. doi: 10.1037/1082-989X.12.1.1

Fingerhut, A. W., Peplau, L. A., \& Gable, S. L. (2010). Identity, minority stress and psychological well-being among gay men and lesbians. Psychology of Sex, 1, 101-114. doi: 10.1080/19419899.2010.484592

Frable, D., Platt, E. S., Hoey, S. (1998). Concealable stigmas and positive self- 
perceptions: Feeling better around similar others. Journal of Personality and Social Psychology, 74, 909. doi: 10.1037/0022-3514.74.4.909

Frost, D. M. \& Meyer, I. H. (2009). Internalized homophobia and relationship quality among lesbians. gay men, and bisexuals. Journal of Counseling Psychology, 56, 97-109. doi: 10.1037/a0012844

Gold, S., \& Stewart, D. (2011). Lesbian, gay, and bisexual students coming out at the intersection of spirituality and sexual identity. Journal of LGBT Issues In Counseling, 5, 237-258. doi: 10.1080/15538605.2011.633052

Grella, C., Greenwell, L., Mays, V. M., \& Cochran, S.D. (2009). Influence of gender, sexual orientation, and need on treatment utilization for substance use and mental disorders: Findings from the California Quality of Life Survey, BMC Psychiatry, 9. doi: 10.1186/1471-244X-9-52

Hamblin, R.J. \& Gross, A.M. (2011). Role of religious attendance and identity conflict in psychological well-being. Journal of Religion and Health. 52, 817-827.doi:10.1007/s10943-011-9514-4

Harris, J., Cook, S. W., \& Kashubeck-West, S. (2008). Religious attitudes, internalized homophobia and identity in gay and lesbian adults. Journal of Gay and Lesbian Mental Health, 12, 205-225.

Hatzenbuehler, M. L.; Pachankis, J. E., Wolff, J. (2012). Religious climate and health risk behaviors in sexual minority youths: A population based study. American Journal of Public Health, 102, 657-663. doi: 10.2105/AJPH.2011.300517.

Helminiak, D. A. (1995). Nonreligious lesbians and gays facing AIDS: A fully 
psychological approach to spirituality. Pastoral Psychology, 43, 301-318. doi: $10.1080 / 19359700802111452$

Herek, G. M. (2009). Hate crimes and stigma-related experiences among sexual minority adults in the United States. Prevalence estimates from a national probability sample. Journal of Interpersonal Violence, 24, 54-74. doi: $10.1177 / 0886260508316477$

Herek, G. M., Gillis, J. R., \& Cogan, J. C. (1999). Psychological sequelae of hate crime victimization among lesbian, gay, and bisexual adults. Journal of Consulting and Clinical Psychology, 67, 945-951. doi: $10.1177 / 088626097012002003$

Hoenig, J. M. \& Heisey, D. M. (2001). The abuse of power: The pervasive fallacy of power calculations for data analysis. The American Statistician, $55,1-6$.

Human Rights Campaign. (2013). Employment non-discrimination act. Retrieved from: http://www.hrc.org/

Jackson, D. L., Gillaspy, J. A., Purc-Stephenson, R. (2009). Reporting practices in confirmatory factor analysis: An overview and some recommendations. Psychological Methods, 14, 6-23. Doi: 10.1037/a0014694

Kline, R. B. (2010). Principles and practice of structural equational modeling ( $3^{\text {rd }}$ ed.). New York, NY: Guilford Press.

Kocet, M. M., Sanabria, S., \& Smith, M. (2011). Finding the spirit within: 
Religion, spirituality, and faith development in lesbian, gay, and bisexual individuals. Journal of LGBT Issues in Counseling, 5(3-4), 163-179. doi: $10.1080 / 15538605.2011 .633060$

Lapinski, J., \& McKirnan, D. (2013). Forgive me father for i have sinned: The role of a christian upbringing on lesbian, gay, and bisexual identity development. Journal of Homosexuality, 60, 853-872. doi:

$10.1080 / 00918369.2013 .774844$

Lazarus, R. S. \& Folkman, S. (1984). Stress, appraisal, and coping. New York, NY: Springer Publishing Company.

Lease, S. H., Horne, S. G., Noffsinger-Frazier, N. (2005). Affirming faith experiences and psychological health for caucasian lesbian, gay, and bisexual individuals.Journal of Counseling Psychology, 52(3), 378-388. doi: 10.1037/0022-0167.52.3.378

Lehavot, K. \& Simoni, J. M. (2011). The impact of minority stress on mental health and substance use among sexual minority women. Journal of Consulting and Clinical Psychology, 79: 159-170. Doi: 10.1037/a0022839

Link, G. \& Dohrenwend, B. P. (1980) Formulation of hypotheses about the ratio of untreated to treated cases in the true prevalence studies of functional psychiatric disorders in adults in the United States. In Mental Illness in the United States: Epidemiologic Estimates (Eds B. P. Dohrenwend, B. S. Dohrenwend, M. S. Gould, et al), pp. 133-148. New York: Praeger.

Locke, B. D., McAleavey, A. A., Zhao, Y., Lei, P., Hayes, J. A., Castonguay, L. 
G., Li, H., Tate, R., Lin, Y. (2012). Development and initial validation of the counseling center assessment of psychological symptoms-34. Measurement and Evaluation in Counseling and Development. 1-19. doi: $10.1177 / 0748175611432642$

Longo, J., Walls, N. E., Wisenki, H. (2013). Religion and religiosity: protective or harmful factors for sexual minority youth? Mental Health, Religion \& Culture, 16, 273-290. doi: 10.1080/13674676.2012.659240

Loon, M. V. (2003). The impact of fundamentalist teaching on gay men. Alhambra, CA: Alliant International University. doi: 10.1037/a0023807

Love, P., Bock, M., Jannarone, A., Richardson, P. (2005). Identity interaction: Exploring the spiritual experiences of lesbian and gay college students. Journal of College Student Development, 46, 193-209. doi: $10.1353 /$ csd.2005.0019

Macionis, J. J., \& Gerber, L. M. (2011) Sociology, 7th ed. Canada: Pearson Education.

Mays, V.M. \& Cochran, S.D. (2001). Mental health correlates of perceived discrimination among lesbian, gay, and bisexual adults in the United States. American Journal of Public Health, 91, 1869-1876. doi: 10.2105/AJPH.91.11.1869

McCabe, P. C., Dragowski, E. A., \& Rubinson, F. (2013). What is homophobic bias anyway? Defining and recognizing microaggressions and harassment of LGBTQ youth. Journal of School Violence, 12(1), 7-26. Doi:

$10.1080 / 15388220.2012 .731664$ 
McGregor, B. A., Carver, C. S., Antoni, M. H., Weiss, S., Yount, S. E., Ironson, G. (2001). Distress and internalized homophobia among lesbian women treated for early stage breast cancer. Psychology of Women Quarterly, 25, 1. Doi: 10.1111/1471-6402.00001

Meyer, I. H. (2003). Prejudice, social stress, and mental health in lesbian, gay, and bisexual populations: Conceptual issues and research evidence. Psychological Bulletin, 129(5), 674-697. doi:10.1037/00332909.129.5.674

Meyer, I. H. (1995). Minority stress and mental health in gay men. Journal of Health and Social Behavior, 36, 38-56. doi: 10.2307/2137286

Meyer, I. H., \& Dean, L. (1998) Stigma and sexual orientation: Understanding prejudice against lesbians, gay men, and bisexuals. In G. Herek, (Ed.); Thousand Oaks, CA: Sage Publications, Inc.

Miller, C. T. \& Major, B. (2000). Coping with stigma and prejudice. In T. F. Heatherton, R.E. Kleck, M. R. Hebel, \& J. G. Hull (Eds.), The social psychology of stigma. New York, NY: Guilford.

Mustanski, B., Newcomb, M. E. \& Garofalo, R. (2011). Mental health of lesbian, gay, and bisexual youths: A developmental resiliency perspective. Journal of Gay \& Lesbian Social Services, 23, 204-225. doi:

$10.1080 / 10538720.2011 .561474$

Nadal, K. L., Rivera, D. P., \& Corpus, J. H. (2010). Sexual orientation and 
transgender microaggressions. In D. W. Sue (Ed.), Microaggressions and marginality: Manifestation, dynamics, and impact (pp. 217-240).

Hoboken, NJ: Wiley.

Nadal, K. L., Wong, Y., Issa, M., Meterko, V., Leon, J., \& Wideman, M. (2011). Sexual orientation microaggressions: Processes and coping mechanisms for lesbian, gay, and bisexual individuals. Journal Of LGBT Issues In Counseling, 5, 21-46. doi: 10.1080/15538605.2011.554606

Osborne, J. (2012). Best practices in data cleaning: A complete guide to everything you need to do before and after collecting your data. Thousand Oakes, CA: Sage.

Otis, M. D., \& Skinner, W. F. (1996). The prevalence of victimization and its effect on mental well-being among lesbian and gay people. Journal of Homosexuality, 30, 93-117. doi: 10.1300/J082v30n03_05

Postmes, T. \& Branscombe, N. R. (2002). Influence of long-term racial environmental composition on subjective well-being in African Americans. Journal of Personality and Social Psychology, 83, 735-751. Doi: 10.1037//0022-3514.83.3.735. 735

Preacher, K. J., Rucker, D. D., \& Hayes, A. F. (2007). Addressing moderated mediation hypotheses: Theory, methods and prescriptions. Multivariate Behavioral Research, 42, 185-227. doi: 10.1080/00273170701341316

Rankin, S.R. (2003). Campus climate for gay, lesbian, bisexual, and transgender people: A national perspective, New York, NY: National Gay and Lesbian Task Force Policy Institute. 
Riggle, E. D. B., Rostosky, S. S., \& Reedy, C. S. (2005). Online surveys for LGBT research: Issues and techniques. Journal of Homosexuality, 49, 121. doi:10.1300/J082v49n02_01

Robinson, C. M. \& Spivey, S. E. (2007. The politics of masculinity and the exgay movement. Gender \& Society October, 21, 650-675. doi: 10.1177/0891243207306384

Rodriguez, E. M. \& Ouellette, S. C. (2000). Gay and lesbian Christians: Homosexual and religious identity integration in the members and participants of a gay-positive church. Journal for the Scientific Study of Religion, 39, 333-347. doi: 10.1111/0021-8294.00028

Rostosky, S.S., Danner, F., \& Riggle, E.D.B. (2007). Is religiosity a protective factor against substance use in emerging adulthood? Only if you're straight! Journal of Adolescent Health, 40, 440-447. doi:

10.1016/j.jadohealth.2006.11.144

Sherry, A., Adelman, A., Whilde, M. R., Quick, D. (2010). Competing selves: Negotiating the intersection of spiritual and sexual identities. Professional Psychology Research and Practice, 41, 112-119. doi: 10.1037/a0017471

Shidlo, A. (1994) Internalized homophobia: conceptual and empirical issues in measurement. In Greene, B. and Herek, G. (eds), Lesbian and gay psychology: Theory, research and clinical applications. Thousand Oaks, CA: Sage.

Silverschanz, P., Cortina, L. M., Konik, J., \& Magley, V. J. (2008). Slurs, snubs, 
and queer jokes: Incidence and impact of heterosexist harassment in academia. Sex Roles, 58, 179-191. doi: 10.1007/s11199-007-9329-7

Smith, W. K. (1987). The stress analogy. Schizophrenia Bulletin. 12, 215-220. doi: 10. 2005-09726-001

Smith, N. G., \& Ingram, K. M. (2004). Workplace heterosexism and adjustment among lesbian, gay, and bisexual individuals: The role of unsupportive social interactions. Journal of Counseling Psychology, 51, 57- 67. doi:10.1037/0022-0167.51.1.57

Steffan, M. (2013, June). Alan chambers apologizes to gay community, exodus international to shut down. Christianity Today. Retrieved from http://www.christianitytoday.com/gleanings/2013/june/alan-chambersapologizes-to-gay-community-exodus.html

Stack, L. (June 12, 2016). Orlando shooting: What we know and don't know. The New York Times. Retrieved from http://www.nytimes.com/2016/06/13/us/orlando-shooting-what-we-knowand-dont-know.html?_r=0.

Stratton, S. P., Dean, J. B., Yarhouse, M. A., LAstoria, M.D. (2013). Sexual minorities in faith-based higher education: A national survey of attitudes, milestones, identity and religiosity. Journal of Psychology and Theology, 41, 3-23. doi: $10.1037 / \mathrm{sgd} 0000162$

Sue, D. (2010). Microaggressions in everyday life: Race gender and sexual orientation. Hoboken, NJ: John Wiley \& Sons.

Szymanski, D. M., (2005). A feminist approach to working with internalized 
heterosexism in lesbians. Journal of College Counseling, 8, 74-85. doi: $10.1002 / j .2161-1882.2005 . t b 00074 . x$

Szymanski, D.M., Chung, Y. B., \& Balsam, K. F. (2001). Psychosocial correlates of internalized homophobia in lesbians. Measurement and Evaluation in Counseling and Development, 34, 27-38. Doi:

$10.1080 / 00918369.2015 .1083779$

Szymanski, D.M., Kashubeck-West, S., Meyer, J. (2008). Internalized Heterosexism: Measurement, psychosocial correlates and research directions. The Counseling Psychologist, 36, 525-574. doi: $10.1177 / 001100007309489$

Szymanski, D. M., \& Ikizler, A. S. (2013). Internalized heterosexism as a mediator in the relationship between gender role conflict, heterosexist discrimination, and depression among sexual minority men. Psychology of Men \& Masculinity, 14 2, 211-219. doi: 10.1037/a0027787

Szymanski, D. M. (2006). Does internalized heterosexism moderate the link between heterosexist events and lesbians' psychological distress? Sex Roles, 54, 227-234. doi: 10.1007/s11199-006-9340-4

Szymanski, D. M., \& Carr, E. R. (2008). The roles of gender role conflict and internalized heterosexism in gay and bisexual men's psychological distress: Testing two mediation models. Psychology of Men and Masculinity, 9, 40-54. doi: 10.1037/1524-9220.9.1.40

Szymanski, D. M., \& Kashubeck-West, (2008). Internalized oppressions and 
lesbian and bisexual women's psychological distress. The Counseling Psychologist, 36 (4) 575-594. doi: 10.1177/0011000007309490

Szymanski, D. M. (2009). Examining potential moderators of the link between heterosexist events and gay and bisexual men's psychological distress. Journal of Counseling Psychology, 56, 142-151. doi: 10.1037/00220167.56.1.142

Waldo, C. R. (1999). Working in a majority context: A structural model of heterosexism as minority stress in the workplace. Journal of Counseling Psychology, 46, 218 -232. doi: 10.1037/0022-0167.46.2.218

Wayne, J. C. (2003). Multiple imputation for missing data: What is it and how can I use it? Paper presented at the Annual Meeting of the American Educational Research Association, Chicago, IL.

Wilcox, M. M. (2002). When shelia's a lesbian: Religious individualism among lesbian, gay, bisexual and transgender Christians. Sociology of Religion, 63, 497-515. doi: 10.2307/3712304

Woodford, M. M., Han, Y., Craig, S., Lim, C., Matney, M. M., (2014). Discrimination and mental health among sexual minority college students: The type and form of discrimination does matter. Journal of Gay and Lesbian Mental Health, 18, 142-

163. doi: 10.1080/19359705.2013.833882.

Woodford, M. R., Howell, M. L., Silverschanz, P., \& Yu, L. (2012). “That’s so 
gay!" Examining the covariates of hearing this expression among gay, lesbian, and bisexual college students. Journal of American College Health, 60 (6), 429-434. doi: 10.1080/07448481.2012.673519

Woodford, M. R., Howell, M. L., Kulick, A., Silverschanz, P. (2012). “That’s so gay":Heterosexual male undergraduates and the perpetration of sexual orientation microaggression on campus. Journal of Interpersonal Violence, 1-20. doi: 10.1080/07448481.2012.673519

Wright, E. R., Perry, B. L., (2006). Sexual identity distress, social support, and the health of gay, lesbian, and bisexual youth. Journal of Homosexuality. 51, 81-110. doi: 10.1300/J082v51n01_05

Wright, A., \& Wegner, R. T. (2012). Homonegative microaggressions and their impact on LGB individuals: A measure validity study. Journal of $L G B T$ Issues in Counseling, 6, 34-54. doi:10.1080/15538605.2012.648578

Yarhouse, M. A., Stratton, S. P., Dean, J. B., \& Brooke, H. L. (2009). Listening to sexual minorities on Christian college campuses. Journal of Psychology and Theology, 37, 96-113.

Yip, A. K. T. (1997). Attacking the attacker: Gay Christians talk back. The British Journal of Sociology, 48, 113-127. doi: 10.2307/591913

Zimet, G. D., Dahlem, N. W., Zimet, S. G., \& Farley, G. K. (1988). The multidimensional scale of perceived social support. Journal of Personality Assessment, 52, 30-41. doi: 10.1207/s15327752jpa5201_2 


\section{APENDICES}

\section{Appendix I - Revised Homonegative Microaggresion Scale}

1. How often have people conveyed that it is your choice to be LGB?

2. How often have people acted as if you have not come out?

3. How often have people asked about former partners based on your perceived gender (i.e. about boyfriends if you are labeled as a woman, or about girlfriends if you are labeled as a man)?

4. How often have people assumed you are straight?

5. How often have people used the phrase "sexual preference" instead of "sexual orientation"?

6. How often have people assumed you align with LGB stereotypes? For example assuming you are more sensitive if you are typically read as a man, or less sensitive if you are typically read as a woman).

7. How often have people assumed you are skilled in stereotypically LGB tasks (like dancing for men or sports for women)?

8. How often have people assumed you knew a lot about stereotypical LGB interests like pop music (if you are typically read as a man) or feminism (if you are typically read as a woman)?

9. How often have people assumed you were knowledgeable about women's clothing (if you are typically read as a man) or men's clothing (if you are typically read as a woman)??

10. How often have people assumed you were attracted to them simply because of your sexual orientation?

11. How often have people told you that they just see you as a person, regardless of your sexual orientation?

12. How often have people said blanket statements about how society is full of diversity, minimizing you experience of being different?

13. How often have family members simply ignored the fact you are a LGB individual?

14. How often have people changed the subject/topic when reference to your sexual orientation comes up?

15. How often have people assumed you were a pervert of deviant?

16. How often have people assumed you were a pedophile?

17. How often have people assumed you have HIV/AIDS because of your sexual orientation?

18. How often have people assumed you are sexually promiscuous because of your sexual orientation?

19. How often have people physically shielded their child/children from you?

20. How often have people avoided proximity, like crossing the street to walk or waiting for the next elevator?

21. How often have people said things like "I watch Ellen, the L Word or Happy Endings" to show they know about gay culture? 
22. How often have people equated themselves and their experience to yours as a minority?

23. How often have people indicated that they know other LGB individuals by saying things like "My hairdresser is gay" or "I have a gay friend."

24. How often have people showed surprise at how not effeminate if you are a man) or not Masculine (if you are a woman) you are?

25. How often have people assumed you like to wear clothing of the opposite sex?

26. How often have people made statement that you are "more normal" than they expected? How often have people addressed you with the pronouns that misgendered you (using she/her when you identify as masculine or he/him if you identify as feminine)

27. How often have people told you to "calm down" or be less "dramatic"?

28. How often have people either told you to be especially careful regarding safe sex because of your sexual orientation, or told you that you don't have to worry about safe sex because of your sexual orientation?

29. How often have people dismissed you for bringing up issues of your sexual orientation at school or work?

30. How often have people stared at you or given you a dirty look when expressing affection towards someone of the same gender identity?

31. How often have people made statements about LGB individuals using phrases like "you people" or "you know how gay people are"?

32. How often have people said it would bother them if someone thought they were gay?

33. How often have people made statements about why gay marriage should be allowed?

34. How often have people made statements against LGB individuals adopting?

35. How often have people directly or indirectly called you a derogatory name like queer, homo or dyke?

36. How often have people told you to act differently at work or school in order to hide you sexual orientation?

37. How often have people made offensive remarks about LGB individuals in your presence not realizing your sexual orientation?

38. How often have people used the phrase "that's so gay" in your presence?

39. How often have people told you it's wrong to be gay or said you were going to hell because of your sexual orientation?

40. How often have people told you to dress differently at work or school in order to hide your sexual orientation?

41. How often have people told you not to disclose your sexual orientation in some context (like work of school)

42. How often have you felt that TV characters have portrayed stereotypes of LGB individuals?

43. How often have you felt like your rights (like marriage) are denied?

44. How often have religious leaders spoken out against homosexuality? 


\section{Appendix 2 - Revised LIHS Scale Short Form (Gender Neutral)}

1. I try not to give signs that I am a lesbian/bisexual/gay person. I am careful about the way I dress, the jewelry I wear, the places, people and events I talk about.

2. I can't stand lesbians who are too butch or gay men who are too effeminate. The make LGB people as a group look bad.

3. Attending LGB events and organizations is important to me. (R)

4. I hate myself for being attracted to people who share the same gender identity as me.

5. I believe homosexuality is a sin.

6. I am comfortable being an "out" lesbian/gay/bisexual person. (R)

7. I have respect and admiration for other lesbian/gay/bisexual individuals. (R)

8. I wouldn't mind if my boss knew I was a lesbian/gay/bisexual person. (R)

9. If some LGB individuals would change and be more acceptable to the larger society, LGB individuals as a group would not have to deal with so much negativity and discrimination.

10. I am proud to be an LGB individual. (R)

11. I am not worried about anyone finding out that I am a LGB person. (R)

12. When interacting with members of the LGB community, I often feel different and alone, like I don't fit in.

13. I feel bad for acting out on my homosexual desires.

14. I feel comfortable talking to my heterosexual friends about my everyday home life with my LGB partner/lover or my everyday activities with my LGB friends. (R)

15. Having LGB friends is important to me. (R)

16. I am familiar with LGB books and/or magazines. (R)

17. Being part of the LGB community is important to me. (R)

18. It is important for me to conceal the fact I am a LGB person from my family.

19. I feel comfortable talking about homosexuality in public. (R)

20. I live in fear that someone will find out I am a LGB person.

21. If I could change my sexual orientation and become heterosexual I would.

22. I do not feel the need to be on guard, lie or hide my LGB identity from others. (R)

23. I feel comfortable joining a LGB social group, sports team or organization. (R)

24. When speaking of my LGB lover/partner to a straight person I change pronouns so other's with think I am in a heterosexual relationship.

25. Being a LGB person makes my future look bleak and hopeless.

26. If my peers knew of my LGB identity, I am afraid that many would not want to be friends with me.

27. Social situations with other LGB people make me feel uncomfortable. 
28. I wish some LGB individuals wouldn't "flaunt" their sexual orientation. They only do it for shock value and it doesn't accomplish anything.

29. I don't feel disappointment in myself for being a LGB person. (R)

30. I am familiar with LGB movies and/or music. (R)

31. I am aware of the history concerning the development of LGB communities and/or the LGB rights movement. (R)

32. I act as if my LGB lovers and merely friends.

33. I feel comfortable discussing my LGB identity with my family. (R)

34. I could not confront a straight friend or acquaintance if she or he made a homophobic or heterosexist statement to me.

35. I am familiar with LGB music festivals and conferences. (R)

36. When speaking of my LGB lover/partner to a straight person, I often use neutral pronouns so the sex of the person is vague.

37. Lesbians are too aggressive.

38. I frequently make negative comments about other LGB individuals.

39. I am familiar with community resources for LGB people (i.e. bookstores, support groups, bars, ect.) (R)

\section{Appendix 3 - Multidimensional Scale of Perceived Social Support (Zimet,}

\section{Dahlem, Zimet \& Farley, 1988)}

Instructions: We are interested in how you feel about the following statements. Read each statement carefully. Indicate how you feel about each statement.

Circle the " 1 " if you Very Strongly Disagree

Circle the " 2 " if you Strongly Disagree

Circle the " 3 " if you Mildly Disagree

Circle the " 4 " if you are Neutral

Circle the " 5 " if you Mildly Agree

Circle the "6" if you Strongly Agree

Circle the "7" if you Very Strongly Agree

1. There is a special person who is around when I am in need. $1234567 \mathrm{SO}$

2. There is a special person with whom I can share my joys and sorrows. 1234

\section{$567 \mathrm{SO}$}

3. My family really tries to help me. 1234567 Fam

4. I get the emotional help and support I need from my family. 1234567 Fam

5. I have a special person who is a real source of comfort to me. $1234567 \mathrm{SO}$

6. My friends really try to help me. 1234567 Fri

7. I can count on my friends when things go wrong. 1234567 Fri

8. I can talk about my problems with my family. 1234567 Fam 
9. I have friends with whom I can share my joys and sorrows. 1234567 Fri

10. There is a special person in my life who cares about my feelings. 1234567

SO

11. My family is willing to help me make decisions. 1234567 Fam

12. I can talk about my problems with my friends. 1234567 Fri

The items tended to divide into factor groups relating to the source of the social support, namely family (Fam), friends (Fri) or significant other (SO).

\section{Appendix 4 Psychological Distress - Counseling Center Assessment of}

\section{Psychological Symptoms-34}

1. I am shy around others

2. My heart races for no good reason

3. I feel out of control when I eat

4. I don't enjoy being around people as much as I used to

5. I feel isolated and alone

6. I think about food more than I would like to

7. I am anxious that I might have a panic attack while in public

8. I feel confident that I can succeed academically (R)

9. I have sleep difficulties

10. My thoughts are racing

11. I feel worthless

12. I feel helpless

13. I eat too much

14. I drink alcohol frequently

15. I have spells of terror or panic

16. When I drink alcohol I can't remember what happened

17. I feel tense

18. I have difficulty controlling my temper

19. I make friends easily $(\mathrm{R})$

20. I sometimes feel like breaking or smashing things

21. I feel sad all the time

22. I am concerned that other people do not like me

23 . I get angry easily

24. I feel uncomfortable around people I don't know

25 . I have thoughts of ending my life

26. I feel self conscious around others

27. I drink more than I should

28. I am not able to concentrate as well as usual

29. I am afraid I may lose control and act violently

30. It's hard to stay motivated for my classes

31. I have done something I have regretted because of drinking

32. I frequently get into arguments 
33. I am unable to keep up with my schoolwork

34. I have thoughts of hurting others

\section{Appendix 5 Identity Conflict}

1. Have there been times when you have been able to be both openly religious and openly LGBTQ at the same time? $1=$ strongly disagree, $2=$ disagree, $3=$ neutral, $4=$ agree, 5 = strongly agree (Dahl \& Galliher, 2009)

2. "To what extent have you combined your sexual orientation and your religious beliefs?" $1=$ strongly disagree, $2=$ disagree, $3=$ neutral, $4=$ agree, 5 = strongly agree (Dahl \& Galliher, 2009

3. How strongly would you agree that you currently perceive conflict between your religious faith and sexual orientation? 1 = strongly disagree, 2 = disagree, $3=$ neutral, $4=$ agree, $5=$ strongly agree (Hamblin and Gross). (reverse coded)

Scoring 0-5 not integrated, 6-10 - moderately integrated, 10-15 fully integrated

\section{Appendix 6 Identity Salience Questionnaire}

1. In general, being Christian is an important part of my self-image.

2. Being Christian is unimportant to my sense of what kind of person I am. (R).

3. Being Christian is an important reflection of who I am.

4. Being Christian is not a major factor in my social relationships. (R)

5. In general, being LGB/SSA is an important part of my self-image.

6. Being LGB/SSA is unimportant to my sense of what kind of person I am. (R).

7. Being LGB/SSA is an important reflection of who I am.

8. Being LGB/SSA is not a major factor in my social relationships. (R)

\section{Appendix 7 Demographic Questionnaire}

1. Age 
2. Have you ever experienced sexual attraction to another person who was of the same gender? Y/N

3. Which labels do you use to describe your sexual identity?

lesbian

gay

bisexual

queer

pansexual

omnisexual

heterosexual/straight

asexual

skoliosexual

(there are others that we can include here...)

4. If you chose heterosexual/straight:

Completely heterosexual, mostly heterosexual, somewhat heterosexual

5. Do you identify as having a Christian religious identity? Y/N

6. Please list your Christian identity

7. How frequently do you attend church?

8. Do you attend a LGB affirming church?

9. What labels do you use to describe your sexual identity? (Gay, Lesbian, Bisexual, Same Sex Attracted)

10. What is you race or ethnicity? Please select all that apply (White, Black, Hispanic, Asian, American Indian, Pacific Islander, Other)

11. What label do you use for your gender identity? (male/female/non-binary)

12. Please name the college or university you currently attend.

13. What is your current GPA

14. Please indicate your education level

High school diploma/GED 
Some college

Associates Degree

$\square$ Bachelors Degree

$\square$ Masters Degree

$\square \mathrm{PhD}$

15. How many semesters have you attended your current academic institution?

16. Were you raised in a Christian household (Meaning at least one adult guardian identified as Christian)? Y/N

17. If yes, what were your parent's religious identity?

18. Please indicate your current income (if you are financially independent, list your own income, if you are financially dependent select your parent's income)

$\square \quad \$ 0-\$ 10,000$

$\square \quad \$ 10,001-\$ 20,000$

$\square \quad \$ 20,001-\$ 30,000$

$\square \quad \$ 30,001-\$ 40,000$

$\square \quad \$ 40,001-\$ 60,000$

$\square \quad \$ 60,001-\$ 80,000$

$\square \quad \$ 80,001-\$ 100,000$

$\square \$ 100,000$ and above 


\author{
CURRICULUM VITAE \\ Elisabeth Romines Latino, M.A. \\ The Ohio State University \\ Counseling and Consultation Service \\ 1640 Neil Avenue \\ Columbus OH, 43210 \\ latino.3@osu.edu
}

\title{
EDUCATION
}

09/2011 - 08/2016 UNIVERSITY OF LOUISVILLE

Anticipated Ph.D. in Counseling \& Personnel Services

(Counseling Psychology)

- Dissertation Progress: Anticipated defense in July 2016

- EPPP passed at doctoral level. Eligible for licensure in state of Ohio upon completion of internship.

09/2009 - 05/2011 BOSTON COLLEGE

Master of Arts in Mental Health Counseling

08/2005 - 01/2009 TAYLOR UNIVERSITY

Bachelor of Arts in Psychology

\section{CLINICAL \& ASSESSMENT EXPERIENCE}

08/2015 - present Psychology Intern: The Ohio State University, Counseling and Consultation Service Columbus, OH: Training Director, Karen Taylor, Ph.D.

- APA Accredited Internship 2000 hour internship

- Provided individual, crisis and triage services in a multidisciplinary university counseling center setting.

- Co-facilitated two year long process groups focused on grief and loss and breakups.

- Developed and co-facilitated an ERP (Exposure and Response Prevention) /ACT (Acceptance and Commitment Therapy) informed therapy group for OCD.

- Provided group and individual supervision to doctoral level practicum students

- Will have conducted 3 comprehensive ADHD assessments upon completion of internship

- Developed outreach events for the general student populations and engineering students.

- Active in advocacy and outreach work for diverse student populations through Stigma Reduction Committee and Trans Advocacy Team. 
- Doctoral level placement at a private practice focused primarily on gender identity issues.

- Conducted outpatient individual therapy, group therapy and consultation in a private practice setting with a variety of presenting issues including gender identity concerns, trauma, mood and anxiety disorders.

- Co-led a 12 week Transgender Process Group

- Utilized the ORS for progress and outcome assessment over the course of therapy.

05/2014 - 09/2014 Practicum Intern: Private Practice Louisville, KY

- Doctoral level placement at a private practice focused on assessment to evaluate eligibility for disability services from the commonwealth of Kentucky.

- Conducted four assessment batteries and completed four integrated reports.

- Administered the MMPI-II, WAIS-IV, KFAST, Rey 15, MMSE, BAI, BDI, and Bender-Gestalt-II.

$05 / 2013-05 / 2014$

Practicum Intern: Spalding University, Counseling Center Louisville, KY

- Doctoral level placement at an outpatient center for staff, students and faculty at Spalding University.

- Involved in campus outreach through Residence Life.

- Conducted four assessment batteries and produced four integrated reports utilizing the WAIS-IV, WIAT-III, WJ-III Achievement, STAI, MMPI-II, PAI, CPT-II.

- Used the AUDIT, CCAPS in intake assessment and the CCAPS for progress and outcome assessment over the course of therapy.

08/2012 - 04/2013

Center

Practicum Intern: University of Louisville, Counseling

$$
\text { Louisville, KY }
$$

- Doctoral level placement at an outpatient center for staff, students, and faculty at the University of Louisville.

- Co-led an LGBT process group with Dr. Joanna Morse 
- Planned and participated in several campus outreach events through PEACC (Prevention, Education and Advocacy on Campus and in the Community).

- Utilized the AUDIT, BAI and BDI for intake assessment and the ORS for progress and outcome assessment over the course of therapy.

08/2010 - 05/2011 Practicum Intern: Obsessive Compulsive Disorder Institute, McLean Hospital. Boston, MA

- Master's level placement at an inpatient unit focused on treating severe and treatment resistant obsessive-compulsive disorder.

- Trained extensively in ERP a type of Behavioral Therapy targeted towards OCD.

- Brief training in ACT for OCD.

- Led group sessions in CBT skills, a group structured to incorporate CBT strategies into motivation for pursuing OCD treatment.

06/2007 - 08/2007 Practicum Intern: Center for Neurobehavioral Services, Fort Wayne, IN

- Undergraduate level practicum experience at an outpatient children's counseling center.

- Worked with a variety of age groups and presenting issues including developmental delays, behavioral disorders, autism and histories of trauma and abuse.

- Shadowed by a licensed counselor.

\section{SUPERVISION EXPERIENCE}

01/2015-present

08/2015-12/2015

$09 / 2013-12 / 2013$
Individual Supervisor

Ohio State University

- Under the supervision of a licensed psychologist, provided weekly individual supervision for one doctoral level practicum student.

Practicum Seminar Co-supervisor

Ohio State University

- Under the supervision of a licensed psychologist, co-provided supervision for three doctoral level practicum students in a group setting.

ECPY 755 Counselor Supervision

-Attended a semester long course on Counselor Supervision 
-Supervised two Master's level Counseling Psychology students over the course of a semester.

$3 / 2012$

ECPY 629 - Theories and Techniques of Counseling and Psychotherapy

- Reviewed tapes of student therapy sessions, and provided feedback.

\section{OUTREACH \& CONSULTATION}

$10 / 22 / 2016$

$10 / 2015$

$10 / 2015$

Fall 2015

$04 / 27 / 2015$

$03 / 20 / 2015$

$06 / 01 / 2014-06 / 2015$

$10 / 17 / 2014$

05/06/2014 - 06/30/2014

$05 / 06 / 2014$

$04 / 01 / 2014$

$02 / 21 / 2014$
Body Image Bazar

The Ohio State University

Let's Talk

The Ohio State University

RECESS

The Ohio State University

Outreach Workshops (Depression and Anxiety)

The Ohio State University

Assessment Issues with Transgender Youth

Bingham Clinic

Trans Issues in Psychiatric Care

University of Louisville: Psychiatric Services

Consulting Therapist on Gender Identity

Private Practice

Title IX Roundtable

University of Louisville

Couples Workshops

Spalding University

Sexual Violence Awareness (Student Development

Presentation) Sacred Heart Academy

Impostor Phenomenon (Staff Professional Development Workshop) University of Louisville

Stress Reduction (Classroom Outreach)

Spalding University 
$10 / 02 / 2013$

Handling Microaggressions in the Workplace (Staff

Professional Development Workshop)

University of Louisville

$10 / 01 / 2013$

Stress Reduction (Residence Life Outreach)

Spalding University

07/2012 - 10/2012

Week without Violence Planning Committee (PEACC)

University of Louisville

\section{TEACHING EXPERIENCE}

July 2014

Guest Lecturer: Learning Theory and Human

Development (EDTP 507) - Motivation, University of Louisville

October 2013

Guest Lecturer: Learning and Human Development (EDTP 107)

- Piaget's Cognitive Stages of Development, University of Louisville

October 2013

Guest Lecturer: Theories and Techniques of Counseling and Psychotherapy (ECPY 629)

- Emotion Focused Therapy, University of Louisville

September 2013

Guest Lecturer: Learning and Human Development (EDTP 107)

- Erikson's Psychosocial Stages of Development and

Attachment Theory, University of Louisville

\section{REPORTS}

Dickinson, E. R., Latino, E. R., \& Adelson, J. L. (July, 2012). A pre-post evaluation of Girls on the Run Louisville: Body Image Satisfaction, Self-Esteem, and Attitudes toward Physical Activity. Report for Girls on the Run Louisville

Adelson, J. L., Latino, E. R., \& Dickinson, E. R. (January, 2012). A pre-post evaluation of Girls on the Run Louisville: Body image, satisfaction, self-esteem, and attitudes toward physical activity. Report for Girls on the Run Louisville.

Nienhus, J., Romines, E., Sawyer, J., Pearson, D. (2012). Problem-based learning and assessment: A review of literature submitted to the Oregon Department of Education. Louisville, KY: National Research Center for Career and Technical Education. 


\section{EDITORIAL EXPERIENCE, PEER-REVIEWED JOURNALS}

2014 Ad Hoc Reviewer for the Peabody Journal of Education Special Issue

\section{PROFESSIONAL PRESENTATIONS}

June 2016 Sinclair Miracle, K., Latino, E. R., Krakow, S. Adding Spice to Buckeye Life: The Importance of Outreach in Stigma Reduction. AUCCCO, Columbus, $\mathrm{OH}$.

Feb 2016 Dehili, V., Hansen, R., Latino, E. R., Kadeba, M., Shim, Y. Surviving to Thriving: A Flourishing Internship Experience. Poster session presented at the The Big 10 College Counseling Center Conference, West Lafayette, IN.

August 2014 Latino, E. R., Kopeikin, K., \& Leach, M. L. (2014). A cross-sectional analysis of the international ethics codes with a focus on supervision and training. Poster session presented at the American Psychological Association Conference, Washington, D.C.

March 2014 Latino, E. R., Kopeikin, K., \& Leach, M. L. (2014). A cross-sectional analysis of the international ethics codes with a focus on multiple relationships. Poster session presented at the Div 17 Counseling Psychology Conference, Atlanta, GA

March 2012 Latino, E. R., Kopeikin, K., \& Leach, M. L. (2012). A cross-sectional analysis of the international ethics codes. Poster session presented at the Great Lakes Counseling Psychology Conference, Lafayette, IN.

August 2009 Gates, J., Snyder, S., Kruegar, J., Booth, T., Dodge, R., Romines, E. (2009). New heights high altitude research program assessment. Poster session presented at the 2009 ASAE Annual Conference \& Exposition.

May 2009 Dodge, R., Romines, E., Snyder, S. (2009). HARP pilot study findings. Academic High-Altitude Conference, Upland, IN.

\section{MEMBERSHIP OF PROFESSIONAL ORGANIZATIONS}

American Psychological Association (APA): Student Affiliate

American Psychological Association (APA) Div 44: Student Affiliate

American Psychological Association (APA) Div 17: Student Affiliate

PROFESSIONAL EXPERIENCE 
08/2012 - 06/2015 Graduate Assistant, Academic Accountability and Unit

Effectiveness, College of Education and Human Development

Dean's Office, University of Louisville

08/2011 - 07/2012 Graduate Assistant, National Research Center for Career and

Technical

Education, University of Louisville

08/2011 - 07/2012 Graduate Assistant, Dr. Jill Adelson, University of Louisville

12/2009 - 07/2010 Graduate Assistant, Boston Catholic School Connects, Boston

College

Supervisor: Dr. Erik Goldschmidt

\section{COMMITTEES}

Spring 2016

Stigma Reduction Committee

Trans Advocacy Team

Training Committee

Intern Selection Committee

The Ohio State University, Counseling and Consultation Service.

Fall 2015

Stigma Reduction Committee

Trans Advocacy Team

Training Committee

Intern Selection Committee

Disposition Committee

The Ohio State University, Counseling and Consultation Service.

$09 / 2013-08 / 2014$

Faculty Liaison: ECPY Doctoral Student Organization

University of Louisville

08/2012-05/2015

Student Representative: CEHD Curriculum Committee University of Louisville

$10 / 2012$ - 05/2015

Student Representative: Conceptual Framework

Committee

University of Louisville

09/2011- 05/2013

Student Member: Diversity Committee

University of Louisville

RESEARCH EXPERIENCES 
$09 / 2011-06 / 2015$

$01 / 2012-06 / 2015$

12/2007 - 07/2009
International Ethics Research Lab

University of Louisville

Supervisor: Dr. Mark Leach

TSTAR Research Lab

University of Louisville

Supervisor: Dr. Stephanie Budge

High Altitude Research Platform (HARP)

Taylor University

Supervisor: Dr. Steven Snyder

\section{PROFESSIONAL DEVELOPMENT}

October 2015

October 2013

September 2013

January 2013

April 2012

April 2011

October 2009
Attended Conference: Dennis H. May Conference on Diversity Issues and the Role of Counseling Centers: Creating TransInclusive and Supportive Campuses. University of Illinois UrbanaChampaign.

Attended Workshop: Couple Therapy Workshop, Level 1 Introduction to Concepts and Skills: Jesse Owen PhD, Johanna Strokoff MA, Meg Mantos, Med, University of Louisville

Attended Workshop: Crisis Intervention: Patrick McKiernan PhD, Spalding University

Attended Workshop: Training in Emotion Focused Therapy for Individuals: Rhonda Goldsmith $\mathrm{PhD}$, University of Louisville

Attended Conference: 2012 Diversity Conference, Cultural Connections: Competence, Quality, and Equity in Mental Health Care. KPA. Louisville, KY.

Attended Training Seminar: ACT Training for OCD. McLean Hospital. Belmont, MA.

Moderated conference session, Diversity Challenge: Institute for the Study and Promotion of Race and Culture. Boston College. Boston, MA. 